\title{
Health profile of Sudanese adolescents (Umbada adolescents health survey)
}

Citation for published version (APA):

Moukhyer, M. E. E. (2005). Health profile of Sudanese adolescents (Umbada adolescents health survey). [Doctoral Thesis, Maastricht University]. Maastricht University. https://doi.org/10.26481/dis.20050218mm

Document status and date:

Published: 01/01/2005

DOI:

10.26481/dis.20050218mm

Document Version:

Publisher's PDF, also known as Version of record

\section{Please check the document version of this publication:}

- A submitted manuscript is the version of the article upon submission and before peer-review. There can be important differences between the submitted version and the official published version of record.

People interested in the research are advised to contact the author for the final version of the publication, or visit the DOI to the publisher's website.

- The final author version and the galley proof are versions of the publication after peer review.

- The final published version features the final layout of the paper including the volume, issue and page numbers.

Link to publication

\footnotetext{
General rights rights.

- You may freely distribute the URL identifying the publication in the public portal. please follow below link for the End User Agreement:

www.umlib.nl/taverne-license

Take down policy

If you believe that this document breaches copyright please contact us at:

repository@maastrichtuniversity.nl

providing details and we will investigate your claim.
}

Copyright and moral rights for the publications made accessible in the public portal are retained by the authors and/or other copyright owners and it is a condition of accessing publications that users recognise and abide by the legal requirements associated with these

- Users may download and print one copy of any publication from the public portal for the purpose of private study or research.

- You may not further distribute the material or use it for any profit-making activity or commercial gain

If the publication is distributed under the terms of Article $25 \mathrm{fa}$ of the Dutch Copyright Act, indicated by the "Taverne" license above, 


\section{Health profile of Sudanese adolescents (Umbada adolescents health survey)}

Mohamed Eisa Eltahir Moukhyer 


\section{ISBN 9090190317}

\section{(C) Copyright Mohamed Eisa Eltahir Moukhyer}

All right reserved. No part of this book may be translated or reproduced in any form by print, photo print, microfilm, or any other means without prior written permission from the publisher.

Cover design by: Patrick van Kasteren

Printed by Datawyse / Universitaire Pers Maastricht 


\section{Health profile of Sudanese adolescents (Umbada adolescents health survey)}

\section{PROEFSCHRIFT}

ter verkrijging van de graad van doctor aan de Universiteit Maastricht, op gezag van de Rector Magnificus

Prof. mr. G.P.M.F. Mols, volgens het besluit van het College van Decanen, in het openbaar te verdedigen op vrijdag 18 februari 2005 om 12:00 uur

door

Mohamed Eisa Eltahir Moukhyer 


\section{Promotores}

Prof.dr. J.Th.M. van Eijk

Prof.dr. N.K. de Vries

\section{Beoordelingscommissie}

Prof.dr. G.J. Dinant (voorzitter)

Prof.dr. H.W. van den Borne

Dr. H. Bosma

Prof.dr. J.A.M. Maarse

The study presented in this $\mathrm{PhD}$ thesis was conducted at Maastricht University, departments of Medical Sociology and department of Health Education and Health Promotion.

All the study and filed work were conducted with financial support from Ahfad University for Women, Omdurman, Sudan. 
For my beloved parents, Amna and Eisa. 

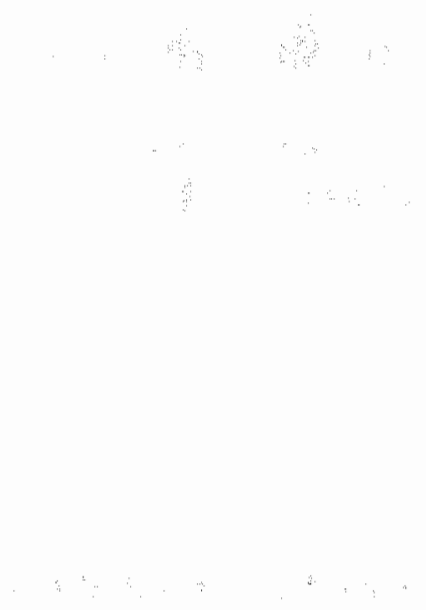


\section{Table of Contents}

Chapter 1 Overview of the study

Chapter 2 Methodology and data source

Chapter 3 Self reported health problems and haemoglobin status among Sudanese adolescents

Chapter 4 Health related behaviours of Sudanese adolescents

Chapter 5 The association between health status (subjective and objective health) and health related behaviours among Sudanese adolescents

Chapter 6 The social context of Sudanese adolescents and health

Chapter 7 Reproductive health: level of knowledge and harmful traditional practices among Sudanese adolescents

Chapter 8 General discussion

Summary

Samenvatting

Arabic summary

Acknowledgement 

Chapter 1

Overview of the study 


\section{Introduction}

WHO delines health as a state of complete physical, mental and social well being and not merely the absence of disease or infirmity (WHO, 1990). This is important when we consider health in adolescence, the second decade of life, since this period is characterized by many rapid, interrelated changes of body, mind and social relationships. Physically the individual grows in height and weight and develops strength and stamina; psychologically, there is an increase in the capacity for abstract thinking; empathy and intemal control, and socially, the nature of relationship changes with both peers and adults.

The concept of adolescence is relatively new in historical terms (Villarreall, 1998).

The social and cultural recognition of the concept of, and values placed on, adolescence as transitional period between childhood and adulthood vary substantially between populations (Schegel \& Barry, 1991; Whiting et al., 1986).

Traditionally, the main health indicator used by health planners, policy-makers, researchers, and program staff has been mortality. Young people have a low mortality rate relative to both older and younger age groups in both developing and industrialized countries. Consideration of mortality rates alone has resulted in young people being seen as healthy age group, and this has led to their being accorded a low priority for health-related interventions (WHO/UNICEF, 1995).

Although the general pattern of mortality with age is similar in developing and industrialized countries, the absolute age-specific death rates for young people are much higher in developing countries, because of a combination of a higher incidence of most diseases and a higher case fatality ratio (United Nations, 1991). Also, partly because of the age structure of the population, the proportion of all deaths, which occur in the 10-24 year age, is much higher in developing countries than it is in industrialized countries. For instance, in Egypt, $7.4 \%$ of all deaths occur in young people, nearly three times the proportion in New Zealand $2.8 \%$, (United Nations, 1991).

Adolescence is a time of learning, which necessarily includes taking risks, but the conditions in which those risks are taken will often make the difference between constructive and destructive outcomes. The health of adolescents is profoundly linked to their development, since their physical and social abilities will determine what they do, how they act and with whom they associate. These abilities change as adolescents mature, reflecting the degree of support and opportunity they are given.

Adolescents in all societies have substantially increased autonomy compared to children, and their own decisions play a vital role in determining their behaviour and relationships. Adolescence is a crossroads in life and is the gateway to the promotion of health. Many of the behavioural patterns acquired during adolescence will last a lifetime. They will affect the health and well being of future children. The benefits, which will acrue to every society in meeting the challenge of promoting the health and development of adolescents, far outweigh the cost of neglecting their needs (WHO, 1997).

Thus research into adolescent's health needs to consider the positive aspects of health, as well as the risk factors for future ill health and disease. Many behaviours that comprise young people's lifestyle may directly or indirectly impinge on their 
health in the short or long term; consequently, a wide range of behavioural variables should be measured. Positive or health promoting behaviour needs to be studied, as well as health damaging or risk behaviour. Certain behaviour is initiated in the adolescent years, while some patterns of behaviour, such as eating patterns, become established in earlier childhood.

Adolescent health research no longer requires justification. There are more than 1.5 billion young people between the ages of 10 and $24 ; 85 \%$ live in developing countries (United Nations, 1995). Changing conditions are bringing about changes in behaviour and the international communities have recognized that behaviour formed in the second decade of life has lasting implications for individual and public health (WHO, 1999).

Health care for adolescents (those aged 10 through 19) presents something of a paradox. In terms of physical morbidity and mortality, adolescents are among the healthiest groups in all societies. They have survived illnesses of infancy and childhood which still take a high toll in many developing countries, and they are not yet suffering from infirmities of old age, or from damage arising from decades of hard labor at home or in the workplace.

As a result the health of adolescents has traditionally been given low priority in public health programs. Yet, in recent years, interest has grown in the health of adolescents for a number of disparate reasons:

1. Public health successes with regard to infectious diseases have made it possible to give attention to health problems arising from behaviour, an issue of particular relevance to the adolescence period;

2. Massive changes underway in socio-cultural and demographic conditions including urbanization, the decline of extended family, and the revolution in telecommunication have eroded traditional support and control systems for adolescents, eased social and sexual constraints and increased the exposure of adolescents to health-threatening situations and substances;

3. In developing countries both the absolute and relative size of the adolescent population has increased rapidly. More than half the world 's population is currently under the age of 25 , and

4. As the adolescence period lengthens because of the generally earlier start of puberty and later age at marriage, there has been growing understanding that adolescence constitutes a series of choice-points which determine whether young people develop behaviour patterns which promote their own health and that of their societies, or embark on life styles which are likely to do lasting tharm to themselves and others. 


\section{Why a study of Adolescents health in Sudan?}

When the United Nations sponsored International Conference on Population and Development was held in Cairo (ICPD, 1994), the issue of adolescent health and well-being linally emerged at the top of global agenda.

Lmportantly, many gowemnents are now in the process of formulating national policies on adolescent health, and some are beginning to implement programs. Not only is the value of taking actions to promote adolescent health being recognized, but so are the multiple and long-terms costs of not taking action. Slowly but surely, the questions being posed are less often whether adolescent health should be given attention, and more commonly, what needs to be done and how best to do it.

Sudan is one of the developing countries from Africa with a lack of data gathered among this young group, and this information gap led to speculation and distortion in the past, as policy planners relied on unscientific information or journalistic inferences to determine the needs and problems of this age group. Nonetheless, available evidence suggests that the health profile of Sudanese adolescents more closely resembles that of other developing countries in Africa and the Middle East in the magnitude and diversity of health related problems. In Sidan there are around 7.5 million adolescents in the age range of 10 to 19 , which is one fourth of the Sudan population (PAPCHLL, 1993).

There are several good reasons for conducting a study about the health profile of Sudanese adolescents. Firstly adolescents are an ignored group in terms of their health compared to young children or the elderly. Secondly some of the most important barriers to the promotion of good adolescent health in Sudan is the widespread lack of health data and of statistical information that constitutes the basis for effective health policies and programs. The third reason for the study is that it contributes to health planning and design of community interventions to improve health in a very interesting target group: adolescents.

In this research we want to look at adolescent health in Sudan and to understand the social context in which young people grow to adulthood. Whereas most of the international literature on adolescence has a rather narrow focus on sexual behaviour, deviance, or rebellion against adults (Blum, 1991), our understanding of this phase of life is broader: it also encompasses the social context in which critical life decisions and developmental tasks bridging childhood to adulthood, take place.

A further point of concern is anamia as the prevalence of anaemia during adolescence is very high. Worldwide numbers range from $51 \%$ in Africa to about 18 $\%$ in Asia (De Maeyer \& Adiels-Teegman, 1985). Anaemia affects young people disproportionately because an increase of iron is needed for growth, development, menstruation, and protection against endemic diseases (Senderowitz J, 1995).

The family as a crucial agent of socialization is of utmost importance here. Numerous health behaviours and attinudes in adolescence and adulthood are begun in the family setting during childhood. Lifestyle-related habits in hygiene, nutrition and physical activity, as well as communication skill and social competences, are an essential part of familial education. Understanding adolescents' health behaviours, family communications and parent-child relations on life skills, psychosocial adjustment, and mental health necessitates the exploration of their relation within the circle of the family and peers. 
Reproductive health knowledge in many parts of the world is not provided either in schools or in other settings, placing young people in vulnerable situations during a period of life when experimental activity is nonmal. Unnecessary emotional stress is created by the lack of infommation and understanding about issues to do with sexuality, bodily changes and functions, and emotional feeling. Inadequate provision of confidential services for young people can also inhibit them from accessing appropriate health care and advice. Traditional reproductive health practices, which specifically affect adolescents, are common in some developing countries. The most serious of these is female genital mutilation (FGM), which is generally performed in childhood or early adolescence. It has been estimated that each year at least two million girls undergo this practice (WHO 1994a). This therefore will be the last point of focus.

This study will provide insight and knowledge, essential for all parties involved in policies for a better adolescent health in Sudan and will give answer to the question how (un) healthy adolescents are and thus provide a baseline of data for those conducting development on behalf of adolescents.

\section{Goals of this study aim at:}

Description of health and health related behaviours of Sudanese adolescents and explore their interrelations in order to assess the determinants of and barriers to Sudanese adolescents health.

The research proposal fits in the framework for country programming for adolescent health adopted by WHO/UNFPA/UNICEF (WHO, 1999) to provide for the first time data for policy makers in Sudan.

\section{Objectives, the model, general research questions, and structure of the thesis:}

As mentioned earlier the study is oriented towards health and behaviour. A grand theory of health and health behaviour among adolescents was not used, as this study was designed to provide information usable for the development of health policy. Of course the study did use a research model that describes information considered to be relevant for the development of health policy. So there in fact was no ambition to test a. theory. Of course determinants of health and heallth behaviours are derived from theoretical and empirical evidence of previous scientific work.

The study itself centres on a survey in which most of information gathered is from the adolescents themselves.

General objectives of this thesis are thus both the description and explanation of the health profile of Sudanese adolescents, and to answer the question how (un) healthy they are.

This thesis addresses the health profile of Sudanese adolescents. Specifically, we investigate, describe and explain the finding in order to reach our objectives. The individual demographic characteristics receive special attention in our theoretical. model, gender, age group and education are important variables, since many studies emphasis their relation to health and determinants of health of adolescents (Sweeting, 1995; Spruijt-Metz, 1996). 
Despite a growing interest in adolescent health, much remains unknown about the pattern of health problems in adolescence. We will try to understand the experienced health problems and health related behaviours and it is determinants in adolescence, and describe the result and the outcomes of the association between them.

Understanding the social context in which young people grow to adulthood, this would allow for exploration of relation and communication within the family, peers relation and it is effect on psychosocial health. This stage becomes more and more important as they are trying to find their independence by orienting themselves away from the authority of parents.

Another objective of this study is to identify knowledge and practice about reproductive health and physiology, which form a critical part of the growing up experience of adolescents. So it is important to understand when and how young people acquire the knowledge that will prepare them for roles as future parents and partner in marriage.

As well to understand the experience of adolescent girls with genital mutilation in order to better understand the correlates and later implication of this practice.

\section{Figure 1 The relationships examined within this thesis in a simplified model}

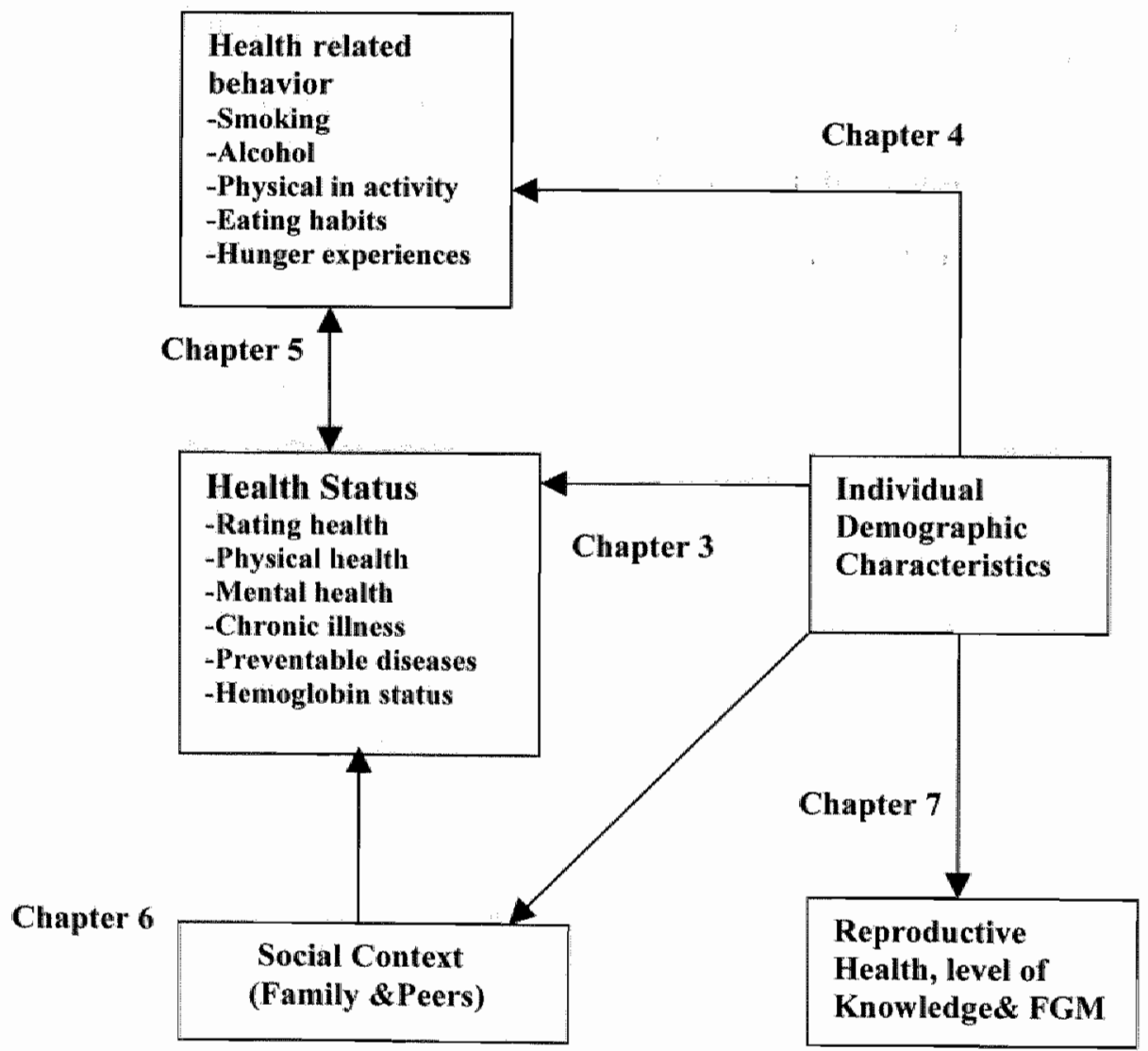




\section{The objectives of this research can be summarized in the following five general research questions:}

1. What is the prevalence of health problems (in terms of rating health, subjective health, chronic and common illness) and haemoglobin status?

2. What are the health related belhaviours and their determinants in adolescence compared across different demographic categories?

3.What is the association between general health problems and health related behaviours among adolescents?

4. What is the relation of social context (family and peers contexts) to the adolescent"s health?

5. What are the level of knowledge, practice and experience concerning reproductive health among adolescents, using different demographic variables?

\section{Structure of the thesis}

This thesis includes after this first chapter another seven chapters. The next, chapter 2 , describes the study design, methods and material of the study, field preparation, data collection procedure and experiences through out the fieldwork. Chapter 3 examines the health status. Several health problems are assessed: self reported health, experienced health complaints, common and cluronic illness; haemoglobin determination was used as a simple, reliable test to detect for anaemia. We compare the findings with respect to socio-demographic characteristics of our study cohort group. Chapter 4 examines the health related behaviours and lifestyle to give an impression of the prevalence of health related behaviours and behavioural determinants in Sudanese adolescents. Chapter 5 will identify the result and the outcome of the associations between health status and health related behaviouns. Chapter 6 will examine the social context relation within the family the circle of influential people around adolescent, it will focus in particular on whether there is a difference in social context between different demographic categories, and the nature of a hypothesized correlation between social context and health. Health related behaviour were additionally controlled for as intermediate variable in this model.

Chapter 7 will identify reproductive health level of knowledge and practices mainly Female Genital Mutilation (FGM) among adolescents' girls and describe their experience and the negative consequences of this practice.

Finally the last chapter of this thesis, Chapter 8, will highlight the main findings and general discussion of these findings. The implications for future research, limitation of the study, health policies and recommendations regarding adolescents' well being in Sudan will be discussed. At the end a summary of the study will be presented in Dutch and Arabic languages as well. 


\section{References}

Blum, R. W. (1991). Global trends in adolescent health. Joumal of the American Medical Association, 265, 2711-2719.

DeMayer, E., \& Adies-Tegman, M. (1985). The prevalence of anaemia in the world. World Health Statistics Quart, 38, 302-316.

ICPD (1994). Report of the International Conference on Population an development, Cairo, Egypt 5-13 September 1994.

Jelliffe, DB. (1966). The assessment of the nutritional status of the community (with special reference to field survey in developing region of the world). WHO Monograph Series, No. 53, 64-69.

PAPCHILD (1993). Pan Arab Project for Child Development, Sudan Maternal and Child Health Survey 1992/93.

Schegel, A., \& Barry, H. (1991). Adolescence: an anthropological enquiry. New York: Free Press.

Senderowitz, J. (1995). Adolescent health: Reassessing the passage to adulthood. World Bank Discussion Paper No.272. Washington, DC., World Bank.

Spruijt-Metz,D. (1996). On everyday health related behaviour in adolescence. Thesis, Free University, Amsterdam.

Sweeting, H. (1995). Reversals of fortune? Sex differences in health in childhood and adolescence. Social Science and Medicine, 40, 77-90.

UNICEF (1994). United Nations Children's Fund, The State of the World Children, Oxford University Press.

UNITED NATIONS. (1990). World Population Prospects. New York: United Nations.

UNITED NATIONS. (1991), Demographic yearbook, 1991. New York: United Nations.

UNITED NATIONS. (1993).1992 population. New York: United Nations, Dept of Economic\& Social development.

UNITED NATIONS. (1995).Demographic yearbook, 1991.New York: United Nations. 
Villarreal, M. (1998). Status of Women, Education, and Attitudes towards Fertility and Female Labour Force Participation Among Costa Rican Adolescents. A Dissertation presented to the Faculty of the Graduate School of Cornell University.

West $\mathbf{P}_{n}, \&$ Sweeting H. (1996) No job, No future: young people and health in a context of unemployment. Health and social care in the community, 4, 5062.

WHO (1990). Constitution, basic documents, $38^{\text {th }}$ ed. Geneva, World Health Organization.

WHO (1994a). Female genital mutilation: information kit.Geneva: World Health Organization.

WHO (1995). World health report $\mathbb{9 9 9 5}$ bridging the gaps. Geneva, World Health Organization.

WHO (1995). Adolescent health and development the key to the future. Paper prepared for the Global Commission on Women's Health. Geneva, World Health Organization (WHO/ADH/94.3 Rev.1).

WHO (1995). Physical status. The use and interpretation of anthropometry. Report of a WHO Expert Committee. WHO Technical Report Series, No. 854, 263311.

WHO/ UNICEF. (1995). A review and annotated bibliography of the health of young people in developing countries, Geneva, New York.

WHO (1997). Coming of age, from facts to action for adolescent sexual and reproductive health. Adolescent health and development programme family and reproductive health, WHO, Geneva.

WHO/UNICEF/UNFPA.(1999).Programming for Adolescent health and development report of a WHO/UNFPA/UNICEF study group on programming for adolescent health.

WHO (2000). Health and health behaviours among young people, Health behaviour in school -aged children a WHO cross national study (HBSC). WHO policy serious: Health policy for children and adolescents Issue 1st International report.

Whiting, J.W.M., Burbank, VK., \& Ratner, M.S. (1986). The duration of maidenhood across cultures. pp. 273-302 In: Lancaster, J. (Ed). School-age pregnancy and parenthood: Biosocial dimensions. New York: Aldine de Gruyter 
.

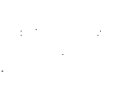

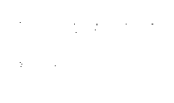

:

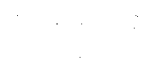

$\therefore \quad \therefore$

$\therefore$
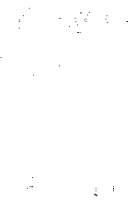

$:$

. 
Chapter 2

Methodology and data source 


\title{
Methodology and data source
}

\begin{abstract}
This Chapter outlines the process of data sources; describes the area of the study at Umbada town A cross sectional, cluster random sampling design was used. A self reported questionnaire was developed for data collection by trained interviewers and a biomedical test for haemoglobin determination was used among our selected 1200 adolescents within the age group 10-19 years. Before data collection statement was first read by the interviewers to the head of the household as well for the respondents to obtain his/her verbal consent. In this chapter sampling design, data collectors training and our experiences from the fieldwork was mentioned.
\end{abstract}




\section{Methodology and data source}

\section{Study area}

The study site is situated in Umbada town, Khartoum state, central Sudan. Umbada town is 4 kilometres west of Khartoum city. Umbada was selected because its multiethnic population, comprises people from different regions and tribes of Sudan. Umbada is a suburban area of the capital city Khartoum with a diversity of inhabitants who migrated from different parts of Sudan and a majority of them are of middle and low socioeconomic status.

\section{Design of the Study}

The health profile of Sudanese adolescents was assessed in a cross sectional, cluster random sampling survey study. A self reported questionnaire was developed for data collection by trained interviewers. A biomedical test to detect haemoglobin level in blood was used.

The population selected for the study comprised adolescents from Umbada community with age group of 10-19 years.

\section{Sampling design}

Calculation of the sample size was based on the percentage of adolescents in Umbada, which is $25 \%$ (CBS, UNFPA, 1993).

The following formula was used: $n=Z_{\frac{2}{d^{2}}}^{2}$

$Z=1-96 \approx 2$. This is the quartile of a normal distribution

$\mathrm{p}=\%$ of adolescents in Umbada

$\mathrm{q}=1-\mathrm{P}$

$d=(0.05)$ level of confidence of the study

$4 \times .25 \times .75=4 \times 25 \times 75=300$ adolescents per block

$(0.0025)$

25

The following multistage sampling procedures was used:

Four blocks were selected by simple random sampling. These represented $10 \%$ of the total number of Umbadla blocks.

Households were selected by systemic random sampling. Starting from the centre of each block (every fifth house), all adolescents found in the households were interviewed, until the number needed in each block was reached. If the selected house did not meet our criteria (at least one adolescent in the age range of 10-19), our method of selection was adjusted by using substitute techniques, adding +2 or -2 to the selected number of the house. Three hundred (300) adolescents per stratum (block) were interviewed. The total number of sampled adolescents was $4 \times 300$ $=1200,568$ boys $(46.8 \%)$ and 632 girls $(53.2 \%)$. 
The total number of heads of households to be interviewed was calculated by dividing the number of adolescents selected in each block by four, which represented the average family size (Sd=6.2) in Sudan (CBS, PAPCHILD 1993). The total was 75 heads of households per block. In two-parent basic family units, only one parent was randomly selected, while in single-parent basic famly units. The parent who was a nember of the sampled household or the responsible person for the household was interviewed, A total of 300 responsible adults were interviewed (119 males and 18 ( females).

The variations in numbers $(N)$ in the analyses are due to differences in missing values between variables. Non-response rates among boys are higher than girls probably due to their mobility outside the house during the survey.

\section{Study population and timeframe}

The total number of adolescents included in this PhD study of Umbada Adolescent Heallh Survey (UAHS) was 1200 . We have no information on haemoglobin status of 65 missing adolescents $(5 \%)$. The data were collected during the periods JuneNovember 2001.

Information related to the responsible household adult was collected. This was, however, found not important for the survey at this stage.

\section{Pretesting}

Following the preliminary version of the structured questionnaires and its Arabic translation for pre- testing, four interviewers were trained on the objectives and how to carry out the fieldwork. One residential block was chosen for implementation of the pretest. Debriefings were held with the interviewers throughout the pretest phase. Based on the results of pretesting, the layout and contents of the structured questionnaire were modified and field procedures revised.

\section{Data collectors training}

Following the pre-test a three days training program was held at the Alnfad Reproductive Health Centre. Twenty-five interviewers were selected from the university students especially those with previous experience in data collection, experience of reliability and validity of information and 15 from the CAFA (Community Animators Friendly Association) for this training program.

To facilitate the process of data collection and to eliminate any possible interviewers bias as far as possible consideration for selecting are based on that interviewers should be of both sex groups, of young age (18-24 years) with different religious background (two out of the forty interviewers are non-Muslims) and preferably not had ties to Umbada community.

The training program was divided into sessions of explanation, introduction of the objectives, and discussion of all variables, role-play, field training and techniques for interviewing young people. All interviewers are well informed about the diseases and how to explain and clarify them to respondents.

The interviewers were instructed to obtain consent for the interviews of both the responsible adult and adolescent(s) from the head of the household after brief explanation of the objectives of the study. Before interviewing the adolescents, the same consent statement was read, emphasizing the voluntary nature of participation. 
The interviewers interviewed each adolescent in priwacy to the best of their capacities:

\section{Ethical consideration}

Before data collection an introductory statement was first read by the interviewer to the head of the household to obtain his/her verbal consent. The head of the household was informed that participation was voluntary and the data will be used for research purpose only. The same statement was read for the adolescents as well, before interviewing commenced.

\section{Data management}

The process of coding and data entry was done simultaneously with the data collection process. Analysis were done using SPSS version 11.0.

\section{Experiences from fieldwork}

Interviewing adolescents is very different from interviewing adults, especially if they are as young as 10 years. Obtaining the parents' consent to interview the adolescents in private was some times difficult. The majority of the adolescents interviewed, on the other hand, were positive about the process, took it seriously, and felt a sense of pride about participating. The interviewers were instructed to carry out the interviews in total privacy, but some-times a responsible adult insisted on attending. In those cases the interviewers were advised to use certain strategies to maintain the privacy of the interview. They would give the responsible-adult a questionnaire to read, or would offer to read the questions to the responsible adult before the interview. Or, if the responsible- adult was selected for interview, the interviews were carried out simultaneously. Altematively, interviewers would suggest that the responsible- adult sit where the interview could be seen but not heard. At worst, the interviewers would accept that the responsible-adult listened to the first few questions and answers, after which the responsible-adult usually became convinced of the importance of the research. In cases where there was more than one eligible respondent from the same household, several interviewers carried out the interviews simultaneously.

In each block a point for blood collection and haemoglobin determination was set in one of the community leaders house, and a laboratory technician was assigned to this activity.

Convincing responsible-adult and adolescents to undergo the haemoglobin determination was a very difficult task, especially in the case of younger adolescents. In this we were helped by the presence of CAFA (Community Animators Friendly Association) members, who accompanied the adolescents for the haemoglobin determination and emphasized the safety of the procedures.

In spite of that some of them refused to give blood. When later on the results of the haemoglobin test where shown to the respondents, they better understood the benefits of participation and how the researchers were trying to help them. Any respondent found with very low haemoglobin level was sent to the university health centre for further examination and treatment, without further follow up from the researcher.

Those with a low haemoglobin level indicating mild and moderate anaemia received more information and nutrition advice from the nutritionist accompanying our team. 
A problem to our survey was the mobility of adolescents, especially boys, who were not always available inside or around the household during our visits, but were away either playing games or attending evening classes.

The successful implementation of the fieldwork was the result of a high level of coordination with the community leaders, CAFA, and the team of interviewers from Ahfad university students and other interviewers from the local community.

\section{Study support}

This study was undertaken with support from Ahfad University for Women in Omdurman, Sudan. 


\section{References}

CBS, PAPCHILD (1993).Central Bureue of statistics and Pan Arab Project for Child Development, Sudan Maternal and Child Health Survey $1992 / 93$.

CBS, UNFPA (1993). Central Buerue of Statistics and UNFPA Sudan Maternal and Child Health Survey 1992/93. 
a 


\section{Chapter 3}

\section{The prevalence of self-reported health problems and haemoglobin status of Sudanese adolescents}

A manuscripts based on this chapter has been submitted for publication as: M.E.Moukhyer., N.K.de Vries., \& J. Th. M. van Eijk. The prevalence of self-reported health problems and haemoglobin status of Sudanese adolescents. 


\title{
The prevalence of self-reported health problems and haemoglobin status of Sudanese adolescents
}

\begin{abstract}
In this paper we describe self-reported health problems and hemoglobin status among 1200 Sudanese adolescents (53.2\% girls, $46.8 \%$ boys). Adolescents report their health as good in general. A large number reports specific physical and psychological compllaints for all subgroups. Girls report more psychological complaints than boys and more psychological problems are reported with increasing age. Chronic diseases are higher reported more by female, age groups 13-15 and those with the high level of education. Malaria consistently has a relatively high prevalence. The overall prevalence of anemia in our study is $32.2 \%$ (46.9\% boys, $19.2 \%$ girls). The lindings in our study do not sustain the traditional assumption that adolescence is a healthy period in human life.
\end{abstract}




\section{Introduction}

The onset of adolescence is a critical period of biological and psychological change for the individual. These years are highly formative for behaviour pattems and activities relevant to health. The basis for developing life styles is laid, affecting young people's health in its broadest sense, encompassing physical, social and emotional wellbeing (WHO, 1990). In accordance with the WHO perspective, we view health as a resource for everyday living, not just the absence of disease. Adolescence and the great rapid changes associated with it may have major effects on the health of individuals, and, conversely, variations in health may significantly affect the transitions of adolescence.

At present much attention is focused on adolescent health in developed countries where there is a considerable health problems of mental disorders and the abuse of alcohol and other substances in adolescents (WHO, 1995).

The attention given to these conditions in developed countries has, to a much more limited extent, been carried over to developing countries (UNICEF / WHO, 1995).

An aspect of the importance of health of young people specific to developing countries, which however has frequently been underemphasized, relates to their role in the work force. A much smaller proportion of young people in developing countries attend school and colleges than in the industrialized world, and a much larger proportion are economically productive. This may be a threat to health development per se, but also an economic necessity. Their youth and vigour implies that they are extremely important producers, so any severe health problem or premature mortality in this age group has major economic implications. The importance of the loss of young people's contributions through death and disability has accordingly been reflected in the weightings used by the World Bank in its assessment of the global burden of disease (World Bank, 1993).

In contrast with the economic importance described above, the few studies that do exist in developing countries are usually limited and existing data and figures on morbidity of adolescents are very selective and relate to diseases and care areas only (WHO, 1995).

Traditionally, the main health indicator used by health planners, policy-makers, researchers, and programme staff has been mortality. However adolescents have a low mortality and lower morbidity rate relative to both older and younger age groups in both developing and industrialized countries (United Nations, 1991). Consideration of mortality and morbidity rates alone has resulted in accordance by this group being seen as a relatively healthy age group, and this has led to their being assigned a low priority for health interventions.

A large number of empirical studies have demonstrated that a person's own appraisal of her/his health is powerful predictor of future morbidity and mortality, even after controlling for a variety of physical, socio-demographic and psychosocial health status indices (e.g., see Kaplan et al., 1996; Mossey et al., 1992).

However research demonstrated that there are many health problems as perceived by adolescents, which appeared to be important predictors of future health.

The traditional view of healthy adolescents is falsified in various empirical studies (Starfield et al., 1993, West \& Sweeting 1996; Tuinstra, 1998). At present much more information is needed by health and social services in order to inform them about the priority that should be given to programs focusing on this age group. 
Anaemia is one of the most widespread public health problems, especially in developing countries, and has important health and welfare, social and economic consequences. These include impaired cognitive development, reduce physical work capacity, and in severe cases risk of mortality. There is also evidence that anaemia may result in reduced growh, increased morbidity and negatiwe impact on learning capacity and cognitive development (INACG 2002). Anaemia can result from nutrition related causes, in particular iron deficiency, from inflammatory/infectious disease, and from blood loss.

In many areas lack of data makes it difficult to assess the true importance of potentially crucial issues related to the health and development of adolescents, especially due to the restricted scope of studies.

In this paper we will address two important indicators of adolescents' health, namely self reported health (self rated health, subjective health, chronic and preventable diseases) and haemoglobin status to determine anaemia. Haemoglobin determination is used in this study as a principal screen test using HemoCue as a simple and suitable device, available away from the laboratory, which is practically easy and reliable in measuring anaemia as a specific risk factor for diseases. Combination of both indicators will be our main focus to give a clear picture of the health status (objective and subjective health). First we will study the prevalence of both indicators and second we focus on their socio-demographic determinants (sex, age group and level of education).

Socio-demographic determinants (sex, age group and level of education) have been chosen to investigate health problems in a broader way and to give a complete picture that includes all subgroups and to give a sufficient basis for health policies in Sudan. Too often, adolescents of all ages are lumped together for research or policy purpose, thus failing to acknowledge the great strides in physical, mental, and emotional capacity teen will make between the ages of 10 and 19 .

The importance of gender perspective in this study to look at patterns of simularity and differences among them and speculate on their implications (Eltawila et al., 1997; Gijsbers van Wijk \& Kolk 1997; Goodman et al, 1997). The age groups division used roughly corresponds with the phases in physical, social, and psychological development in the transition from childhood to adulthood (Johnson, 1989).

In-depth examination of demographic predictors of health in Sudanese adolescents will generate information, which is not yet available on specific groups that are particularly vulnerable to health problems. Not much is know about how Sudan in this respect, and wondering about what is the health status of Sudanese adolescents compared with other studies in developed and developing countries (Sweeting 1995; Tuinstra 1998; El- Tawila et al., 1997). Using physical, mental, subjective and objective health indicators are more appropriate in this age range than morbidity and mortality indicators solely.

Traditionally, health policy in Sudan is considered a restricted policy field dominated by the biomedical model of health with it is focus upon delivery of health care services. As a result many psychological, social and behavioural health problems including adolescence are undressed in the National Health Policy of Sudan. As consequences adolescent's health cannot be fully integrated with national programs. Furthermore, hardly any comprehensive intervention strategy or program focusing 
adolescence can develop in the country. There is a need to develop a comprehensive National policy focusing upon not only the delivery of health care services but also other determinants of health in accordance with modern health paradigms. Such study could be a sufficient basis for adolescent health policy, but should also provide inputs for subsequent survey to investigate more in adolescent health.

\section{Methods}

\section{Design and population}

The health profile of Sudanese adolescents was assessed in a cross sectional, cluster random sampling survey study. The specific population selected for the study was adolescents from the Umbada community who were aged 10-19 years. Umbada was selected because its population is multi-ethnic, comprising people from different regions and tribes of Sudan. Umbada is a suburban area where the majority of people are of middle and low socioeconomic status.

\section{Sample size}

A random sample of 4 blocks from the total 38 blocks of Umbada was drawn. Households were selected by systematic random sampling starting from the centre of each block (every fifth house). All adolescents found in the households were interviewed', until the number needed in each block. was reached (the number that refused was not registered).

We acquired 300 adolescents from each block. A total sample of 1200 adolescents (53.2\% girls and $46.8 \%$ boys) was interviewed and a blood sample for haemoglobin measurement was collected from 1135 ( 65 refused to give blood).

\section{Data collection}

Data was collected during the period July-November 2001 as part of a study on the health profile of Sudanese adolescents. The data collection was done with the help of trained interviewers from the Ahfad University for Women and the Community Animators Friendly Association (CAFA) of the Umbada community.

Before data collection an introductory statement was first read by the interviewer to the head of the household to obtain his/her verbal consent. The same statement was presented to the adolescents as well, before interviewing commenced.

\section{Measurements}

The data were collected using a self-report questionnaire and laboratory investigation for haemoglobin determination, which included the following measures.

\footnotetext{
'Unfortunately, it was not recorded which adolescents live in the same household; the statistical dependency in the data could therefore not be corrected for. However analysis of single adolescents in a household shows the same patterns of result with the exception of anaemia in which case they were less anaemic compared to adolescents who have brothers and sisters in the same household.
} 


\section{Self-rated health}

Was measured by asking one question, which is a well-established measure on self, reported health (Idler \& Benyamini, 1997) to the respondents to rate their health as excellent, good, fair, and poor. There are many studies from the international literature confirming the relationship between this variable, and morbidity and mortality over a long period (Kaplan et al., 1996).

\section{Subjective health complaints}

To asses subjective health we measured physical health and psychological health complaints. We used the 8-item version developed for the survey of Health Behaviour among School-aged Children (HBSC) (King et al., 1996) which has also been used in an Egyptian study (Eltawila et al., 1997). It is a self-report closed ended questionnaire consisting of statements about aspects of current health, expressed in physical health complaints such as headache, stomachache and backache, and psychological health reports about aspects of well-being which cause regular problems, such as feeling low, irritability or bad temper, feeling nervous, loss of sleep and feeling dizzy.

Views of adolescents concerning their subjective health were obtained by a single question for each complaint, i.e.: does [complaint] cause you regular problems?

Response options were every day, more than once a week, about every week, once a month, rarely or never. Data were dichotomized by combining the first three responses in one category: at least once a week, and the remaining responses in the category: rare.

A summary measure of psychological complaints was created by summing the number of complaints experienced at least once a week. The same summary measure done for Physical complaints.

\section{Chronic and Preventable illness}

Were assessed by means of a questionnaire based on previous health interviews done in Sudan among the general population by the Sudan Central Bureau for Statistics (SCBS), the federal Ministry of Health (MOH) based on international literature (King et al.1996; Eltawila et al. 1997; Tuinstra 1998). Based on a pilot study the questionnaire was improved. The questionnaire provided a selection of seven chronic illnesses (asthma, renal, diabetes, sinusitis, rheumatism, migraine, eczema) and three acute illnesses (malaria, bilharzias, and parasitic infestation), which are most prevalent among the Sudanese population. The respondents were asked whether or not they (had) suffered from any of these chronic and acute illnesses by answering yes or no.

A summary measure of chronic illness was created by adding the number of illness. The same summary measure done for preventable diseases. 


\section{Haemoglobin determination}

Biomedical data such as haemoglobin determination have been used as simple, reliable tests for the detection of anaemia. Capillary blood is obtained by pricking the fingertip with a sterile lancet. A drop of blood is collected into a disposable microcuvette and the level of haemoglobin can be determined using the HemoCue photometer (HemoCue AB, Angelholm, Sweden). The HemoCue instrument allows the detection of anaemia by estimating the haemoglobin level in a sample of blood. It provides accurate results that are comparable to the cyanmethemoglobin method (Von Schenck et al., 1985; Be.W.K et al., 1991). No processing of the blood specimen is needed, and the result can be read directly without calculation in less than 45 seconds. Moreover, the instrument is portable, which makes it usable in the field and quite practical for use in surveys. Anaemia is considered to be present if the haemoglobin value is below $12 \mathrm{~g} / \mathrm{dl}$ for adolescent girls, and below $13 \mathrm{~g} / \mathrm{dl}$ for adolescent boys (WHO, 1968).

\section{Socio-demographic variables}

These factors include sex, age (10-12,13-15 and above 16 years) and educational level, which were classified into three levels, ranging from no education through basic to secondary education.

\section{Analysis}

The analysis was done using the statistical software package SPSS version 11.0

First analyses were performed separately for sex, level of education and age group. We used bivariate analysis (cross tabulations with no controls) and chi-square statistics to test the degree of association between the column and row variables and understand the relationship (if any) between those variables. A p $\leq 0.05$ (2-sided) level was used to determine significance.

Secondly, logistic regression analysis was used separately for each dependent variable with all independent demographic variables (sex, age group and level of education) as predictors to assess the degree of association using odd ratios (OR) with $95 \%$ confidence intervals $(\mathrm{Cl})$. The application of this model is justified by the dichotomous nature of the dependent variables. For continuous variable we used linear regression coefficients (b).

The variation in numbers $(\mathrm{N})$ in the analyses is due to differences in missing values between variables. 


\section{Results}

\section{Self-rated health}

Table 1 shows the answers of adolescents conceming their self-rated health. Males more often reported their health status as being excellent compared to females. A very small percentage of males and females reported their health as being bad ( $5.3 \%$ females and $3.4 \%$ males). The youngest age group frequently reported excellent health. The age group above 16 reports poor health status much more often. Those with no education reported poor health status more often than those with education.

Table 1. Percentage of self-rated health by different background characteristics $(\mathrm{N}=1200)^{*}$

\begin{tabular}{|c|c|c|c|c|c|c|}
\hline & & Etscellent & Good: & Fair & Poor & p- พ-allate \\
\hline Ovintsl & $(\mathrm{n})$ & $39.00^{\circ \%}$ & $45.000^{4 \%}$ & $90 \%$ & $4.30 \%$ & \\
\hline \multicolumn{7}{|l|}{ Sex } \\
\hline Male & 554 & 43.9 & 43.9 & 8.8 & 3.4 & \\
\hline Fetnale & 622 & 36.2 & 47.7 & 108 & $\$, 3$ & 0.03 \\
\hline \multicolumn{7}{|l|}{ Age group } \\
\hline $10-12$ & 367 & 43.9 & 46.0 & 7.6 & 2.5 & \\
\hline $13 \times 15$ & 422 & 43,4 & 43.1 & 92 & 4.3 & \\
\hline $16 \%$ & 387 & 32,0 & 48.8 & 127 & 6.5 & 0.0 \\
\hline \multicolumn{7}{|c|}{ Level of educiation } \\
\hline No educathot & 32 & 37.5 & 37.5 & 12.5 & 12.5 & \\
\hline Basiéc & 803 & 41.7 & 458 & 8.7 & 3.7 & \\
\hline Secondary & 341 & 35.5 & 46,9 & 123 & 5.3 & 0.05 \\
\hline
\end{tabular}

Significance $p<0.05$

*(Missing 24)

\section{Subjective health complaints}

Physical health

Table 2 shows the percentage of adolescents reporting subjective health complaints at least once a week. The physical complaints head aches and stomachaches were reported by a relatively large number of adolescents. Headaches are often reported by both gender groups (females $49.4 \%$, males $48.4 \%$ ) and younger adolescents $(50.2 \%$ ) at age 13-15 years old and for those with basic level of education $(50.0 \%)$.

Weekly stomachache is less frequent than head ache. The results show no differences between sexes. Those with no education report stomach ache more often than those with basic and above secondary education.

Fewer adolescents have weekly backache than stomach and headache. More males report backache, and backache increases modestly with age for both gender groups from $9.9 \%$ for $10-12$ years old to $14.9 \%$ for those above 16 years old and is also slightly higher for those without and basic education than for those with secondary education and above. 


\section{Psychological health}

As we can see from Table 2 females report more psychological complaints than males with the exception of feeling low, and rritability, which are almost equal. More problems are reported with increasing age for feeling low being irritable, feeling nervous, and difficulty to sleep. Those without education frequently reported feeling low, irritability and difficulty to sleep.

Table 2. Subjective health reported at least once a week by different demographic characteristics $(\mathrm{N}=1200)$

\begin{tabular}{|c|c|c|c|c|c|c|c|c|}
\hline & \multicolumn{3}{|c|}{ 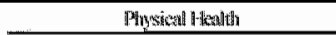 } & \multicolumn{5}{|c|}{ 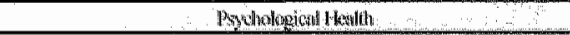 } \\
\hline & Hendathe & Sornitatiactio & Pathate & Pacling liow & Brinthiliby & Nernotis & 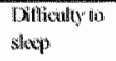 & Iixalling dizty \\
\hline areallio & $48.90 \%$ & $20.10 \%$ & $11.0 \% \%$ & 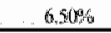 & $1300 \%$ & $1840 \%$ & $3.46 \%$ & 470 \\
\hline $\mathrm{sex}$ & $\%$ & $\%$ & 噌 & 8 & 然 & 然 & 牾 & w \\
\hline Male & $\#$ \# & 220 & 13.1 & 6.9 & 13.8 & 16.5 & 8.5 & dill \\
\hline Fentale & 49.4 & 18.4 & 10.8 & 6.1 & 129 & 20.1 & 100.2 & 5.4 \\
\hline \multicolumn{9}{|l|}{ Age groras } \\
\hline $10-12$ & 48.5 & 211.0 & 9.9 & 5.8 & 8.2 & 13.7 & 64 & 3.4 \\
\hline $13-15$ & 50.2 & 20.2 & 10.8 & 4.8 & 120 & 17.8 & 8.5 & $3 \%$ \\
\hline \multirow[t]{2}{*}{$16 \mathrm{t}^{\circ}$} & 47.9 & 880 & 14.9 & 8.9 & 19.6 & 23.6 & 1xt & 70 \\
\hline & & & & & * & $\infty$ & $*$ & \\
\hline \multicolumn{9}{|c|}{ Letel of Education } \\
\hline Mo linesition & 469 & 310.3 & 125 & 15.6 & 185.8 & 219 & 15.6 & 43 \\
\hline Hasic & 500 & 19.7 & 12.5 & 6.1 & 11.0 & 16,5 & 8.5 & 4.1 \\
\hline \multirow[t]{2}{*}{ Scoonsthiny it } & 466 & 19.7 & 10.4 & 6.6 & 18.3 & 22.6 & 11.1 & 6., हA \\
\hline & & & & & * & & & \\
\hline
\end{tabular}

(Missing varying between 21-168)

* Significance $\mathrm{p}<.05$

\section{Chronic and Preventable diseases}

\section{Chronic diseases}

Table 3 shows the reported patterns of chronic diseases. The reports by females are higher than those of males for six chronic diseases out of seven. Two chronic diseases are highly reported by boys and girls; migraine, and sinusitis. Females suffer from migraine twice as frequently as males did.

Migraine as a chronic disease is more prevalent within the age group of 13-15 years. Those with a high level of education reported higher prevalence of chronic diseases; migraine is at the top followed by sinusitis and renal diseases.

The percentage of those with report of multiple morbidity is $17.8 \%$ (one or more chronic diseases, data not shown). 


\section{Preventable diseases}

Table 3 shows that malaria has a relatively high prevalence for adolescents regardless. of their sex, age and level of education (within the range of $71.9 \%-85.9 \%$ ). It is slightly more reported by those in the older age group than the younger, and by those with higher education compared to those with no education.

Bilharziasis shows higher prevalence among males compared to females.

Parasitic infestation is equally highly prevailing among all subgroups.

Table 3. Reported chronic and Preventable diseases by different demographic characteristics $(\mathrm{N}=1200)$

\begin{tabular}{|c|c|c|c|c|c|c|c|c|c|c|}
\hline & \multicolumn{4}{|c|}{ 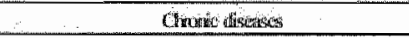 } & \multirow[b]{2}{*}{ 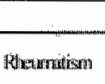 } & \multirow[b]{2}{*}{ Mgrifin } & \multirow[b]{2}{*}{ 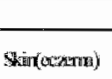 } & \multicolumn{3}{|c|}{ Preveruble dissases } \\
\hline & Aalum: & Syinumits & Rerenal & Datibetes & & & & Mhangiai & Bullumis & Paratioficas \\
\hline Ohendl & $3 \pm 6$ & $6.2 \%$ & $47 \%$ & $8.3 \%$ & $3.2 \%$ & $11.2 \%$ & $3.7 \%$ & $80.0 \%$ & $54 \%$ & $14.4 \%$ \\
\hline \multicolumn{11}{|l|}{$x+x$} \\
\hline Mulle & 3.5 & 5.3 & 2.8 & 1.1 & $\$ 18$ & 7,4 & 3.4 & 81.2 & 79 & 132 \\
\hline \multirow[t]{2}{*}{ Premille } & 26 & 710 & 63 & $1: 5$ & 4.4 & 14.6 & 3.9 & 72.0 & 33 & 155 \\
\hline & & & $*$ & & $*$ & . & & & $*$ & \\
\hline \multicolumn{11}{|l|}{ Age grouifes } \\
\hline $16-12$ & 4,7 & $4: 4$ & 3.6 & 4.6 & 310 & 7.2 & 30 & 76.4 & 4.9 & 14.8 \\
\hline $13-15$ & 3.1 & 58 & 4.1 & 4.7 & 3.4 & 15 & 4.7 & 78.5 & 6.8 & 158 \\
\hline \multirow[t]{2}{*}{165} & 3.2 & 84 & 6.3 & 0.5 & 3.1 & $\$ 0.8$ & 32 & 852 & 45 & 120 \\
\hline & & & & & & $*$ & & $*$ & & \\
\hline \multicolumn{11}{|l|}{ Lewet on Bitscition } \\
\hline 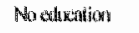 & 0.0 & 00 & 00 & 0,0 & 94 & 63 & 3.4 & 71.9 & 3.1 & 00 \\
\hline 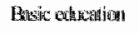 & 3.8 & 4.9 & 39 & 1.5 & 28 & 10.7 & 36 & 77.9 & 59 & 15.2 \\
\hline \multirow[t]{2}{*}{ Secorraty } & 2.1 & 9.9 & 69 & 0.9 & 3.6 & 129 & 39 & 85.9 & 4.5 & 14.1 \\
\hline & & 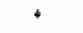 & 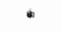 & & & & & * & & \\
\hline
\end{tabular}

(Missing varying between 23-136) * Significance $\mathrm{p}<0.0$

\section{Haemoglobin status}

Based on the cut-offs $(12 \mathrm{~g} / \mathrm{dl}$ for females and $13 \mathrm{~g} / \mathrm{dl}$ for males) the overall prevalence of anaemia among adolescents in our study is $32 \%$.

Table 4 shows a gender difference in anaemia for males compared to females $(46.9 \%$ males, $19.2 \%$ females).

The age group 10-12 years old has a prevalence of $39.8 \%$ which is high compared to the other age groups, then followed by a decline through the age group 13-15 years old which is $33.5 \%$ and reaching $23.7 \%$ at the age group above 15 years old. So anaemia declines with age.

Differentials are quite evident within each gender group across ages among anaemic adolescents (data not shown). For boys anaemia prevalence was $59.3 \%$ for the age group 10-12 years old, then decline reaching $31.2 \%$ at the age above 16 years old, which was also higher compared with girls across the ages (data not shown). 
Level of education differences were quite evident for those without education the level of anaemia was $273 \%$, this rises to $36.7 \%$ for those with basic education and then declines sharply to $22.5 \%$ for those with secondary education and above.

Table 4. Percentage of anaemia among adolescents by different demographic characteristics $(\mathrm{N}=1200)$

\begin{tabular}{lccc}
\hline & Anaemia & & Refused \\
\hline & $(\mathrm{n})$ & $\%$ & $(\mathrm{n})$ \\
Overall Prevalence & 366 & 32.2 & 65 \\
Sex & & & \\
Male & 251 & 46.9 & 27 \\
Fenale & 115 & 19.2 & 38 \\
& $*$ & & \\
Age group & & & \\
$10-12$ & 142 & 39.8 & 21 \\
$13-15$ & 135 & 33.5 & 26 \\
$16+$ & 89 & 23.7 & 18 \\
& $*$ & & \\
Level of education & & & \\
No education & 9 & 27.3 & 1 \\
Basic & 282 & 36.7 & 50 \\
Secondary * & 75 & 22.5 & 14 \\
& $*$ & & \\
\hline
\end{tabular}

Significance $\mathrm{p}<0.05$ 
In order to show the effect of the socio-demographic variables on the adolescent's report for health problems, we calculated the odd ratios and unstandardized regression coefficient. Table 5 shows that poor health is reported significantly more often by the age group above 16 years. Male adolescents are more anaemic than females OR $0.28(0.21,0.36)$ and the youngest age group 10-12 are most anaemic.

Adolescents above 16 years of age report psychological complaints significantly more often than other age groups.

Female respondents significantly report less chronic diseases than male adolescents does.

Those with no education report preventable diseases to a higher extent. 


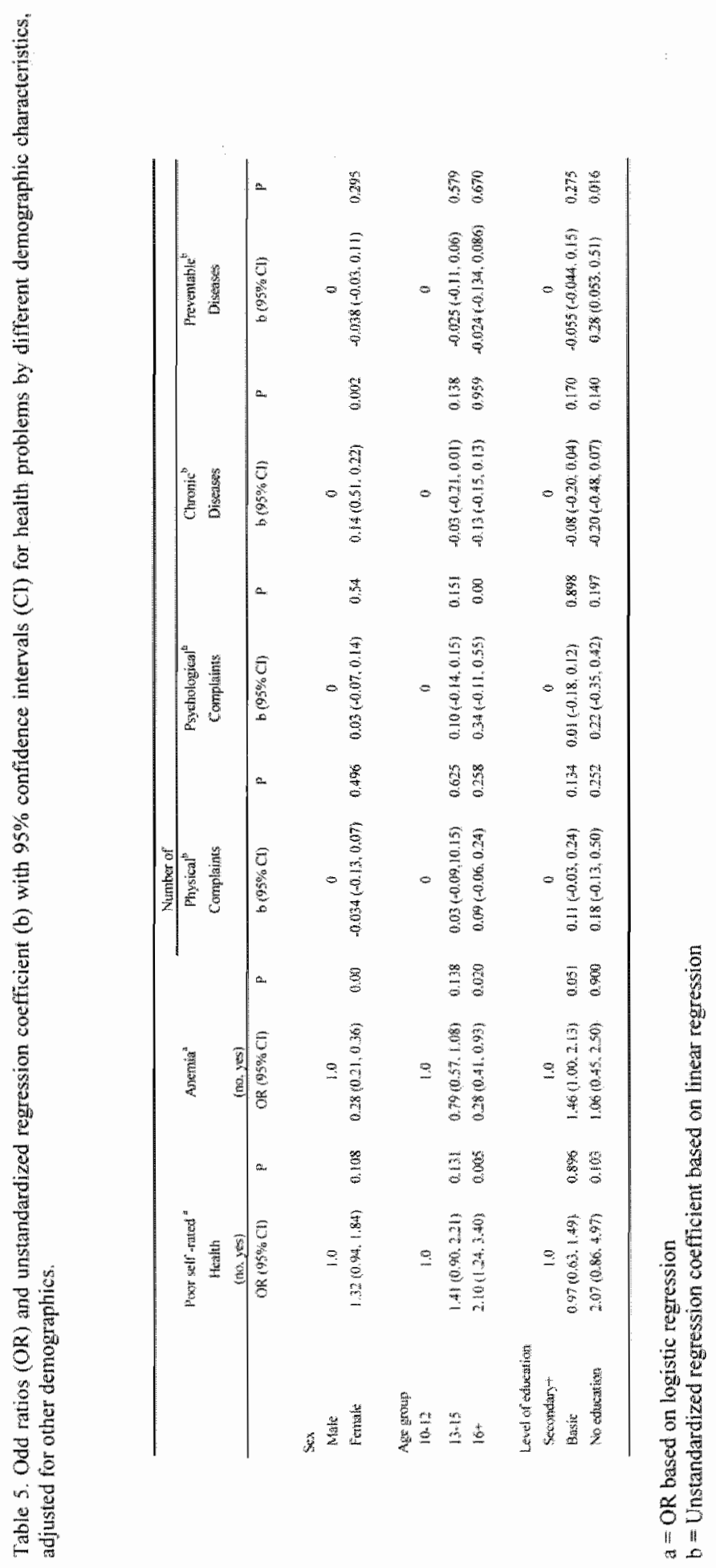




\section{Discussion}

Our findings show a remarkably high number of adolescents evaluating their health as excellent and good. Males evaluated their health more positively than females. King et al, (1996) reported similar patterns of gender differences in self-rated health in 24 European countries and Canada. West et al (1990) and Glendinning et al. (1992) confirmed these findings in Scottish adolescents. Tuinstra (1998) in Dutch adolescents, and Eltawila et al. (1997) in the Egyptian national survey on adolescent's health.

Adolescents in all subgroups report high percentages of physical complaints, such as headaches, stomachaches and backaches, particularly headaches $48.9 \%$. These are consistent with other studies (Goodman \& MacCrath, 1991; King et al., 1996; Mikkelsson et al., 1997).

Psychological health problems are not highly reported (except for nervousness $18.4 \%$ ) by adolescents. In the age group above 16 years prevalence is significant in three items (irritability, feeling nervous, and difficulty to sleep), and for those with no and secondary education it is significant with regard to irritability.

Females report a thigh prevalence of six chronic diseases out of seven, such as migraine, and renal and rheumatic diseases, and in the age group of 13-15 years. Around $17.8 \%$ of the total group reports at least one or more chronic disease (data not shown).

Also, all respondents in all categories reported mallaria, which is an endemic disease in Sudan, frequently. The high rate of malaria $(80 \%)$ could be due to ineffective control measures; poor housing and people cannot afford bed nets. Billharzias is as well was reported often (to some extent especially by males) due to their swimming in water contaminated by infected snails (Michelson, 1993). Parasitic infestations were frequently reported by most of our respondents as a common problem in most communities in developing countries (WHO, $1990 \mathrm{~b}$; WHO, 1992a) and this is due to water born disease, food handling or sanitation problems.

Another conciusion of our study is the high level of anaemia among males, which confirm findings from other studies (DeMayer \& Adiels-Tegman, 1985).

Across our study adolescent females and the older age group consistently report a higher frequency of general health problems and negative effects of psychological health problems with the exception of anaemia. These patterns should be explored with more detailed cross-national analysis. Attention should be paid to psychological health especially for the older age groups, as well as to physical health (headaches, stomachaches and backaches), and chronic disease (migraine, sinusitis, renal diseases, and malaria). School health programs, and health insurance schemes for school children (to which most of our study group belong) will be the most effective way, because adolescents did not have health insurance coverage and were required to seek health services in either public or private sector facilities. However such services were out of reach for a large proportion of the population living below the poverty line. Developing an effective delivery point for adolescent health services would not only improve the well-being of people in this age group but would allow the govermment to allocate and utilize its limited resources more effectively. Adolescents have greater information and counselling needs and problems unique to this life stage; providers must be able to respond to those needs and make adolescents feel comfortable. Treating chronic yet common health conditions will lead not only 
to improved well-being among adolescents, but also to increased productivity, scholastic performances, and retention in school.

Anaemia is a major problem among adolescents; some of the possible causes are the inadequate intake of iron or other blood forming nutrients (i.e., poor quality diet) poor absorption of iron, extreme breakdown of the red blood cells and excessive loss of blood due to menstruation, malaria and parasitic worms, infections and genetic disorders like sickle cell disease. According to WHO Eastem Mediterranean Region (EMR) there are several reasons why iron deficiency is common in the EMR. Total intake of rich sources of iron such as meat is low. Bioavailability is limited due to grain-based diets common throughout the Region, containing substances that prevent the absorption of iron by the body. Thus nutrition and hygiene education campaigns would be important first steps in eradicating these problems. These campaigns should address the importance of and the components of a healthy diet, including more iron. in the diet and increasing the bioavailability of the iron. To increase the bioavailability, education and behaviour change measures are needed to promote positive dietary habits so as to reduce intake of inhibitors to iron absorption such as tea and to increase intake of enhancers to iron absorption such as vitamin $\mathrm{C}$ rich fruits and vegetables. Intervention through iron supplementation with folic acid and other micro-nutrients to prevent and correct anaemia can be effective in improving the haemoglobin level (Ballin et al., 1992) and fortification of common foodstuffs like sugar and/or flour with iron has been suggested as a preventive strategy (MacPhail \& Bothwell, 1989).

In addition, any intervention needs an educational component, which includes counselling and information that will encourage and support the target population to take the supplements.

Policy makers hardly consider policy interventions and programs in accordance with new public health and health promotion. There is a need to renew and upgrade the national policy with stronger emphasis upon al॥ the determinants, which will help to combat the problem of adolescents in an effective way.

The findings of our study do not sustain the traditional assumption that adolescence is a healthy period in human life.

Some observations should be made about this study.

Actually we are dealing with self- report questionnaires. It is not clear just how valid these responses are and how large any over-or under-reporting may be. The uncertainty here is caused by the absence of objective criteria provided by 'the best measure". Is the best measure the personal opinion, or that of a proxy such as parent(s) for example, or the expert opinion of a doctor? (Ecob et al., 1993).

However, comparable results are found in other studies, which supports our findings (Tuinstra, 1998; Eltawila et al., 1997). Equally high prevalence was reported in studies that interviewed both adolescents and their parents (Power \&Peckham 1990; Ecob et al., 1993). Additional bias could by caused by the specific categories of symptoms and diseases, in which other complaints cannot manifest. As well selfreport questionnaire used as the best measure to know subjective heallh.

Our sampling strategy led in most cases to members of the same household being participant in the study. As members of the same household may share environments and genes, observations were not completely independent. We, however, by omission camnot identify members of the same household (which would have enabled us to use appropriate (multilevel) teclmiques). Future research should find out the extent to 
which household characteristics have additional influences on the health of adolescents. Further investigations are needed to detect determinants of the relatively high prevalence of anaemia.

The findings suggest that adolescents in Sudan should be the target and that attention should be paid to their health problerns, which still are preventable, reversible and can be influenced by serious commitment of policy makers. 


\section{References}

Ballin, M.D., Berar, M., Rubinstein, U., Kleter, Y., Hershkovitz, A., \& Meytes, D. (1992). Iron state in female adolescents. American Jownal of Disabled Child, 146, 803-805

Be. W K., Kerkkamp. H E., \& Booij, L H. (1991). HemoCue- a new haemoglobinometer in the clinic. European Journal of Anaesthesiology, 8 , 55-58.

DeMayer, E., \& Adies-Tegman, M. (1985). The prevalence of anaemia in the world. World Health Statistics. Quart, 38, 302-316.

Ecob, R., Macintyre S., \& West P. (1993) Reporting by parents of longstanding illness in their adolescent children. Social Science and Medicine, 8, 10171022 .

EL-Tawila. S., Ibraham.B., Salam.S.,E] Gibaly.O., \& El Sahan.F. (1997). Transition to Adulthood, A National Survey of Egyptian Adolescents.

Gijsbers van Wijk., C.M.T., \& Kolk, A. M. (1997). Sex Differences in Physical Symptoms: the Contribution of Symptoms Perception Theory. Social Science and Medicine, 2, 231-246.

Glendinning, A., Love, JG., Hendry, LB., \& Sucksmith, J. (1992). Adolescence and Health Inequalities: extension to Macityre and West. Social Science and Medicine 5, 679-687.

Goodman, E., Amick, B.C., Rezendes, M.O., Tarlow, A.R., Rogers, Wh., \& Kagan J.(1997). Influences of Gender and Social Class on Adolescents' Perception of Health. Archives of Pediatric and Adolescent Medicine, 151, 899-904.

Goodman, J. E., \& MacCrath, P. (1991). The epidemiology of pain in children and adolescents: a review. Pain, 46, 247-264.

Idler, E. L., \& Benyamini, Y. (1997). Self-rated health and mortality: A review of twenty-seven community studies. Journal of Health and Social Behaviour. $3821-37$.

International Nutritional Anaemia Consultative Group (NACG). (2002). Anaemia iron deficiency, and iron deficiency anaemia.

Johnson, R. (1989). Adolescent growth and development. In: Hofman A.D., and Greydanus, D.E. (Eds). Adolescent Medicine.2 ${ }^{\text {nd }}$ Edition.Norwalk, Conneticut: Appleton and Lange. 
Kaplan GA., \& Camacho T. (1996). Perceived health and mortality: a nine-year follows up of the human population laboratory cohort. American Journal of Epidemiology, 117, 292-304.

King.A., Wold.B., Smith.C.T., \& Harel.Y. (1996). The Health of Youth a Cross National survey, Development patterns of behaviours and attitudes. WHO Regional Publications. European serious No.69.

Kooiker, S. (1996). Illness in everyday life. A health diary study of common symptoms and their consequences. Thesis, University of Groningen.

Kruz, K.M., \& Johnson- Welch, C. (1994). The mutrition and lives of adolescents in developing countries: Findings from the nutrition of adolescent Girls

Research Program. Washington, D.C. International Center for research on Women.

Macphil, A.P., \& Bothwell, T.H. (1989). Fortification of the diet as a strategy for preventing iron deficiency. Acta Paediatrica. Scand. Suppl, 361,114-124.

Michelson, E.H. (1993). Women and schistosomiasis. Social Science and Medicine, $37,493-501$.

Mikkelsson, M., Salminen, J., \& Kautiainen, H. (1997). Non-specific musculoskeletal pain in preadolescents. Prevalence and 1-year persistence. Pain, 73, 29-35.

Mossey, JM., \& Shapiro E. (1992). Self-rated health: a predictor of mortality among the elderly. American Journal of Public Health, 72, 800-08.

Power, C., \& Peckham, C. (1990). Childhood morbidity and adulthood ill health. Journal of Epidemiology and Community Health, 44, 69-74.

Starfield, B., Begner, M., Ensminger, M., Riley, A., Ryan, S., Green, B., Mcgauhey, P., Skinner, A., \& Kim, S. (1993). Adolescent health status measurement: development of the Child Health and IIIness Profile. Paediatrics, 91, $430-435$.

Sweeting. H. (1995). Reversals of fortune? Sex differences in health in childhood and adolescence. Social Science and Medicine, 40, 77-90.

Tuinstra, J. (1998). Health in Adolescents. An Empirical Study of Social Inequality in Health The Prevalence of self-reported health problems in male and female Dutch adolescents. Thesis, Groningen University, The Netherlands.

UNICEF \& WHO. (1995). The State of the Wold's Children. New York: Unicef. 
United Nations. (1991). Demographic yearbook, 1991. New York: United Nations.

Von Schenck., Falkensson, M., \& Lundberg, B. (1986). Evaluation of "HemoCue," a new Device for determining Haemoglobin. Clinical Chemistry, 32, 526529.

West, P., Macintyre, S., Anmandale, E \& Hunt, K. (1990). Social Class and health in Youth: findings from the West of Scotland Twenty 07 Study Social Science and Medicine, 6, 665-673.

West, P., \& Sweeting H. (1996). No job, No future: young people and health in a context of unemployment. Health and social care in the community, 4, 5062.

WHO (1968). Nutritional anaemias: report of a WHO scientific Group. WHO Technical Report Series, No. 405. Geneva, Switzerland: WHO;

WHO (1990). Basic documents, $38^{\text {th }}$ ed. Geneva.

WHO (1990b). Informal consultation on Intestinal Helminth Infections. Geneva, 9-12 July 1990. Document WHO/CDS/IPI/90.1, Geneva: World Health Organization.

WHO (1992a). WHO/PAHO Informal Consultation on Intestinal Protozol infections, Mexico, 21-23 October 1991.Document WHO/CDS/IPI/92.2,Geneva: World Health Organization.

WHO (1995). The provision of reproductive health services to adolescents in Indonesia, Nigeria and The Philippines. Unpublished document.

World Bank. (1993). World Development Report: Investing in Health, New York: Oxford University Press. 

Chapter 4

\section{Health related behaviours of Sudanese adolescents}

A manuscripts based on this chapter has been submitted for publication as: M.E.Moukhyer., J. Th. M. van Eijk., \& N.K.de Vries. Health Related Behaviours of Sudanese Adolescents. 


\title{
Health related behaviours of Sudanese adolescents
}

\begin{abstract}
Adolescence is the period (10-19 years) during which lifestyle patterns of behaviours are being formed. These behaviours set the stage for funure health problems, as risktaking and health compromising lifestyles are major causall factors for many health problems. Behaviours and lifestyle are determinants of future health, illness, disability, and premature mortality.
\end{abstract}

\section{Objectives:}

To gain new insight into and better understanding of health behaviours, lifestyle and their context in these young people in order to assess the determinants and barriers to improve health related behaviours.

\section{Methods:}

A cross sectional descriptive study. Random samples of 1200 adolescents within the age group $10-19$ years ( $53.2 \%$ females and $46.8 \%$ males) were interviewed.

\section{Main outcomes:}

The overall prevalence of smoking among adolescents is $4.9 \%$. More males $(9.1 \%)$ than females (1.3\%) report to smoke. Older participants report more tobacco use, as well as those with higher level of education.

Drinking alcohol is significantly more common for boys (2.3\%). It is slightly more reported by those in older age group than the younger, and by those with no education compared to those with education.

More males than females report to be actively engaged in sport activities; inactivity is significantly higher amongest older age groups and is associated with no education. $58 \%$ of girls are physically inactive.

More than half of the males go hungry because there is not enough food in the house; this is somewhat less common for females $(43 \%)$.

Adolescents above 16 years old significantly teport less consumption of nutritious food (healthy eating) as well less consumption of non-nutritious food (unhealthy eating) than other age groups.

\section{Conclusion:}

Our research contributed to greater understanding of current health related behaviours among Sudanese adolescents. A number of implications (e.g. hunger experience and physical inactivity for females) for interventions arise from the finding. 


\section{Introduction}

Adolescence is the period during which lifestyle patterns of behaviour are being formed. These behaviours set the stage for future health problems, as risk-taking and health compromising lifestyles are major causal factors for many health problems.

Behaviour and lifestyle are conceived to be crucial determinants of future lhealth, illness, disability, and premature mortality. There is considerable evidence that unhealthy behaviours increase the risk of the development of many diseases and therefore can be considered as a cause of future disease (Hansell et al., 1999 \& Aarons et al., 1999). Overall, it has been estimated that $40 \%$ of premature deaths in developing countries, and $70-80 \%$ in developed countries, are attributable to behaviours, many of which begin in adolescence (WHO, 1995).

Adolescence is a time of learning, which necessarily includes risk taking, but the conditions in which those risks are taken will often make the difference between constructive and destructive outcomes.

The most important health related behaviours appear to be smoking, alcohol consumption, eating habits and physical inactivity, which will be studied in this paper.

There appears to be an increase in the use of tobacco and alcohol among young people in developing countries, where restrictions on advertising and access are often weaker than in industrialized countries. These behaviours, which typically begin in adolescence, bring about a host of problems, not only in the short term but also in the longer term. Both tobacco and alcohol use have been shown to be prominent causes of morbidity and premature mortality.

In fact, tobacco use alone accounts for nearly three million deaths each year and has been identified as the leading cause of preventable death in the developed world (Peto et al., 1992; Pan American Health Organization, 1992).

Thus it is now recognized that smoking is associated with a wide range of diseases, such as cardiovascular disease, cancer, and respiratory illness (WHO, 1993; Johnson, 1991).

Over the past 30-40 years, more and more young people have started to drink alcoholic beverages. Alcohol consumption has uncreased in quantity and frequency (Plant, 1985) and the age at which drinking starts has declined.

Islamic law forbids drinking alcohol, and this law is followed strictly in the northern of Sudan where the majority are Muslim. Nevertheless alcohol is widely available in the northern cities of the Sudan. Distinctions that once separated cultures, sexes and social classes are vanishing, as young people in developed and developing countries alike are increasingly using and abusing alcohol (Giesbrecht, \& Fisher, 1987).

Similarly to smoking the adverse and long-term effects of excessive alcohol consumption on health have been established and include certain cancers, stroke, hypertension, liver disease and depression.

Public health strategies across many developed countries have set targets that include reducing the number of new smokers, increasing the age of the onset of smoking and reducing the overall level of consumption (Harkin,1997). Many also aim to support 
smoking cessation, promote moderation in alcohol use and reduce the risk of alcohol abuse. Nevertheless, the frequency of such behaviour is reported both to be high and to appear earlier among young people.

Childhood is an important time for establishing healthy eating habits, and maintaining healthy-eating patterns remains important as children grow into adolescents. When young people are hungry or undernourished, they have difficulty resisting infection and therefore are more likely to become sick, to miss school and to fall behind in class. They are irritable and have difficulty concentrating, which can interfere with learning, and they have low energy, which can limit their physical activity (Miles \& Eid, 1997).

One dietary habit widespread among Sudanese regardless of sex social class or age is the drinking of tea, particularly after meals. Tealeaves contain a substance (tannic acid), which inhibits the absorption of dietary iron (Garrow \& James, 1993). The habit of drinking tea after meals is clearly problematic for adequate iron intake.

In the past 20 years, several large, long-term studies of adults have shown that physical inactivity is a major risk factor for morbidity and premature mortality from coronary heart diseases (CHD) (Leon et al., 1987; Powel et al., 1987). Regular physical activity can benefit young people, as well (Sallis \& Faucett, 1992). Since risk-factor levels in childhood predict levels in young adulthood (Cresanta et al., 1986), decreasing them in young people is an important health consideration.

In addition to benefits related to the prevention of CHD, physical activity appears to promote mental health in adults (Taylor et al., 1985) and enhance self-esteem in young people (Gruber, 1986). Physical activities and sport, as well as other important types of health behaviour constitute important socialization arenas for young people (Kenyon \& McPherson, 1973).

Health behaviours and lifestyle in adulthood is, to a large extent, the product of development during adolescence. From a public health perspective, young people therefore are an important target group for health education and health promotion efforts. Health behaviours are highly complex, and each behaviour has numerous influences or determinants.

Examination of the generally accepted behavioural factors and evidence of their causal relationship to disease, their prevalence in the population, and their potentially combined effects, lead to the conclusion that there is a large effect on the health of the population from just a few major health related behaviours.

This paper is focuses on the health-related behaviour of Sudanese adolescents and aims to gain new insight into and better understanding of health behaviours, lifestyle and their context in these young people in order to assess the determinants and barriers to improve health related behaviours. Secondly to contribute in planning, design and intervention to improve the health of this group. Thirdly to target the policy makers to consider this ignored group in their agenda.

In this paper we compare adolescents' self- reported health behaviours of different gender, and age, and educational groups. 


\section{Methods \\ Design and population}

The health profile of Sudanese adolescents was assessed in a cross sectional, cluster random sampling survey study. The specific population selected for the study were adolescents from the Umbada community who were aged $10-19$ years. Unbada was selected because its population is multi-ethnic, comprising people from different regions and tribes of Sudan. Umbada is a suburban area where the majority of people are of middle and low socioeconomic status.

\section{Sample size}

A random sample of 4 blocks from the total 38 blocks of Umbada was drawn. Households were selected by systematic random sampling starting from the centre of each block (every fifth house). All adolescents found in the households were interviewed, until the number needed in each block was reached.

We selected 300 adolescents from each block. A total sample of 1200 adolescents ( $53.2 \%$ girls and $46.8 \%$ boys) were interviewed.

\section{Data collection}

Data was collected during the period July-November 2001 as part of a $\mathrm{PhD}$ study on the health profile of Sudanese adolescents. The data collection was done with the help of the trained interviewers from the Ahfad University for Women and the Community Animators Friendly Association (CAFA) of the Umbada community.

Before data collection an introductory statement was first read by the interviewer to the head of the household to obtain his/her verbal consent. The same statement was presented to the adolescents as well, before interviewing commenced.

\section{Measurements}

We included four health-related behaviours in this study: smoking, alcohol consumption, physical inactivity and eating habits.

\section{Smoking}

Smoking habits were measured by asking one question to the respondents: Have you ever tried smoking a cigarette? There were three possible answers, ranging from " 1 have never; Yes, but I quitted smoking; Yes, I smoke".

The last two responses were combined to distinguish those who tried smoking and currently smoked, from those who do not smoke (no, yes).

\section{Alcohol}

Respondents were asked one question: do you drink alcohol? There were two possible answers, no or yes. 


\section{Physical inactivity}

(No) Physical exercise was assessed, yes/no, by the question: "Do you do any sports?" (Tuinstra, 1998). For exploratory purpose, further questions were asked: "If yes what type of sport? And where do you play this sport?"

\section{Eating habits}

Concening eating behaviours participants were asked to indicate the frequency of eating or drinking each listed food item (frut, raw vegetables, cooked vegetables, coke or other soft drinks that contain sugar, sweet, potato crisps, meat, salty food, tea, and bread) by giving one of the following six responses: never, less than a day, once a day, more than once a day (King et al., 1998).

The two response categories of more than once a day and once a day were combined to derive a frequency of daily consumption for each item in contrast with the other four, indicating infrequent use.

The responses of adolescents about foods and drink items are divided in two categories: nutritious (healthy) foods which include fruit, vegetables (raw vegetables and cooked vegetables combined together), meat and bread and non-nutritious (unhealthy) foods which include coke or other soft drinks containing sugar, sweet, potato crisps, salty food, and tea (Eltawila et al., 1997).

The respondents were also asked how often are you hungry because there is not enough food in the house? There were three possible answers, never/hardly ever, sometimes, and a lot. The second and third responses were combined to distinguish those who go hungry because there is not enough food in the house from those who said never/hardly ever.

\section{Socio-demographic variables}

These factors include sex, age groups (10-12, 13-15 and above 16 years) and educational level which was classified into three levels: no education, basic, and above secondary education.

\section{Analysis}

The analysis was done using the statistical software package SPSS version 11.0.

First analyses were performed for the separate health related behaviour variables to test the association with sex, level of education and age group. We used bivariate analysis (cross tabulations) and chi-square statistics to test the significance of the associations between the dependent and independent variables and to understand the relationship (if any) between those variables. $\mathrm{A} \leq 0.05$ (2-sided) level was used to determine the significance.

Secondly logistic regression was used separately fol. each dependent variable with all independent demographic variables (sex, age group and level of education) as predictors to assess the degree of association using odd ratios (OR) with $95 \%$ confidence intervals (Cl). Logistic regression used in this paper for simultaneous analysis, which could not be done by cross tabulation and chi-square alone. 


\section{Results}

\section{Separate health related behaviours association}

The first set of analyses shows the effect of gender age group, level of education and the association between these three variables on the separate health related behaviours.

Table 1 shows that the overall prevalence of smoking among adolescents is $4.9 \%$. More males than females report to smoke. More older participants report tobacco use, as well as those with higher levell of education.

Consumption of alcohol is significantly more common for males although modest in reported prevalence. It is slightly more reported by those in older age group than the younger, and by those with no education compared to those with education.

More males than females report to be actively engaged in sport activities; inactivity issignificantly higher amongest older age groups and is associated with no education. $40.5 \%$ of those who are actively involved in sport are playing football. $23.8 \%$ of their activity are practiced at home and $17.5 \%$ at neighbouring streets (data not shown).

Table 1 shows that more than half of the males go hungry because there is not enough food in the house; this is somewhat less common for females. Experiences of hunger are equally highly prevalent among different age groups and levels of education.

Table1. Percentage of adolescents who are currently smokes; drink alcohol, physical inactive and hunger experiences by different background characteristics $(N=1200)$

\begin{tabular}{|c|c|c|c|c|c|c|c|c|c|}
\hline & & \multicolumn{2}{|c|}{ Smating } & \multicolumn{2}{|c|}{ Aloghtwi } & \multicolumn{2}{|c|}{ 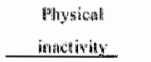 } & \multicolumn{2}{|c|}{$\begin{array}{c}\text { Hunuger } \\
\text { experiences }\end{array}$} \\
\hline & $\mathbb{N}$ & 桠 & $\mathrm{p}$ & $w / \%$ & $p$ & $\%$ & H & $\%$ & $p$ \\
\hline Oterall & & 40 & & 11. & & 35.8 & & $\operatorname{sen} A$ & \\
\hline \multicolumn{10}{|l|}{$5 \times x$} \\
\hline hatalie: & $36 ?$ & 5.1 & & 2.3 & & $\$ .7$ & & 306 & \\
\hline Fenendute & 6.188 & 13 & (1) & 0,5 & 0.05 & 583 & 0.018 & Fit & 099 \\
\hline \multicolumn{10}{|l|}{ 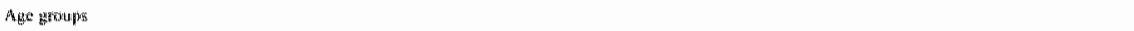 } \\
\hline $10-12$ & 370 & $1 . \mathrm{A}$ & & 1.1 & & $\mathbb{2} 8.8$ & & HAt. & \\
\hline $13+13$ & 420 & 13 & & 13 & & $32 s$ & & 48.2 & \\
\hline I & 393 & 10.4 & 0.09 & 1.8 & 0.639 & 4. & $0 ; 8$ & $4^{2}=5$ & 0.512 \\
\hline \multicolumn{10}{|c|}{ Heted of colntestias } \\
\hline 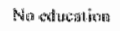 & 34 & $3 \%$ & & 2.9 & & 529 & & 48 & \\
\hline Eligsin & 819 & 3.8 & & $2 \%$ & & 52.8 & & 48.6 & \\
\hline Sesmontry & 347 & 79 & $\operatorname{sen} 3$ & 12 & $0: 69$ & $88: 0$ & (1) 915 & 42 & 0.153 \\
\hline
\end{tabular}




\section{Nutritious (healthy) foods}

Table 2 shows that a third of the males and females eat fruits. The older group reports lower fruit consumption. Half of those with no education report eating fruits on a daily basis. More than half of all subgroups report consumption of vegetables.

Meat consumption is equally prevalent among all subgroups. Bread consumption is significantly less for those with no education compared to those with above secondary and basic education. About $49.1 \%$ reported they eat more than two nutritious food items on a dailly basis (data not shown).

\section{Non-nutritious (unhealthy) foods}

Table 2 shows that the consumption of soft drinks is equally reported among subgroups. Differences of daily consumption of sweets between boys and girls are small. Daily consumption of sweets is significantly lower for the age group above 16. Potato crisps consumption is equally reported among all subgroups.

More males significantly consume salty food than females do. Consumption is reported less frequently with older age and higher level of education.

As Table 2 shows most adolescents drink tea, significantly more males than females do, and especially the youngest age group. Those with no education drink less tea compared to those with higher education.

Table 2. Percentage of respondents reported daily consumption of different types of food by different background characteristics $(\mathrm{N}=1200)$

\begin{tabular}{|c|c|c|c|c|c|c|c|c|c|c|}
\hline & \multicolumn{4}{|c|}{ Nutritious (hedithy) froods } & \multicolumn{6}{|c|}{ Mlsn nutritinass (umheraliny) foods } \\
\hline & & W'uat & Vegactistoliss & Mutegit & Breat & Soll drinks: & Swent & Crisps & Saliy lood & Tea: \\
\hline Detrogerapliate & $N$ & $\%$ & $\%$ & $\%$ & $\%$ & $\%$ & $\%$ & $\%$ & $9 / 3$ & $\%$ \\
\hline \multicolumn{11}{|l|}{$\sin x$} \\
\hline Marlic & 502 & 33.5 & 70.1 & 55.7 & 062 & 439 & 55,4 & 38.7 & $4 \geq 9$ & 91.0 \\
\hline ffituille & 43 & 31.9 & 69.7 & the & 07.4 & 44.8 & 60.65 & 3,2 & 320 & 望4.6 \\
\hline \multicolumn{11}{|l|}{ A } \\
\hline$t h-12$ & 378 & $M 0$ & 70.0 & $5 \%$ & 57.8 & $44 \pi$ & (n) & 40.4 & .40 .1 & C月.2 \\
\hline $13-15$ & $\times 29$ & 31.8 & 73.4 & 61 & ant. & 40. H & 64.3 & 30.5 & 37.4 & sh. \\
\hline $66 i$ & 903 & 303 & 65.6 & 360 & 9.5 .67 & 48.2 & 48 & 36.9 & 3.9 & $\begin{array}{c}3.6 \\
*\end{array}$ \\
\hline \multicolumn{11}{|c|}{ 4. } \\
\hline Novedtication & 34 & 500 & d) & 67.6 & 88.6 & 42. & 48.5 & 39. ․ㅐ & $\$ 8.5$ & 79,4 \\
\hline Mansic & mis & 314 & 70.1 & 57.5 & 97.8 & 43.6 & 58.7 & चाia.4i & 37 & 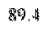 \\
\hline Socondist & $14 y$ & 337 & 70.3 & 50.6 & 9 & 48.8 & 98.9 & 15.5 & M.S: & 㤎4.2 \\
\hline
\end{tabular}

*Significance $\mathrm{p}<0$ 
Table 3 shows odd ratios and unstandardized regression coefficient with $95 \%$ confidence intervals for the association between health related behaviours and different demographic characteristics controlling other demographics. Smoking prevalence is lower for femalles, and age predicts smoking. Females also show low incidence of alcohol consumption. Physical inactivity is higher for females than for males, and also higher for those with higher education and older age. Hunger: experiences are lower for females, and higher for the older age above 16 years.

Adolescents above 16 years old significantly report less consumption of nutritious food (healthy eating) as well less consumption of non-nutritious food (unhealthy eating) than other age groups.

When other demographic variable are taken into account, Jogistic regression analysis shows no significant association between smoking behaviour and level of education.

\section{Table 3.}

Odd ratios (OR) and unstandardized regression coefficient (b) with $95 \%$ confidence intervals (CI) for health related behavior by different demographic characteristic, simultaneously adjusted for other demographics.

\begin{tabular}{|c|c|c|c|c|c|c|c|}
\hline & $\begin{array}{l}\text { Smownge" } \\
\text { (Imo yes) }\end{array}$ & $\begin{array}{l}\text { Avand } \\
\text { (arayes) }\end{array}$ & \multicolumn{2}{|c|}{ 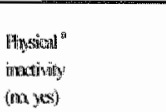 } & 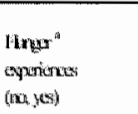 & 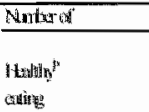 & 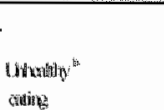 \\
\hline \multicolumn{8}{|l|}{ Domgraghic } \\
\hline \multicolumn{8}{|l|}{$8 x^{2}$} \\
\hline Farralk: & 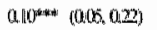 & $0.19 \%(00606)$ & $1524^{*}$ *aw & $(1086,21.40)$ & $075+(10005)$ & 006 ( 6100,018$)$ & - $1130(030,000)$ \\
\hline \multicolumn{8}{|l|}{ Agegram } \\
\hline $13-15$ & $335+4001036)$ & $1,30(0.22 .4 .55)$ & $(40)$ & $(014 \times 200)$ & $136 \quad(10.5,1.68)$ & $0,06,(4,10,0,2)$ & a $4123,40303,0053$ \\
\hline $16 \%$ & $1560 \quad(511.47 \%)$ & $2610060.1071)$ & $26 \times 4 * 1$ & $(1.7,7,4.68)$ & $150^{\circ},(1,09221)$ & $\left.+105^{*}(0), 01000\right)$ & 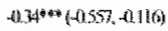 \\
\hline \multicolumn{8}{|c|}{ 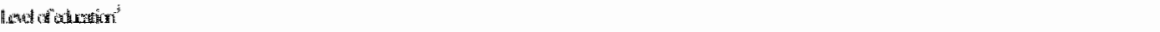 } \\
\hline Motic & $1.81 \quad\{0202148\}$ & $0,2(0 k, 3,6)$ & (Lit4 & $(0,19,1.04)$ & $104 \quad(25 \%, 2) \%$ & 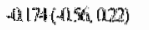 & $(0,4,4,40)$ \\
\hline Sritombay & $14 \div(0121212)$ & $0.27048 .261)$ & $\left(22^{0.04}\right.$ & $(012,0,0)$ & 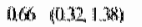 & 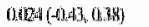 & 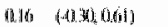 \\
\hline
\end{tabular}

$a=$ OR based on logistic regression

$b=$ Unstandardized regression coelficient based on linear tegression

1) Male reference group

2) 10-12 reference group

3) No education reference group

${ }^{*} \mathrm{p}<05, * \mathrm{p}<.01, * * * 0<, 001$ 


\section{Discussion}

This study provided insight in the most important health related behaviours: stnoking alcohol, nutrition and physical inactivity among Sudanese adolescents.

Although prevalence of smoking and alcohol consumption among Sudanese adolescents is low, this will not exclude the harmful effects. A possible explanation of this low prevalence could be due to the culture and to the method of data collection of oral interview, Programs to promote healthy behaviours to reduce ill health and death due to smoking and alcohol consumption should be stimulated. These include the creation of smoke -free environments, and the restriction of the availability, sale (there is no age restriction on the purchase of cigarettes in Sudan), and advertising of tobacco. More intensive awareness campaigns are needed, particularly in areas where adolescents meet, such as schools, universities, clubs, youth centres, and religious institutions.

For example, given the relatively high levels of smoking found among boys compared with females in this study, a campaign to promote smoke free schools could be organized, encouraging all adults and students to refrain from smoking on school ground. Such a campaign would emphasize the value of a smoke-free enviromment but also encourage health behaviour among adolescents (e.g. The European Smoking Prevention Framework Approach, ESFA could be of use after adaptation to Sudan situation), (De Vries, H. et al., 2003).

A school based curriculum on health promotion for the younger age, focusing on consequences of tobacco use and the contents of tobacco and cigarette smoke and how to make informed decisions about the use of tobacco, will be of great benefit.

In spite of Islamic religion and cultural reservation in the northern of Sudan, the use of alcohol is a fact in Sudanese society. The first battle to be won is to accept the reality of alcohol drinking in the Muslim societies, so that we can approach it realistically. Any general condonement of drinking alcohol seems to increase the number of drinkers

(N. N.Wig, 2003) url: http:/Www.unkkoked.com/sep/thirdworl.htm.

Also it is equally dangerous not to educate our adolescents about the side effect of drinking especially if uninformed about the consequences. The solution is somewhat similar to the dilemma of sexual education in AIDS programs. Sexual education may encourage promiscuity and disrupt traditional societies but unsafe sex can lead to the death of our children. Ideas like sensible drinking (for non Muslims) will succeed only if they are conveyed as part of larger programs of public policy and health education in which moderation in all spheres of human behaviours is accepted as a basis for healthy life. The old debates and old solutions have become irrelevant.

The level of sport activity among adolescents is relatively high for males compared to females. Other studies have also shown that males are generally more physically active than females (Sallis \& Faucette, 1992).

"The reasons for this may be that males receive a great deal of encouragement from their families and from society to play sport and be physically active. Moreover in Sudan there is a cultural belief that a female's place is in the home. Attitude and policy should be changed regards females involvement in physical activities out side the school. where there are also fewer facilities designated for the use by young females. 
Cultural norms and values in Sudan are more permissive for males and tend to encourage male socialization in the outside world. Although this varies across $\$ 00$ io economic levels, subcultures, and rural/urban origin, sport facilities available for femalle adolescents are generally more limited. This may require much closer attention.

Improvements in opportunities for physical activity are also needed in schools (and elsewhere), particularly for females.

Schools should be active in promoting physical activity among all adolescents, but especially among girls. Because of mobility restrictions, females have fewer venues for physical activity available to them. Moreover, official agencies and NGOs should invest more in appropriate sport facilities for females.

As could be expected, food consumption patterns vary widely across different categories of demographic variables. Besides personal and social factors, food availability and culture play an important role.

There are however difficulties in interpreting the data about adolescents' dietary habits. The diets of a significant number do not conform to the current nutritional advice; as adolescents mature and gain more control over their own food consumption patterns, they seems less likely to choose healthy foods. For the older adolescents, there are limited possibilities for obtaining a balanced diet due to factors such as economics, culture, and lack of availability of foods. Therefore, national local and school based food programs could be an effective intervention.

Interventions should include environmental approaches, for example, availability, price reduction of fruits and vegetables in schools and easily accessible food supplementation programs.

At present in Sudan there is no clear policy and commitment to school health programs as there is no legislative Act for school health. The main activities of school health were periodical examination, and some personal health services (Bayoumi, 1979).

WHO (1987) Eastern Mediterranean Region (EMRO) describes the level of Sudanese school health as underdeveloped, without a national plan and without services focusing on curative care.

Our research contributed to greater understanding of current health related behaviours among Sudanese adolescents. A number of implications for interventions arise from the findings.

It is clear from the data presented, and from other research done around the world, that comprehensive health promotion interventions are needed. A program like Healthy For Life (HFL) designed to equip school stuclents with the social competencies and life skill necessary to manage a situation in which high-risk behaviours are expected and rewarded by others. It seeks to improve health behaviours in nutrition, tobacco, and alcohol and could be adapted to cover physical activity.

Maximizing the health potential of adolescents requires a sustained and coordinated program of action, including school health education, health promotion programs targeted at parents, and community with adolescent's organizations. 
The magnitude, resources, and time frame for addressing these issues should not be underestimated. However the cost to the state and society of delaying a response is high and the damage that may result is irreversible. Moreover, the future of the country in terms of its productive capacity and its ability to compete globally hinges on how well the state and society are able to prepare adolescents for the challenges of the new millennium. 


\section{References}

Aarons, GA, brown, SA., \& Coe, MT. (1999). Adolescents alcohol and arug abuse and health. Joumal of Adolescent Healh, 24,412-421.

Bayoumi A. (1979). The history of Sudan health services, Kenya literature burea, Nairobi.

Cresanta, J.L . (1985). Prevention of atherosclerosis in childhood: prevention in primary care. Paediatric Clinic North America, 33, 835-858.

De Vries, H., Mudde, A., Leijs, I., Charlton, A., Vartiainen, GB., Clemente, MP., Storm, H., Navarro,GA., Nebot, M., Prins, T., \& Kremers, S.(2003). The European Smoking prevention Framework Approach (EFSA): an example of integral prevention. Health Education Research, 18,(5): 611626.

EL-Tawila, S., Ibraham.B., Salam.S., El Gibaly.O., \& El Sahan.F. (1997).Transition to Adulthood, A National Survey of Egyptian Adolescents.

Giesbrecht, N., \& Fisher, H. ed. (1995). Alcohol-related casualties (proceedings of an international symposium, Toronto, Canada, 1985). Toronto, ARF Books, 1987.

Gruber, J.J. (1986). Physical activity and self-esteem development in children:

a meta-analysis. In: Stull, A.G. \&Eckert, H.M., ed. Effects of physical activity on children. Champaign, IL, Human Kinetics Books.

Harkin AM. (1997). Smoking drinking and drug taking in the European Region. Copenhagen, WHO Regional Office for Europe.

Hansell, S., White, HR., \& Vali, FM. (1999). Specific alcoholic beverage and physical and mental health among adolescents. Journal Studies Alcohol, 60 , 209-218.

Johnson, K. (1991). The smoking epidemic. London: Health Education Authority.

Kenyon, G.S., \& McPherson, B.D. (1973). Becoming involved in physical activity and sport: a process of sociallization. In: Rarick G., ed. Physical activity: human growth and development. New York, Academic Press.

King.A., Wold.B., Smith.C.T., \& Harel.Y. (1996). The Health of Youth a Cross National survey, Development patterns of behaviours and attitudes. WHO Regional Publications. European serious No.69. 
Leon, A.S., Connett, J., \& Jacobs, DR. (1987) Leisure-time physical activity levels and risk of coronary heart disease and death: the multiple risk factor intervention trial. Joumal of the American Medical Association, 258, 23882395 .

Miles, G., \& Eid, S. (1997). The dietary habits of young people. Nursing times, 93(50): 46-48.

(N. N.Wig, 2003) url: http://wow unkkoked.com/sep/thirdworl.htm.

Pan American Health Organization (1992). Smoking and health in the Americas: a 1992 report of the Surgeon General. Atlanta, GA: Public Health Service Office on Smoking and Health (DHHS publication, NO.[CDC] 92-8419).

Peto, R., Lopez, A.D., \& Boreham, J. (1992). Mortality from tobacco in developed countries: Indirect estimation from national vital statistics. Lancet,339 (8804) : 1268-1278.

Powell, K.E., Thompson, P.D., \& Caspersen, CJ. (1987). Physical activity and the incidence of coronary theart disease. Annual review of public health 8: 253287.

Plant M. A.. (1985) Alcohol, drugs and school lever. London, Tavistock Publication.

Sallis, J.F., \& Faucette, N. (1992). Physical Activity. In: Wallace, H.M. et al., ed. Principle and practices of student health. Oakland, CA, Third Party Publishing.

Taylor, C.B., Sallis, J.F., \& Needle, R. (1985). The relationship between physical activity and exercise and mental health. Public health reports 100(2):195202.

Tuinstra, J. (1998). Health in Adolescents. An Empirical Study of Social Inequality in Health. The Prevalence of self-reported health problems in male and female Dutch adolescents. Thesis, Groningen University, the Netherlands.

WHO (1987). Health problem of children and youth: a challenge for schools health education .Geneva: WHO printing press.

WHO (1993). Press Release. World no-tobacco day: Health versus smoking.

WHO (1995). Adolescent health and development: the key to the future. Geneva, World Health Organization (WHO/ADH/94.3). 


\section{Chapter 5}

\section{The Associations between health status (subjective and objective health) and health related behaviours among Sudanese adolescents}

A manuscripts based on this chapter has been submitted for publication as: M.E.Moukhyer., N.K.de Vries., \& J. Th. M. van Eijk. The Associations between health status (subjective and objective health) and health related behaviours among Sudanese adolescents. 


\title{
The Associations between health status (subjective and objective health) and health related behaviours among Sudanese adolescents
}

\begin{abstract}
In this paper we aimed to explore the association between general health problems and health related behaviours among 1200 Sudanese adolescents. The findings show that two important health behaviours, namely smoking and hunger were associated with less favourable self-rating of health. Adolescents who smoke or experienced hunger actually reported poorer subjective/ perceived health than those who did not smoking or experienced hunger. Anaemia was found to be associated with smoking. The study also revealled a significant association between psychological complaints and experiences of hunger. On these grounds it was concluded that subjective health (rated health and psychological complaints) and objective health (anaemia) were sensitive and scientifically interesting indicators that could be meaningfully related to health behaviours such as smoking and hunger experience.
\end{abstract}




\section{Introduction}

The study of health behaviours and the health status of adolescents provide public health planners with information to improve program planning (cf. the Intervention Mapping protocol, Bartholomew et al., 2000; Precede/Proceed, Green \& Kreuter, 2001). In Sudan often there is a concern about the lack of specific information regarding this group. This lack of information is not limited to Sudan alone; lack of such information is also a problem in Africa and globally (Nyamwaya, 2003). This can make health planning for this group potentially less targeted and effective.

Previous research, conducted in many developed countries to ascertain the relationship between health status and particular behaviours, strongly indicates that nutrition, smoking tobacco, drinking alcohol; sexual practices and exercise have a significant impact on both the physical and mental health of adolescents. These behaviours exacerbate and increase the risk for physical and psychological health and chronic illness in later life.

Healthy eating and physical activity patterns during adolescence promote optimal growth and development, help to prevent immediate health problems, and may prevent long-term chronic diseases (Story \& Neumark-Sztainer, 1999). Additionally, adolescence can contribute to morbidity and mortality (smoking, heavy drinking, no regular participation in sports and exercise, traffic accidents, and violence) (Hurrelman \& Losel, 1990). According to Berenson et al. (1980) 60\% of the children in the United States had at least one modifiable adult risk factor for coronary heart disease by the age of 12 . In this regard, it should be noted that recent research suggests that the consequences of adolescents' risky behaviour can be observed already in early adulthood (Hansel et al., 1999).

In the Minnesota Adolescent Health Survey (MAHS) higher rates of eating disorders (anorexia nervoasa \& bulima) were found among adolescents with chronic illness than among those without (Neumark-Sztainer et al., 1995). Ferraro and Yu (1995) found that obese persons with Body Mass Index (BMI) $>30.5$ rated their health more negatively than others, even after controlling for a variety of indicators of ill health and physical functioning.

There is growing interest in the study of adolescent health and behaviour in different cultures, both within and between countries. Importantly, most of these studies have been conducted in North America and Western Europe. Relatively little is known about this association in developing countries. However, the poor nutritional situation, the increase of tobacco use, the spreading of sexually transmitted disease and the lack of spare time to exercise are all factors that suggest that adolescents' health status might be worse in the developing world than in Europe (WHO, 1999).

In this study smoking, physical inactivity and hunger experience were chosen to represent health related behaviours of Sudanese adolescents as they have been proven to be strongly associated with other types of health risk behaviours. Alcohol use was not included in this paper due to the small number of respondents who reported drinking alcohol; this result perhaps relates to religious norms in the Sudan were the majority are Muslims.

By exploring the associations between health status (subjective and objective health) and health related behaviours (early smoking, physical inactivity and hunger 
experience), we will be able to shed light on the expected future general health of adolescents in Sudan where previously no studies have been done.

In this chapter, we investigated whether associations can be found between health status and health related behaviours among Sudanese adolescents. Such associations would be an indication of the importance of health behaviours that ouglit to be changed by health education or health promotion.

\section{Methods}

\section{Design and population}

The health profile of Sudanese adolescents was assessed in a cross sectional, cluster random sampling survey study. The specific population selected for the study consisted of adolescents from the Umbada community who were aged 10-19 years. Umbada was selected because its population is multi-ethnic, comprising people from different regions and tribes of Sudan. Umbada is a suburban area where the majority of people are of middle and low socioeconomic status.

\section{Sample size}

A random sample of 4 blocks from the total 38 blocks of Umbada was drawn. Households were selected by systematic random sampling starting from the centre of each block (every fifth house). All adolescents found in the households were interviewed, until the number needed in each block was reached.

We selected 300 adolescents from each block. A total sample of 1200 adolescents ( $53.2 \%$ gir $\|_{\mathrm{S}}$ and $46.8 \%$ boys $)$ was interviewed.

\section{Data collection}

Data was collected during the period July-November 2001 as part of a PhD study on the health profile of Sudanese adolescents. The data collection was done with the help of trained interviewers from the Ahfad University for Women and the Community Animators Friendly Association (CAFA) of the Umbada community.

Before data collection an introductory statement was first read by the interviewer to the head of the household to obtain his/her verbal consent. The same statement was presented to the adolescents as well, before interviewing commenced.

\section{Measurements}

Smoking, physical inactivity and hunger experience were chosen in this study to represent health-related behaviours. Less than good rating of health and the number of psychological complaints represent subjective health. Anaemia and the number of chronic illnesses represent physical well being (objective health).

\section{A. Subjective health}

\section{Self- rated health}

Was measured by asking the respondents to rate their health as excellent, good, fair, or poor. There are many studies from the international literature confirming the relationship between this variable, and morbidity and mortality over a long period (e.g., Kaplan et al., 1996). Data were dichotomized by combining the first two 
responses in one category: good health and the remainung responses in the category. less than good health.

\section{Psychological health complaints}

For the assessment of psychological complaints we used the version developed for the survey of Health Behaviour among School-aged Children (HBSC) (King et al., 1996) which has also been used in an Egyptian study (Eltawila et a 1 ; 1996). It is a self-report questionnaire consisting of five statements about regular psychological problems; feeling low, irritability or bad temper, feeling nervous, loss of sleep and feelling dizzy. For each statement there are five possible answers; every day, between once a day and once a week, about once a week, between once a week and once a month, or less than once a month.

Views of adolescents concerning their subjective health complaints were obtained by a single question for each complaint, i.e.: does [complaint] cause you regular problems?

Data were dichotomized by combining the first three responses in one category: at least once a week, and the remaining responses in the category: less than once a week.

A summary measure of psychological complaints was created by summing the number of five complaints experienced at least once a week.

\section{B. Objective health}

\section{Chronic illness}

Was assessed by means of a questionnaire based on previous health interviews done in Sudan among the general population by the Sudan Central Bureau for Statistics (SCBS) and the federal Ministry of Health (MOH). Based on a pillot study the questionnaire was improved. The questionnaire provided a selection of seven chronic illnesses (asthma, renal disease, diabetes, sinusitis, rheumatism, migraine, eczema). The respondents were asked whether or not they (had) suffered from any of these chronic illnesses by answering yes or no.

A summary measure of chronic illness was created by adding the number of illnesses.

\section{Anaemia}

Anaemia was measured as a proxy for biomedical health status using a simple, reliable test. Capillary blood was obtained by pricking the fingertip with a sterile lancet. A drop of blood was collected into a disposable microcuvette and the level of haemoglobin was determined using the HemoCue photometer (HemoCue AB, Angel Holm, Sweden). The HemoCue instrument allows the detection of anaemia by estimating the haemoglobin level in a sample of blood. It provides accurate results that are comparable to the cyanmethemoglobin method (Von Schenck et al., 1985 and Be et al., 1991). No processing of the blood specimen is needed, and the result can be read directly without calculation in less than 45 seconds. Moreover, the instrument is portablle, which makes it usable in the field and quite practical for use in surveys. Anaemia is considered to be present if the haemoglobin value is below 12 $\mathrm{g} / \mathrm{dl}$ for adolescent girls, and below $13 \mathrm{~g} / \mathrm{dll}$ for adolescent boys (WHO, 1968). 


\section{Health related behaviours}

\section{Smoking habits}

Were measured by asking one question to the respondents: Have you ever tried smoking a cigarette? There were three possible answers, ranging from 'I have never', 'Yes, but I quitted smoking", "Yes, I smoke".

The last two responses were combined to distinguish those who tried smoking and currently smoked, from those who never smoked (no, yes).

Physical activity

(No) Physical exercise was assessed, yes/no, by the question: "Do you do any sports?" (Tuinstra, 1998).

\section{Hunger experience}

The respondents were also asked how often are you hungry because there is not enough food in the house? There were three possible answers, never/hardly ever, sometimes, and a lot. The second and third responses were combined to distinguish those who go hungry because there is not enough food in the house from those who said never/hardly ever (yes/no).

\section{Socio-demographic variables}

These variables include sex, age (10-12, 13-15 and above 16 years) and educational level, which were classified into three levels, ranging from no education through secondary to high education.

\section{Analysis}

The analysis was done using the statistical software package SPSS version 11.0 .

Logistic regression analysis was used separately for each dependent variable (less than good health and anaemia) and linear regression (number of chronic illness and number of psychological complaints) with all independent variables (smoking, no sport, and hunger experience) controlling for demographic variables (sex, age groups and level of education) to assess the degree of association using odd ratios (OR) with 95\% confidence intervals (Cl) and unstandardized regression coefficient (b).

The variation in numbers (N) in the analyses is due to differences in missing values between variables. 


\section{Results}

Table 1 shows that the odd ratio of less than good rating of health was significantly higher for those who smoke and with liunger experience.

When simultaneously adjusted for the other health behawiours and controlling for demographic these relations were replicated.

Psychological complaints were univariately associated with hunger experience. When simultaneously adjusted for the three behaviours and controlling for demographic variables these relations were replicated (Table 2).

Table 3 shows that chronic ilmess with no association with health behaviours (not simultaneously or simultaneously adjusted), controlling for demographic variables.

Table 4 shows that anaemia was univariately associated with smoking. When simultaneously adjusted for the three behaviours and controlling for demographic variables these relations were replicated.

\section{Table 1}

Odds ratios $(95 \%$ confidence interval) of less than good rating health as dependent and smoking, physical inactivity and hunger experiences as independent variables controlling for sex and age groups and level of education

\begin{tabular}{|c|c|c|c|c|}
\hline & & & 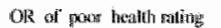 & of of pors keallth rating \\
\hline & & & 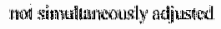 & 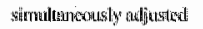 \\
\hline & $(n)$ & $9 \%$ & OR (OSwC) & OR $05 \%$ \\
\hline Redhiswiouss: & & proor hestldin & & \\
\hline \multicolumn{5}{|l|}{ Simbaking } \\
\hline Nio & 1.118 & 14 & 1.0 & $1.0 \mathrm{i}$ \\
\hline Yis & 58 & 26 & $2.17(11.13, * 1,15)$ & $2.01(1,04,3.90)$ \\
\hline \multicolumn{5}{|c|}{ 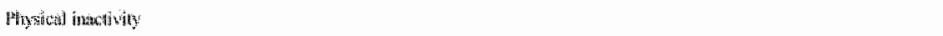 } \\
\hline sho & 703 & 12 & it. 0 & 10 \\
\hline Tiss & 413 & 18 & $0.72(0.90,100)$ & 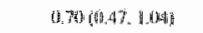 \\
\hline \multicolumn{5}{|c|}{ intuger experishts } \\
\hline No & 621 & 11 & 1.91 & 100 \\
\hline $\mathrm{Ves}$ & $\$ 46$ & 19 & $2065(1-46,298)\}$ & 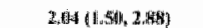 \\
\hline
\end{tabular}


Table 2 Unstandardized regression coefficient (b) with $95 \%$ confidence interwal wh number of psychological complaints as dependent and snoking, physical mactivity and huger experiences as independen variables, controlling for sex, age and level of education.

\begin{tabular}{|c|c|c|c|c|}
\hline & & & 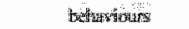 & betherioder: \\
\hline & & & 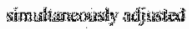 & 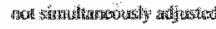 \\
\hline \multirow[t]{3}{*}{ 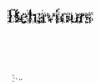 } & (a) & 8 & & \\
\hline & & hast onte & & \\
\hline & & Wyothedogita & $60 \% \%$ & b. \\
\hline \multicolumn{5}{|l|}{ Wmathing } \\
\hline ia & 144 & 20,16 & is & 0 \\
\hline $\mathrm{Yes}_{\mathrm{s}}$ & 59 & $37.3 \%$ & $0,21,0,05,0,46]$ & 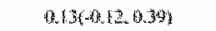 \\
\hline \multicolumn{5}{|c|}{ 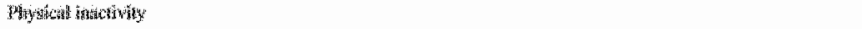 } \\
\hline no & 778 & $30 \%$ & $a$ & 0 \\
\hline Yers & 4h2 & the $6 \%$ & 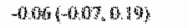 & $0.640(-0.09,0), 0)$ \\
\hline \multicolumn{5}{|c|}{ flangen enperane } \\
\hline wh & 627 & $25.4^{\circ / 4}$ & ほ & 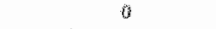 \\
\hline Yes & 58 & $35.4 * \%$ & a.ts $30.69,0.30 \%$ & 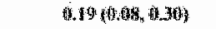 \\
\hline
\end{tabular}

Table 3 . Unstandardized regression coefficient (b) with $95 \%$ confidence interval of number of chronic thnesses as dependent and smoking, physical inactivity and hunger experiences as independent variables controlling for sex, age and level of education

\begin{tabular}{|c|c|c|c|c|}
\hline & & & bethavionstase & hathaviours \\
\hline & & & 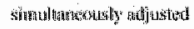 & 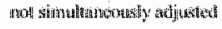 \\
\hline \multirow[t]{2}{*}{ Mehaw } & (1) & $0 \%$ & & \\
\hline & & $\begin{array}{l}\text { A lews calk } \\
\text { duronis: }\end{array}$ & b $(45, \%)$ & $605 \% \mathrm{cl}$ \\
\hline \multicolumn{5}{|l|}{ samking } \\
\hline Wa & 154 & $22.809 \%$ & 0 & in \\
\hline Yess & 39 & $217.70 \%$ & $004\{0017,024\}$ & $-402(-0,23,0,19)$ \\
\hline \multicolumn{5}{|c|}{ 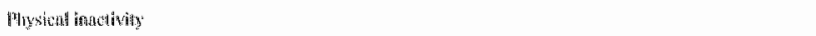 } \\
\hline 祉 & 779 & $20.80 \%$ & a & 0 \\
\hline Ywitio & 421 & $26,61)$ & $0,06,-40 \%, 0,124$ & $0,02(-0.190,0.12\}$ \\
\hline \multicolumn{5}{|c|}{ 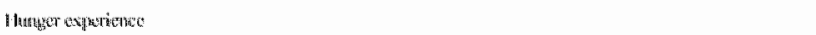 } \\
\hline Nom & $\{27$ & $2 x 80 \%$ & 0 & 0 \\
\hline$l_{1}$ & 351 & $27.80 \%$ & 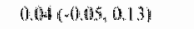 & $0.04+6,0050,039$ \\
\hline
\end{tabular}


Table 4 . Odds ratios (95\% confidence interval) of anaemia as dependent and smoking, physical inactivity and hunger experiences as the independent variables, controlling for sex; age and level of education

\begin{tabular}{|c|c|c|c|c|}
\hline & & & 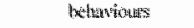 & 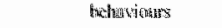 \\
\hline & & & 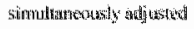 & 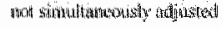 \\
\hline & (i) & 想 & & \\
\hline Bexhyviouss & & matanis & $4 \times(4 \times 600)$ & b $(0,40)$ \\
\hline \multicolumn{5}{|l|}{ Snnoking } \\
\hline $\mathrm{Nos}$ & $107 \%$ & 33 & 1.0 & 10 \\
\hline Yes & 58 & 26 & 0.5) $(0.2 \%, 00,97)$ & U.S.SI $(0.27,69.97)$ \\
\hline \multicolumn{5}{|c|}{ Physical inativity } \\
\hline $\mathrm{Na}$ & 739 & 38 & 1.0 & 1.0 \\
\hline Yes & 396 & 22 & $0.060 \%, 1.38$ & $0.58(0.60,1.3 \mathrm{y})$ \\
\hline \multicolumn{5}{|c|}{ Nhinger experionse } \\
\hline$N(x)$ & 589 & il & 1.0 & 1.0 \\
\hline Yos & 525 & 34 & $1.03(0.790 .35\}$ & $105(0.80 .4,38)$ \\
\hline
\end{tabular}

\section{Discussion}

The results of this study show that two important health behaviours, smoking and hunger experience, are associated with poor health rating among the Sudanese adolescents, but not physical inactivity. Adolescents who smoke or experience hunger actually report poorer perceived health than those who do not.

The results show a significant association between smoking and anaemia (objective health).

Our data showed no association between chronic illness and health-reiated behaviours.

Chronic illness and functional limitations are rare among adolescents and may show up later in adulthood. Bad objective health could, for example, be too mild to be diagnosed at this age, although it may still cause respondents to perceive his or her health less than good.

The data showed a significant association between psychological complaints and hunger experience. Hunger and eating are compensatory processes that function to maintain the body's energy resources at a set point. Polivy (1996) and Keyes, (1950) showed in their studies the consequences of food reduction /hunger and it is psychological effects on human being.

In conclusion this study shows that subjective health (rated health and psychological complaints) and objective health namely anaemia are sensitive and scientifically interesting indicators that can meaningfully be related to health behaviour. They can 
be used in epidemiological research to identify young people's association of health status with health related behaviours (Ravens-Sieberer et al., 2000). It also demonstrates the necessity of providing early support and education to this age group. 


\section{References}

Bartholomew,L.K., Parcel,G.S., Kok,G., \& Gottlieb, N.H. ( 2000). Intervention Mapping, theory and evidence-based health promotion programs. Mayfield Publishing Company, Mountain View, California.

Be. W K., Kerkkamp. H E., \& Booij, L H. (1991). HemoCue- a new haemoglobinometer in the clinic. European Jownal of Anaesthesiology, 8 , 55-58.

Berenson, GS., McMahon ,CA., \& Voors, AW. (1980). Cardiovascular risk factors in children: The early natural history of atherosclerosis and essential hypertension. New York: Oxford University Press.

EL-Tawila. S., Ibraham.B., Salam.S., El Gibaly.O., \& El Sahan.F. (1997). Transition to Adulthood, A National Survey of Egyptian Adolescents.

Ferraro, K.F. \& Yu, Y.(1995). Body weight and self rating of health: mechanisms of health decline. Joumal of Health and Social Behaviowr, 36, 274-284.

Green \& Kreuter. (2001). Health promotion planning. An educational and environmental approach. CA: mountain view, Mayfield.

Hansell, S., White, HR., \& Vali, FM. (1999). Specific alcoholic beverage and physical and mental health among adolescents. Jourmal of Studies Alcohol, $60,209-218$.

Hurrelman, K., \& Losel, F. (1990). Health hazards in adolescence. Berlin; de Gruyter.

Kaplan GA., \& Camacho T. (1996). Perceived health and mortality: a nine-year follows up of the human population laboratory cohort. American Journal of Epidemiology, 117, 292-304.

Keys, A., Brozek, J., Mickelson, O., \& Taylor, HL. (1950). The biology of human starvation. 2 vols. Minneapolis, Minn: University of Minnesota Press.

King.A., Wold.B., Smith.C.T., \& Harel.Y. (1996). The Health of Youth a Cross National survey, Development patterns of behaviours and attitudes. WHO Regional Publications. European serious No.69.

Neumark-Sztainer D., Story M., Resnick M., Garwick A., \& Blum RW. (1995). Body dissatisfaction and unhealthy weight-control practices among adolescents with and without chronic illness: a population-based study. Archive Paediatric Adolescent Medicine. $\$ 49,1330-1335$. 
Nyamwaya, D. ( 2003). Health promotion in Africa; strategies, players challenges and prospects, Health promotion international yol.18. no 2 .

Polivy, J. (1996). Psychological consequences of food restriction. Journal of American Dietician Association. 96, 589-592.

Ravens-Sieberer, U., Gortler, E., \& Bullinger, M. (2000) Subjective health and health behaviour for children and adolescents a survey of Hamburg students within the scope of school medical examination. Gessundheitswesen, $62,(3), 148-55$

Story, M., \& Neumark-Sztainer, M. (1999). Promoting healthy eating and physical activity in adolescents. Adolescent Medicine, 10, 109-123.

Tuinstra, J. (1998). Health in Adolescents. An Empirical Study of Social Inequality in Health. The Prevalence of self-reported health problems in male and female Dutch adolescents. Thesis, Groningen, University, the Netherlands.

Von Schenck., Falkensson, M., \& Lundberg, B. (1986). Evaluation of "HemoCue," a new Device for determining Hemoglobin. Clinical Chemistry, 32, 526529.

WHO (1968). Nutritional anemias: report of a WHO scientific Group. WHO Technical Report Series, No. 405. Geneva, Switzerland: WHO.

WHO (1999). Programming for Adolescent Health and Development, report of WHO/UNFPA/UNICEF Study group on Programming for Adolescent Health, WHO, Geneva. 


\section{Chapter 6}

\section{The social context of Sudanese adolescents and health}

A manuscripts based on this chapter has been submitted for publication as: M.E.Moukhyer., J. Th. M. van Eijk., \& N.K.de Vries. The social context of Sudanese adolescents and health 


\title{
The social context of Sudanese adolescents and health
}

\begin{abstract}
This paper describe the social context and health among 1200 Sudanese adolescents $(53.2 \%$ girls, $46.8 \%$ boys) The findings show that the majority of respondents live with their parents and are able to communicate more easily with their mothers and older sisters than with their fathers and brothers. In general, female adolescents showed more difficulty in talking to family members of the opposite sex (father and elder brother) and friends than males.

A positive family environment significantly correlates with a good health status indicated by rating good health, happy feelings and optimistic about the future.

A lless restrictive and more communicative and receptive family environment seem to be correlated with positive development of the adolescent's character.
\end{abstract}




\section{Introduction}

Attitudes and behaviours in adolescence and adulthood are largely rooted in the childhood family setting. Lifestyle-related habits in hygiene, nutrition and physical activity, as well as communication skills and social competencies, are essential products of familial education (WHO, 2000). Deficits in these areas are among the main reasons for health impairments in later life. The family is therefore a decisive factor in adolescents' health and health behaviors that needs further investigation (Galambos \& Ehrenberg, 1997; Ryan, 1994).

Studies of adult populations have demonstrated that social relations are important predictors of future morbidity and mortality (Landies \& Umberson, 1988; Cohen \&Syme, 1985; Berkmans \& Syme. 1979) but far less research has been done focusing on adolescent populations in this context. With reference to the adolescent population, however, very few studies have been published (Tuinstra, 1998; El Tawila et al., 1997; King et al., 1996).

Similarly, the social relations of adolescents have not been analysed to any major extent within the public health literature in developing countries and it is generally unclear which aspects of social relations are most important for health among adolescents. It is, therefore, an important area of interest to describe the social relations of adolescents and to understand how aspects of the interaction between adolescents and their family and peers, that shape their everyday life, influence adolescents' health behaviours and well-being.

In the few studies on adolescent health that could be retrieved, (El Tawila et al, 1997; King et all, 1996; Tuinstra, 1998) it has been reported that risk behaviours have a significant impact on both the physical and mental health of adolescents. In accordance with what was found in adult populations, these findings reveal a strong correlation between adolescent's health risk behaviours and the nature of their social relationships (King et al., 1996). It is clear that the health behaviours of adolescents are directly influenced by relationships with parents and peers. These relationships do not appear to differ from culture to culture, as confirmed by a number of studies in developed countries around the porld (Dinges \& Oetting, 1993; McDonald \& Towberman, 1993; Clayton, 1991; Chassin et al., 1986; Krohn et al., 1986).

Peers play an increasingly important role in the psychological and social development of adolescents as they emerge from childhood into teenage years. They spend an increasing amount of time with friends, and the relationships they form with peers are generally more intimate than those they had in childhood. The relationship between the individual and the peer group is more delineated during this stage, and adolescents vary in the extent to which they conform or separate themselves from the values, customs, and fads of peer culture (El Tawila et al., 1997).

Contrary to the growing importance of peer influences, the educational role of the family decreases during adolescence. In search of individual identity, adolescents tend to orient themselves towards peer groups. In most cases this also means orientation towards adolescent subcultures. Risky health behaviours, such as alcohol 
and tobacco consumption, are the product of social interaction within these peer groups. While experimentation with potentially dangerous behaviour can be considered a regular developmental phase, group pressure may cause the maintenance of such behaviour, which jeopardizes future health (WHO, 2000).

Studies of peer relationships suggest that having friends is associated with positive self-concept, a sense of belonging, a positive prospect and success in future relationships (Hartup, 1993). Adolescents who believe their peers do not accept them may be lonely and become depressed, especially if they suffer extreme forms of exclusion such as bullying and avoidance (Ramsey, 1994; Vara, 1994; Kafka \&London, 1991):

Particularly in developed countries legislation is lacking and not specifically oriented to covers health education and other aspects of special relevance to adolescents such as smoking and alcohol consumption (WHO, 1993). Most policies and laws dealing with public health are mostly not directed specifically at adolescents as a subgroup. It can thus be concluded that developing countries are in need of policies and programs for health promotion. Such policies and programs could contribute towards the prevention of problems and identification of, and care for those at risk.

Lack of information in this field can be a major disadvantage in the design and implementation of programs and policies tailored to the needs of adolescents. The potential contribution of a study on the social context of Sudanese adolescents to policy development and, indirectly, to effectively contribute to a solution to adolescents" problems, is thus evident.

This study explores the nature of family and peer relationships among Sudanese adolescents. It aims to determine (a) whether there is a difference in social context between different demographic categories, and (b) the nature of a hypothesized correlation between social context and health as variables.

\section{Methods}

\section{Design and population}

The health profile of Sudanese adolescents was assessed in a cross-sectional, health survey. The specific population selected for the study consisted of adolescents from the Umbada commuinity who were aged 10-19 years. Umbada was selected as an appropriate site because its population is multi-ethnic, comprising people from different regions and tribes of Sudan. Umbada is a suburban area where the majority of people are of middle and low socioeconomic status. 


\section{Sample size}

A random sample of four blocks from the total of 38 blocks in the town of Umbada were drawn. Households were selected by systematic random sampling, starting from the centre of each block (every fifth house). All adolescents found in the households were interviewed, until the number needed in each block was reached.

A total number of 300 adolescents were selected from each block. A gross-sample of 1200 adolescents (comprising $53.2 \%$ females and $46.8 \%$ males) were interviewed.

\section{Data collection}

Data were collected during the period Jully-November 2001 as part of a study on the health profile of Sudanese adolescents. The data collection was done with the help of trained interviewers from the Ahfad University for Women and the Community Animators Friendly Association (CAFA) of the Umbada community.

Before data collection commenced, an introductory statement was first read by the interviewer to the head of the household to obtain his/her verbal consent. Prior to the interview, the same statement was presented to all the adolescents present in the house.

\section{Measurements}

Three groups of variables were taken into account. Shape of the family and peer relations was categorized as independent variables. Health status, including self-rated health, anaemia and psychological profile, were taken as dependent variables, while health related behaviours served as confounding variables.

\section{Shape of the family}

Living with parents

To determine the shape of the family, respondents had to indicate with whom they lived most of the time. There were four responses alternatives, namely parents, mother, father, or none of the above. The last three responses were combined to derive a category indicating those who are not living with both of their parents, while the first response were indicative of those who are living with both parents.

\section{Family communication}

To measure the ease/unease respondents felt when communicating with members of their families, a question, asking how easy it was to talk to their fathers, mother, elder brother, and elder sister about things that really bothered them, was included. Quality of communication was rated on a 5-point Likert-type scale for increasing level of difficulty, ranging from don't have or see this person (0) to very difficult (4). The responses alternatives easy and very easy were combined to distinguish those who easily communicate within their families. The remaining responses were grouped to indicate those that experienced difficulty with communication in the family environment. 


\section{Peer relations}

\section{Number of close friends}

A question was included to determine the number of close friends respondents had. Responses altematives were grouped to form three categories to indicate those who had none or only one close friend, those who had two, and those who had three or more.

\section{Meeting with friends}

Respondents were asked whether they were permitted to meet with friends outside the school (work) context, and also whether they were only permitted to sit or also to go out with them. There were two possible answers: permitted to meet friends and go out with them, and not permitted to meet with friends.

\section{Communication with friends}

In the subsequent questionnaire item, respondents were asked whether they felt at ease when they talked to a friend of the same sex about things that really bothered them. There were five possible answers, ranging from don't have or see this person, very difficult, difficult, easy and very easy. The later two alternatives were combined to distinguish those who easily communicated with their friends of the same sex. The remaining responses formed a single category, difficult to communicate.

The same procedure was followed to categorise responses to the question whether they found it easy to talk to friends of the opposite sex about things that really bothered them.

\section{Health status variables}

Self-rated health

In this item respondents were asked to rate their health as either excellent, good, fair or poor. There are many studies from the international literature confirming the relationship between this variable, and morbidity and mortality over a long period (Kaplan et al., 1996). Data were dichotomized by combining the first two responses in one category: good health, while the remaining responses were grouped in the category, less than good health.

\section{Anaemia}

Biomedical data such as haemoglobin determination was used as a simple, reliable test to detect for anaemia. Capillary blood was obtained by pricking the fingertip with a sterile lancet. A drop of blood was collected into a disposable microcuvette and the level of haemoglobin was determined by using the HemoCue photometer (HemoCue AB, Angelholm, Sweden). The HemoCue instrument allows the detection of anaemia by estimating the haemoglobin level in a sample of blood. It provides accurate results that are comparable to the cyanmethemoglobin method (Von Schenck et al.; 1985; Be et al., 1991). No processing of the blood specimen is needed, and the result can be read directly without calculation in less than 45 seconds. Moreover, the instrument is portable, which makes it usable in the field and quite practical for use in surveys. Anaemia is considered to be present if the 
haemoglobin value is below $12 \mathrm{~g} / \mathrm{dl}$ for adolescent girls, and below $13 \mathrm{~g} / \mathrm{dl}$ for adolescent boys (WHO, 1968).

\section{Psychological profile}

Respondents' psychological profile was determined by focusing on feelings of loneliness and happiness, as well as on their future expectations.

\section{Feeling lonely}

Respondents could indicate their perceived degree of loneliness by choosing one of the following alternatives: Yes, very often, Yes, rather often, Yes, some times and No. The first three responses were combined to derive a category indicating those who experienced loneliness, whereas the last response was reserved those who never experience loneliness.

\section{Happiness}

Feeling of happiness, in turn, were measured on a scale with alternatives: I feel very happy, I feel quite happy, I don't feel happy, and I am not happy at all. The first two and the last two responses were dichotomized to derive two distinct categories, namely those who were happy and those who were unhappy.

\section{Expectation of the future}

As far as their expectations for the future were concerned, respondents were asked if they saw their future life and condition as better, same and worse as what they were experiencing at that point in time. Respondents who picked one of the first two responses were categorized as those who were optimistic about there future. The remaining responses were taken together to signify the group that lacked optimism.

\section{Health related behaviours variables}

\section{Smoking}

Smoking habits were measured by asking one question to the respondents: Have you ever tried smoking a cigarette? There were three possible answers, ranging from 'I have never; Yes, but I quit snoking; Yes, I smoke'. The last two responses were combined to distinguish those who tried smoking or currently smoked (yes), from those who never smoked (no).

\section{Physical inactivity}

After Tuinstra (1998), physical exercise was assessed by a question generating either a positive or a negative answer to the question: Do you do any sports?

Hunger experiences

Answers to a question on how often respondents felt hungry because there was not enough food in the house, were elicited by means of three altematives, never/hardly ever, sometimes, and a lot. The second and third responses were combined to distinguish those who went hungry because there was not enough food in the house from those who responded negatively (never/hardly ever). 


\section{Socio-demographic variables}

In this study, socio-demographic variables included sex (male, female), age groups (10-12, 13-15 and above 16 years) and educational level (no education, basic, and above secondary education).

\section{Analysis}

Data analysis was done using the statistical software package SPSS version 11.0.

First analyses were performed for the separate social context variables (shape of the family and peer relations) to test the association with demographic variables (sex, age group and level of education). Bivariate analysis (cross tabulations) and chisquare statistics were used to test the significance of the associations between variables and to understand the relationship (if any) between those variables. A PS 0.05 (2 -sided) level was used to determine the significance.

Logistic regression was used separately for each health status variable as dependent variable with social context variables (shape of the family and peer relations) as predictors while controlling for demographics. Health related behaviours variables were additionally controlled for as intermediate variable in this model.

To assess the degree of association, odd ratios (OR) with $95 \%$ confidence intervals (CI) were used.

The variation in numbers $(N)$ in the analyses is due to differences in missing values between variables. 


\section{Results}

Table 1 shows that the majority of the adolescents study population were living with both parents. This was found to be significantly more frequent for male adolescents and the younger age group (10-12 years). Even though male adolescents and the younger age group (10-12 and 13-15 years) indicated that they found it easy to communicate with their fathers, the majority of adolescents reported conmunicating easily with their mother about things that really bother them.

Easy talking with elder brothers was more frequent for male and for younger adolescents and also for those with basic education. On the whole, however, more adolescents said they found it easy to communicate with their elder sister (femalle, younger age 10-12 and those with no education).

Table 1.

Percentage of adolescents in relation to family context (who are living with one or both parents and who found it very easy or easy to talk to their father, mother, elder brother and elder sister) by different background characteristics ( $\mathrm{N}=1200)$

\begin{tabular}{|c|c|c|c|c|c|c|c|c|c|c|c|c|c|c|c|}
\hline & \multicolumn{3}{|c|}{$\begin{array}{l}\text { Lining with: } \\
\text { both prants }\end{array}$} & \multicolumn{3}{|c|}{$\begin{array}{l}\text { Easy loulath } \\
\text { to lived hather }\end{array}$} & \multicolumn{3}{|c|}{$\begin{array}{l}\text { Easy to thath } \\
\text { to troeir molner }\end{array}$} & \multicolumn{3}{|c|}{ 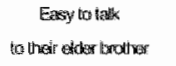 } & \multicolumn{3}{|c|}{ 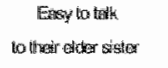 } \\
\hline & (nit) & $\%$ & $\Gamma^{H}$ & (n) & 9 & $p$ & $(n)$ & 纤 & $P^{x}$ & $\ln y$ & 响 & $p$ & N & wis & $\mathrm{p}$ \\
\hline M:Ls:lli & & 812 & & & 4.7 & & & 60 & & & 213 & & & mats & \\
\hline \multicolumn{16}{|l|}{ Sa } \\
\hline Make & 47 & 838 & & 79 & 30.9 & & $4 \leqslant 2$ & $80: 4$ & & 158 & $3 x .1$ & & 32 & mis & \\
\hline falate & 503 & 78 & 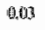 & 117 & 183 & $0,0)$ & 512 & 80,3 & b. & $l(0)$ & $15, \pi$ & 0.00 & 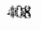 & Wis. & 0.00 \\
\hline \multicolumn{16}{|l|}{ Ane groms } \\
\hline $10-12$ & 322 & $8 \leq 2$ & & 105 & 27.8 & & 321 & 264 & & 400 & 36.5 & & 241 & 614 & \\
\hline $10-35$ & 315 & 84 & & $11 \mathrm{H}$ & 263 & & 334 & 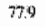 & & 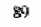 & 20.7 & & 265 & 69. & \\
\hline $16+$ & 397 & 78.1 & $\mathrm{OOH}_{\mathrm{A}}$ & 76 & 19.8 & 909 & 399 & 386 & 0.11 & 6 & 17.6 & $0, k$ & 204 & 57 & (1), 00 \\
\hline \multicolumn{16}{|c|}{ Lenel of od ication } \\
\hline Moddhestional & 36 & 76.5 & & 11 & $n 1$ & & 28 & 735 & & $i$ & 2016 & & 24 & 70.6 & \\
\hline Brisit: & $t a$ & 81.3 & & $2\}$ & 230 & & $6 A^{7}$ & $x$ & & $\mathbb{S H}_{4}$ & 27 & & 498 & $61 \%$ & \\
\hline Socktalay & $2 x$ & 81.3 & a灌 & 73 & 31 & 027 & xy: & 㪵. Ii & and & 85 & 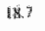 & wokl & 20 & 50 & 6 ans \\
\hline Tutal & 976 & & & $a_{\infty}^{z}$ & & & ats & & & 258 & & & 730 & & \\
\hline
\end{tabular}

Table 2 shows that the vast majority of adolescents had three or more close friends. Boys score significantly higher than girls on this item and those with higher education scored higher than those without. Significantly more males (78\%) than females $(52 \%)$ were permitted to meet and go out with friends. The majority of adolescents reported communicating more easilly with friends of the same sex $(90 \%)$. Easy talking to a friend of the opposite sex was generally low for all subgroups $(24 \%)$. Males reported talking to friends of the opposite sex more frequently than females. 
Table 2. Percentage of adolescents in relation to peer's context (who have three or more close friends, permitted to meet friends and go out, and who found it very easy or easy to talk to their friends of the same and opposite sex) by different background characteristics $(\mathrm{N}=1200)$

\begin{tabular}{|c|c|c|c|c|c|c|c|c|c|c|c|c|}
\hline & \multicolumn{3}{|c|}{$\begin{array}{l}\text { Three or thiuge } \\
\text { chose fricknti }\end{array}$} & \multicolumn{3}{|c|}{ 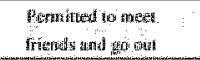 } & \multicolumn{3}{|c|}{ 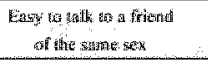 } & \multicolumn{3}{|c|}{ 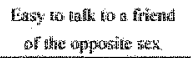 } \\
\hline & (sii) & $\%$ & fy & (n) & $1 / 4$ & $p$ & $\mathrm{~N}$ & $\%$ & $p$ & (at) & $\psi_{\mu}$ & in \\
\hline grergil & & 786 & & & 1645 & & & גa. & & & 24.2 & \\
\hline \multicolumn{13}{|l|}{9} \\
\hline Male & $4 \%$ & S. & & 44 & 78.5 & & $\operatorname{sit}$ & 91.1 & & 18 & 322 & \\
\hline 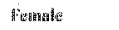 & 46 & r.s. & 0.00 & 383 & 52.2 & (6. $.6 \mathrm{fo}$ & 5.49 & 802 & 0.54 & 500 & 171 & 0.60 \\
\hline \multicolumn{13}{|l|}{ Ahge grotutis } \\
\hline 10.12 & 393 & 77.5 & & 237 & 163.7 & & 346 & 21.5 & & 77 & 20.4 & \\
\hline $43 \times 15$ & 333 & 77.6 & & $2: 81$ & 655 & & 378 & 28.1 & & 101 & 235 & \\
\hline 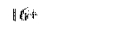 & $3 y$ & 40.7 & 043 & 286 & 63. & $0.6 x$ & $35 \%$ & 90.8 & 0.54 & 112 & 28.5 & 0.11 \\
\hline \multicolumn{13}{|c|}{ 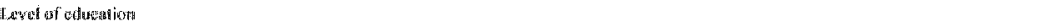 } \\
\hline 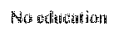 & 21 & 50.6 & & 30 & 88 & & 30 & 188,2 & & 11 & 32,4 & \\
\hline 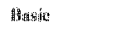 & 759 & 78.4 & & 530 & 163.5 & & $n \%$ & 400 & & 185 & 226 & \\
\hline Sogererattanger & 328 & 81.8 & 0.00 & 23 & $67 \mathrm{~A}$ & 0.34 & 314 & 90.5 & 0 , 目? & 94 & 27.1 & 1030 \\
\hline Tisian & 0,3 & & & rind & & & 1081 & & & 290 & & \\
\hline
\end{tabular}

Table 3 shows that self-rated good health was associated with living with both parents and easy communication with mother and elder sister. Happy feelings were associated with easy communication with fathers, and elder sisters. Responses reflecting optimism about the future were associated with easy communication with fathers, mothers and elder brothers. Adding health related behaviours variables to the model as possible co-variates the same results are replicated, which mean that the social context has a direct relationship with health, irrespective of health behaviour of the adolescents concerned. 
Table 3. Odd ratios (95\% confidence interval) of health status variables as dependent variables and shape of the family variables as independent variables, adjusted for sex, age group and level of education $(\mathrm{N}=1200)$

\begin{tabular}{|c|c|c|c|c|c|}
\hline & 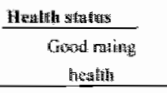 & Non andwatic & 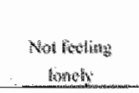 & Feeling hapysy & 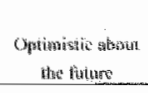 \\
\hline Shape of the family & QR, $9.9 \% \mathrm{dm}$ & OR $\{95 \%$ Cl & 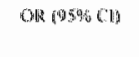 & on $\left(\mathrm{ps}_{\mathrm{s}} \mathrm{ch}\right.$ & Ok (a) \\
\hline $\begin{array}{l}\text { Liwing with } \\
\text { fowh pasentas }\end{array}$ & $1.54 h(162,2.23)^{*}$ & $0.810 .57,1.16 \%$ & $1.29(0,94,1.77)$ & $1,36,00,91,203)$ & $140.91,28 \%$ \\
\hline $\begin{array}{l}\text { Easy to thith of } \\
\text { their father }\end{array}$ & $10101(18.67 .453)$ & $10000.24,96$ & $1.03(0) 79,1.36$ & $1.0011 .0,2,480^{*}$ & $2.8011 .61,4.89 q^{4}$ \\
\hline $\begin{array}{l}\text { Easy tis talk to } \\
\text { their mosther }\end{array}$ & $1,50(1,012,2,22)^{e}$ & v. $56(1,64,1.22\}$ & $1.19(0,8), 1.6)\}$ & $1.27(0.85 .1 .90)$ & $1.88(1,33,287\}^{*}$ \\
\hline 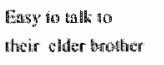 & $1.37(68.87,2.16)$ & $0.830601,1.32)$ & $1.05(0 ; 78.1 .40$ & 1.540 .06 .2393 & 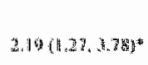 \\
\hline 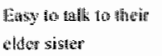 & $1+46(10,04,2,05)^{*}$ & $0.78(0.89,1,03)$ & 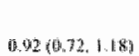 & $1.70(1.22,2.38)^{\circ}$ & 1 198488, 1964 \\
\hline
\end{tabular}

*Significance $\mathrm{p}<05$

Table 4 shows that those who had three or more friends were feeling happy, but less optimistic about the future. Those who were permitted to meet friends and go out also reported feelings happiness. Happy feelings, in turn, correlated positively with responses indicating that it was easy to talk to friends of the same sex and permitted to go out and meet with friends.

Easy communicating with friends of the opposite sex showed a negative association with anaemic status and loneliness (increase of anaenia and feeling lonely).

When health related behaviors variables are added to the model as possible covariates, the same results are replicated. 
Table 4. Odd ratios ( $95 \%$ confidence interval) of health status variables as dependent variables and peer relations variables as independent variables, adjusted for sex, age group and level of education $(\mathrm{N}=1200)$

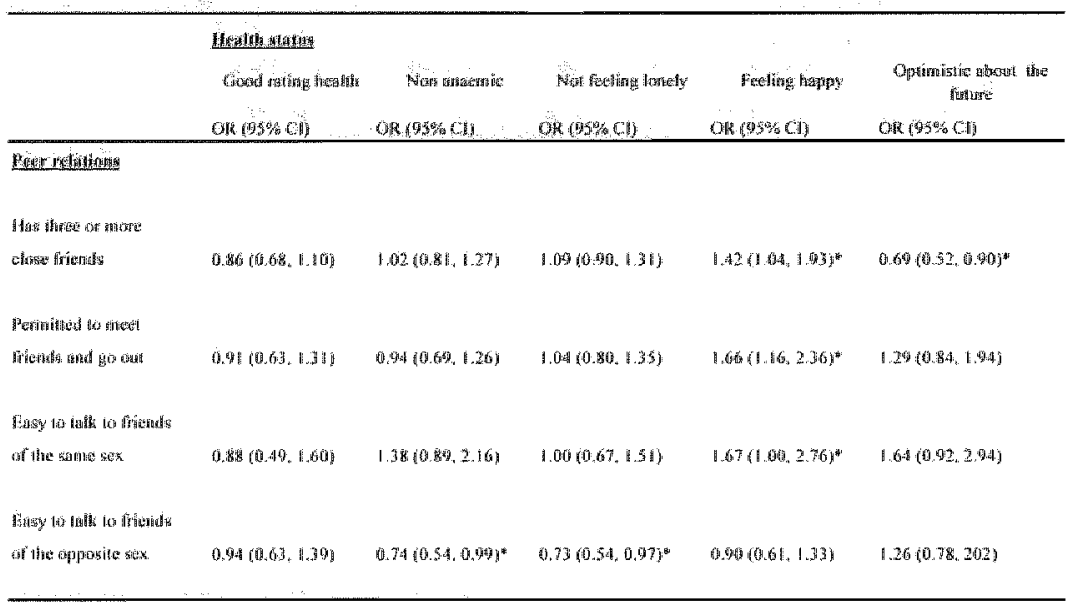

* Significance $p<05$

\section{Discussion}

The findings in this study show that the majority of adolescents' communicate easily with their mothers and elder sisters. These data support Shulman's (1993) finding that young people tend to find it easier to communicate with their mothers than with their fathers.

There were many differences among adolescent subgroups in the area of relationships within the family. The majorities live with parents and are able to communicate more easily with their mothers and older sisters than with their fathers and elder brothers.

However, females report such difficulty significantly more often than males.

In general female adolescent show difficulties in talking to opposite sex from their family (father and elder brother) and friends. This could be due to the cultural habits and norms, which structure the Sudanese family.

A positive family environment significantly correlates with a good health status indicated by rating good health, happy feelings and optimistic about the future.

The basis of an effective parent-child relationship is open communication (King et al., 1996). It can thus be concluded that the quality of the relationship in families where children find it easy to talk with their parents, brothers and sisters will almost certainly be better than in circumstances where children find communication difficult. A less restrictive and more communicative and receptive family environment seem to be correlated with positive development of the adolescent's character. The development of communication skills could therefore increase 
adolescents' maturity on the physical and psychological levels as they experience the changes of during this stage of life.

The complexities of friendship are clearly difficult for a small number of adolescents. It has become apparent in this study that more boys are allowed to go out with friends compared to girls, while girls are more likely to be limited to exchanging visits with friends in their houses only, or not at all. Permission to socialize with peers manifests in the form of happiness. Interestingly, a good communicative relationship with friends of the opposite sex has a negative effect by increasing the level of anaemia and loneliness. Having three or more close friends is inversely related to optimism about the future. These results might be due to chance because of multiple testing.

These seemingly contradictory associations need further analysis and an in-depth assessment of adolescent mental health. There could be a third factor affecting these relations (e.g. epidemiological). Eltawila et al., (1997) found in an Egyptian adolescent national survey that association between peers, communication and feelings of loneliness is indeed mediated by a third factor, namely approaching full maturation. Maturation, in turn, is positively related to good interaction with friends, but simultaneously to an increased sense of loneliness.

From this study it may be concluded that a more communicative and receptive family environment is needed to ensure good adolescent health. The family context emerges as a major agent of socialization in the perception of adolescents. The family furthermore provides a model for exchange of support and a range of communications models that adolescents may follow at present and in the future. Since parents and family members usually remain close to adolescents and find themselves in a position where they can exercise some degree of authority over adolescents' behaviour, they are vital to any configuration of social factors shaping adolescent health behaviours.

The importance of interventions to help parents and older siblings, with a special focus on fathers and brothers to communicate with their daughters and sisters simultaneously. Similarly, interventions focusing on adults who work with adolescents may be useful. 


\section{References}

Be. W K , Kerkkamp. H E., \& Booij, L H. (1991). HemoCue- a new haemoglobinometer in the clinic. European Journal of Anaesthesiology, 8 , 55-58.

Chassin, L., Presson, C.C., \& Sherman, S.J. (1986). Changes in peer and parent influence during adolescence: Longitudinal versus cross-sectional perspectives on smoking initiation. Developmental Psychology, 22(3): $327-334$.

Clayton, $_{*}$ S. (1991). Gender differences in psychosocial determinants of adolescent smoking. Journal of School Health, 16(3): 115-120.

Dinges, M.M., \& Oetting, E.R. (1993). Similarity in drug use patterns between adolescents and their friends. Adolescence, 28(110): 246-266.

EL-Tawila. S., Ibraham.B.,Salam.S., El Gibaly.O., \& El Sahan.F. (1997). Transition to Adulthood, A National Survey of Egyptian Adolescents.

Galambos, N.L., \& Ehrenberg, M.F. (1997). The family as health risk and opportunity: a focus on divorce and working families. In Schulenberg, J. et all,ed. Health risks and development transitions during adolescence. Cambridge, Cambridge University Press.

Hartup, W.W. (1993). Adolescents and their friends. New directions for Child Development, 60, 3-22.

Kafka, R.R., \&London, P. (1991). Communication in relationships and adolescent substance use: The influence of parents and friends. Adolescence, 26(103):586-598.

Kaplan GA., \& Camacho T. (1996). Perceived health and mortality: a nine-year follows up of the human population laboratory cohort. American Journal of Epidemiology; 117, 292-304.

King, A.J.C., \& Peart, M.J. (1996). Factors inhibiting the transition of youth to work and to adulthood. In: Galaway, B. Hudson, J.(Eds.). Youth in transition. Perspective on research and policy. Toronto: Thompson Education Publishing.

King.A., Wold.B., Smith.C.T., \& Harel.Y. (1996). The Health of Youth a Cross National survey, Development patterns of behaviours and attitudes. WHO Regional Publications. European serious No.69. 
Krohn, M.D., Naughton, M.J., \& Skinner, W.F. (1986). Social disaffection, friendship patterns and adolescent cigarette use: The Muscatine study. Journal of School Health, 56(4): 146-150.

McCauley, AP., \& Salter, C. (1995). Meeting the needs of young adults. Population report, Series J. 41.

McDonald, R.M., \& Towberman, D.B. (1993). Psychosocial correlates of adolescent drug involvement. Adolescence, 28(112): 924-936.

Ramsey, M. (1994). Student depression: General treatment dynamics and symptom specific intervention. School Counselor, 41(4): 253-283.

Ryan, R.M. (1994). Representations of relationships to teachers, parents and friends as predictors of academic motivation and self esteem. Journal of early adolescence, 14 (2): 226-249.

Shulman, S. (1993). Close relationship and coping behaviour in adolescence. Special Issue: Stress and Coping in Adolescence. Joumal of Adolescence, 16(3): 267-283.

Tuinstra, J. (1998). Health in Adolescents. An Empirical Study of Social Inequality in Health. The Prevalence of self- reported health problems in male and female Dutch adolescents. Thesis, Groningen, University, the Netherlands.

Vara, V. (1994). Community reported problems in middle-school children. Percepiual and Motor Skills, 78(3, PT.2): 1283-1286.

Von Schenck., Falkensson, M., \& Lundberg, B. (1986). Evaluation of "HemoCue," a new Device for determining Hemoglobin. Clinical Chemistry, 32, 526529.

WHO (1968). Nutritional anemias: report of a WHO scientific Group. WHO Technical Report Series, No. 405.Geneva, Switzerland: WHO.

WHO (1993). The health of young people, A challenge and a promise, WHO, Geneva.

WHO (2000). Health and Health behaviour among Young People, WHO Policy

Series: Health policy for children and adolescents Issue I International report. 


\section{Chapter 7}

\section{Reproductive health: Level of knowledge and harmful traditional practices among Sudanese adolescents}

A manuscripts based on this chapter has been submitted for publication as: M.E.Moukhyer., N.K.de Vries., \& J. Th. M. van Eijk. Reproductive health: Level of knowledge and harmful tradlitional practices among Sudanese adolescents 


\title{
Reproductive health: Level of knowledge and harmful traditional practices among Sudanese adolescents
}

\begin{abstract}
In this paper we found respondents level of knowledge about maturation signs was low. Only one-third of the respondents knew the exact meaning of family planning and they lacked basic knowledge of the reprocuctive process: the majority did not know how to determine the fertile period in women; almost half of the respondents had never theard of family planning; knowledge about STDs was limited. The majority of females were circumcised $(89.6 \%)$. Almost for half of the circumcised female respondents, the procedure was carried out between the ages of six and ten years. More than one-third reported some sort of complications, following mutilation. However, almost two-fifths of the respondents believed that circumcision is a prerequisite for marriageability.
\end{abstract}




\section{Introduction}

Promoting adolescent reproductive health in the developing world has become a major issue on the international agenda. Since the International Conference on Population and Development (ICPD, 1994) in Cairo, the focus in reproductive health research is no longer on numbers of people and demographic targets only.

At present, the world's group of adolescents is larger than ever before in the history ( 1.2 billion people) with some $85 \%$ living in developing countries (UNFPA, 2003). In Sudan, about $25 \%$ of the population adolescent according to the Pan Arab Project for Child Development (PAPCHILD, 1993). As in many other countries, there is virtually no information on adolescent health in general in Sudan, let alone information on this group's level of knowledge or behavioural practices concerning reproductive health.

Within the general framework of reproductive health, this study will pay special attention to Sudanese adolescents' level of knowledge on reproductive health and the practice of female genital mutilation (FGM). Adolescence in this context refers to the transition stage between childhood and adulthood, spanning the period between 10 and 19 years.

According to the definition used by the World Health Organisation (WHO), reproductive health addresses the reproductive process, with reference to its functions and system, and implies that people are able to have a responsible, satisfying and safe sex life, with the capacity to reproduce and the freedom to decide if, when and how often to do so (WHO, 1997).

Reproductive health is a broad area that encompasses sexuality education, pregnancy prevention, pregnancy related health services, pregnancy, abortion, and childbearing. These topics have to be seen within the broader context of social normative behaviour and gender relationships, which are shaped not only by family, peers, the local community, and the social environment, but also by such pervasive influences as the media and public policies (English et al., 1999).

It is important to understand when and how adolescents acquire the knowledge that will prepare them for the roles as parents and partners in marriage. Traditionally, adolescents in Sudan have been shielded from information about reproduction and sexuality until the time of marriage. Even information about physical maturation is often not discussed within the family, on the assumption that the silence will convey the taboo nature of this topic, protect a child's innocence, and discourage inappropriate behavior. However, the lack of proper knowledge and the silence surrounding the topic of reproductive health may be assumed to contribute to health problems, such as prevalence/incidence of sexually transmitted diseases (STD's), $\mathrm{FGM} / \mathrm{FC}$ and unwanted pregnancy.

The vulnerability of adolescents for HIV infection and other sexually transmitted diseases (STDs) has been recognized over the past years. Recent research has shown that transmission of STDs and HIV infection is extremely high among adolescents in many sub-Saharan countries (Obasi et al., 1999; Konde-Lule et al, 1997; Munodawafa \& Gwede, 1996; Brabin et al., 1995). Each year more than one out of 
20 adolescents contracts a curable STD (WHO, 1986). HIV/AIDS has become a disease of the young, fuelled by poverty, inequality and a severe lack of knowledge and services for prevention (UNFPA, 2003).

Globally, more than half of all new HIV infections are among 15-24 years old (WHO, 1995) and of the estimated 333 million new STDs that oceur in the world every year, at least 111 million occur in young people under 25 years (UNAIDS, 1997).

One of the most harmful traditional practices, which affect the health of African women, is female genital mutilation (FGM) or female circumcision (FC). FGM/FC constitutes all procedures involving partial or total removal of the external female genitalia, or other injury to the female genital organs, whether for cultural or other non-therapeutic reasons (WHO, 1996). FGM is linked to gender inequalities entrenched in the political, social, cultural and economic structures of societies in which this practice is upheld. In Sudan FGM/FC has been perpetuated for many generations. As such, the practice has been institutionalized as a habit or custom that has become an integral part of the social system. FGM/FC is now well known for its negative clinical, psychological and social consequences. Many women appear to be unaware of the consequences of FGM; in particular the complication affecting sexual intercourse and childbearing many years after mutilation has taken place (WHO, 1995).

Generally Genital mutilation is commonlly performed when girls are quite young and uninformed preceded by acts of deception, intimidation, coercion, and violence by trusted parent friends. For many girls, genital mutilation is a major experience of fear, submission, inhibition of feeling and thinking. This experience becomes a vivid landmark in their mental memory of which persist throughout life (WHO, 1995). The Sudan Safe Motherhood Survey (SSMS, 1999) has shown an urban prevalence of $93 \%$, a rural prevalence of $89 \%$, and overall prevalence of $90 \%$ in Sudan, which at the best can be evaluated as static since about three decades ago (overall $89 \%$ according to SDHS, 1979)

Lack of knowledge, skills, and access to contraception and vulnerability to sexual abuse put adolescents at highest risk of unwanted pregnancy (Senderowitz, 1995) resulting in several risks. In developing countries, maternal mortality in girls under 18 is two to five times higher than in women between 18 and 25 years of age (Harrison, 1985; Chen.L. et al., 1974). The number of abortions among adolescents is estimated at between 1 million and 4.4 million per year. Most of these cases are unsafe because they are performed illegally and under hazardous circumstances by unskilled practitioners (WHO, 1994).

Given this situation, many educators, public health professionals and parents currently recognize the need for adolescents to be informed about maturation and reproductive health. However, there is no general consensus about what should be taught of what the appropriate channels of transmission would be. Unfortunately, the response of societies in general, and health policy in particular, to the vulnerability of adolescents' reproductive health problems has so far been inadequate in most countries in the region. This state of affairs may be attributed, firstly, to the great scarcity of data with respect to reproductive health knowledge. Secondly, the lack of 
such data is often compounded with myths and fears on the side of adults and institutions about these important aspects of adolescent life (Knlin, 1988; Obasi et al., 2000). Lastly, as a result of the first two reasons, few interventions (if any) have been developed that are aiming to safeguard the sexual and reproductive health of adolescents. There is thus an urgent need to collect such information for the identification of indicators relevant for appropriate interventions.

The aim of this paper is to identify the level of knowledge and practices concerning reproductive health among Sudanese adolescents. In gathering the data, various demographic variables were taken into account in order to (a) target the design of future programs to increase awareness and improve adolescent's reproductive health situation in this country and, (b) add to existing knowledge of adolescent reproductive health in Africa and Eastern Mediterranean Region (EMR) in general.

\section{Methods}

\section{Design and population}

The health profile of Sudanese adolescents was assessed in a cross-sectional survey study. The specific populations selected for the study were adolescents, aged 10-19 years, from the Umbada community, Khartoum state. Umbada was selected as a suitable source of information because its population is multi-ethnic, comprising people from different regions and tribes of Sudan. Umbada is also a suburban area where the majority of people are of middle and low socioeconomic status.

\section{Sample size}

A random sample of 4 residential blocks was drawn from a total of 38 blocks in the town of Umbada. Households were selected by systematic random sampling, starting from the centre of each block (every fifth house). All adolescents found in the households were interviewed, until the number needed in each block was reached. Three hundred individual adolescents were selected from each block. A total sample of 1200 adolescents ( $53.2 \%$ girls and $46.8 \%$ boys) was interviewed.

\section{Data collection}

Data were collected during the period July-November 2001. The data collection was done with the help of trained interviewers from the Ahfad University for Women and the Community Animators Friendly Association (CAFA) of the Unbada community. Prior to data collection, the interviewer first read an introductory statement to the head of the household to obtain his/her verbal consent. The same statement was also presented to the adolescents before interviewing conmenced

\section{Measurements}

\section{For all adolescents}

Knowledge of maturation

Adolescents were asked about the most important changes that occur with boys and girls during maturation stage? There were seven possible answers concerning boys' maturation changes: Pubic hair appears, ampit hair appears, increase in body muscles, testis enlargement, acne appears, facial hair appears, do not know. The 
responsess were combined by categories: do not know, one sign and more than one sign.

Similarly there were seven possible answers for girls' maturation changes: menstrual cycle commences, breasts enlarge, pubic hair appears, armpit hair appears, increase in height and weight, acne appears, do not know. The responses were combined by categories: do not know, one sing and more than one sign.

Source of maturation knowledge

Adolescents were asked: how and from whom did you come to know about physical changes of maturation? There were six possible answers: By myself, family members (mother, father, brothers, sisters and relatives), friends, schoolbooks, media (TV, Radio, and others) and do not know.

Opinion of family planning (FP)

Adolescents were asked: what does family planning mean to you? Answers were coded into one of eight categories: That a woman could have one child, a girl or a boy, that a woman should have a small number of children, that a woman should have no children, that a women can control when to have children, that a woman space her birth, heard about FP but do not know what it means, never heard about FP and others. The first three responses were combined to indicate a demographic goal (small number of family or not at all) as category one. The fourth and fifth responses were combined to indicate autonomy or choice to a couple or a woman (to have the desired number and her own control on spacing) as a second category. The third category indicates those who have heard of FP but do not know what it means. The fourth category indicates those who never heard of FP. The fifth and last category indicates other responses.

Knowledge of fertile period

Adolescents were asked: For a married woman, when is the time she is most liable to get pregnant from the beginning of one cycle to the beginning of the next? Answers were: The few days after the end of the cycle, in the middle, during the second half and $\mathbb{d}$ do not know. The first and the third responses were combined to derive the category of the incorrect answer, and in the middle of the cycle for correct answer.

Knowledge about sexually transmitted diseases (STDS)

Adolescents were asked: what diseases do you know that are transmitted through sexual relations? There were five possible answers; AIDS, gonorthoea, syphilis, others and I do not know any STDs.

\section{For adolescent girls}

Adolescent girls were asked additional questions on the onset of menarche and FGM practices.

Reaction to the menarche (the cycle)

Adolescent girls were asked: The first time you got your cycle, what was your reaction, what did you feel? There were three answers shock/cried/afraid, indifferent and happiness. The first and the second responses were combined to drive the category of negative reaction versus the third one, happiness. 
Reproductive health practice

Female Genital Mutilation (FGM) or Female Circumcision (FC); Adolescent girls were asked: Are you circumcised? There were two responses yes / no

Age of circumcision

How old were you when circumcised? Responses were coded into five categories: The age group 0-5, 6-10,11-15 and above16 years and those who do not know.

Complications of circumcision

Did you become ill or have any health problems after the circumcision? Responses were coded into two categories: Those who mention complications or any health problems and those who do not report having experienced any complications or problems.

\section{Necessity of circumcision}

Do you think female circumcision is an important or necessary thing for a woman to be married or is it not really necessary? There were two answers, yes/no.

\section{Analysis}

The analysis was done through the use of the statistical software package SPSS version 11.0 .

First analyses were performed for all reproductive health variables (knowledge of maturation, knowledge of fertile period, knowledge about sexually transmitted infections (STDs) and meaning of family planning (FP) for all adolescents to test the association with demographic variables (sex, age group and level of education). We used bivariate analysis (cross tabulations) and chi-square statistics to test the significance of the associations between variables and to understand the relationship (if any) between those variables. A P $\leq 0.05$ ( 2 -sided) level was used to determine the significance.

Secondly the same analyses were done for reaction to the menarche (the cycle) and reproductive health practices (FGM) variables for girls.

The variation in numbers $(N)$ in the analyses is due to differences in missing values between variables. 


\section{Results}

Table 1 shows no differences in knowledge about describing maturation signs for male by both sexes. Knowledge increases sharply with increase in age and level of education in reporting of two or more signs of maturation.

With regard to female signs of maturation, difference in response by sex was observed for two or more signs (Females report more significant knowledge than males) and do not know. It was noticed, though, that knowledge sharply increases with age and level of education for those who are reporting two or more signs of maturation.

Table 1. Percentage of adolescents' knowledge about signs of maturation changes in boys and girls by different background characteristics $(\mathbb{N}=1137-1146)$

\begin{tabular}{|c|c|c|c|c|c|c|c|c|c|c|}
\hline & & \multicolumn{5}{|c|}{ 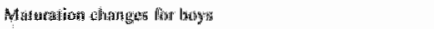 } & \multicolumn{4}{|c|}{ 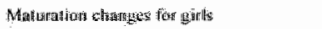 } \\
\hline & & $\begin{array}{l}\text { Hom not } \\
\text { fwotow }\end{array}$ & Ones sign & Procis ar & & & $\begin{array}{l}\text { Bo now } \\
\text { knowi }\end{array}$ & One vign & 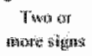 & \\
\hline & $\sin t$ & की: & $\%$ & wh & $p$ & (a) & $\mathscr{\%}$ & 施 & $\%$ & $y$ \\
\hline \multicolumn{11}{|l|}{ sox } \\
\hline Misle & 5 sil 7 & $4 \%$ & 14.6 & 41.3 & & $5+1$ & $\$ 03$ & 190 & 90,7 & \\
\hline 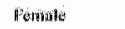 & 5 so & $4 \% 8$ & 13.7 & 38 & 0.38 & 6ia 5 & 32.6 & 19.8 & $4 i 7.6$ & 0.00 \\
\hline \multicolumn{11}{|l|}{ A Acter } \\
\hline $10-12$ & 360 & 71.11 & $10 . \sqrt{3}$ & 3 & & 358 & $70: 4$ & s.t. & 15.6 & \\
\hline 13.15 & 403 & $\$ 4.4$ & 86.6 & 36.0 & & mats & Af.6 & $2 \pi$ & 37.6 & \\
\hline Het & 34 & 100.9 & 15,0 & 65.2 & 0.6 & 382 & 12.6 & 223 & 6.2 & 0,800 \\
\hline \multicolumn{11}{|c|}{ 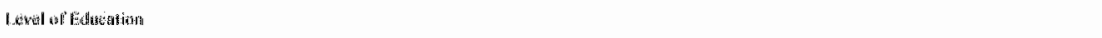 } \\
\hline 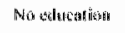 & 32 & 93.1 & 18.8 & 28.1 & & $3+4$ & 50,0 & 208 & 29,4 & \\
\hline Basho & $7 \times 1$ & 589 & 13.2 & 279 & & $m$ & 53.6 & istid & 201 & \\
\hline Secosatiary + & 34 & 15.1 & 15.8 & 6 66) 2 & 0.60 & 339 & 112 & 21.8 & 67.0 & 0.64 \\
\hline Overall & 1137 & $4.5,8$ & 14.2 & 10. & & 11047 & 40.9 & 19.5 & $3 \overline{4}, 4$ & \\
\hline
\end{tabular}

Table 2 shows that for $41.3 \%$ of adolescents' knowledge about maturation signs, "schoolbooks" were the most prominent formal sources of knowledge for both sexes and those with high level of education. Family, members are highly reported by those without education. Source of knowledge as friends were highly reported by males, younger age groups and those without and with basic education. Overall $20 \%$ of the adolescents do not know their source of knowledge. Most of them are older in age and with higher level of education. Other sources mentioned are friends (more reported by boys), my self, family members (more reported by girls) and media were least reported by all subgroups and their effect decreases with increase in age and level of education. 
Table 2. Percentage distribution of adolescents source of knowledge about maturation changes by different backgiound characteristics $(\mathrm{N}=874)$

\begin{tabular}{|c|c|c|c|c|c|c|c|c|c|}
\hline & & Myseats & 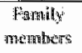 & pricicteds & 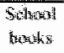 & Mortikg & $\begin{array}{l}\text { Alligne thes } \\
\text { sollase }\end{array}$ & $\begin{array}{l}\text { Do hat } \\
\text { husw }\end{array}$ & \\
\hline & (n) & 8 & $\%$ & 酧 & $\%$ & 列 & $a_{6}$ & 桠: & 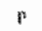 \\
\hline \multicolumn{10}{|l|}{ Sex } \\
\hline Malz: & 396 & 86 & 4 & 131 & Hit? & 18 & 134 & 146 & \\
\hline Fernoratio & 478 & 4.7 & 9.2 & 7.1 & .39 .3 & 盟。密 & 9.1. & 24.5 & a.gis \\
\hline \multicolumn{10}{|l|}{ Age aroups } \\
\hline $\operatorname{lng} 2$ & 241 & 9 & 79 & 14.8 & 335 & ? & 315 & 74 & \\
\hline $13 m: 15$ & 392 & 7.1 & 照! & 8.4 & 472 & 具: & $1: 1.2$ & 163 & \\
\hline 16 th & 340 & 13.5 & 5 & 86 & 40 & 0.1 & 0.5 & $\$ 0: 7$ & 1) \\
\hline \multicolumn{10}{|c|}{ 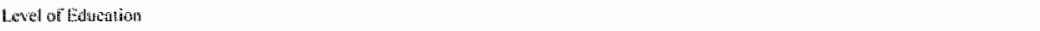 } \\
\hline 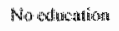 & 28 & 00 & 179 & 321 & 7.1 & 3.6 & .32 .1 & 7.1 & \\
\hline Briste & 520. & 3.1 & : 8.1 & 198 & 58.6 & 9.8 & 17 & 14 & \\
\hline Secondary & $y[7$ & 10 & 4.1 & 28 & ats 8 & 1.6 & 0.8 & 306 & 800 \\
\hline Overatl & 874 & 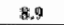 & 2.0 & 9.8 & 41.9 & 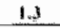 & 11,4 & 20.1 & \\
\hline
\end{tabular}

Table 3 shows that overall of $24.1 \%$ indicated that family plaming is autonomy or choice; this is reported more by females than males and with increase in age and level of education. About (12.6\%) indicated that family planning was a demographic goal, about equally distributed across all subgroups. About forty one percent $(41.2 \%)$ never heard of family planning, more males than females and this percentage decreases with increase in age and education.

Table 3. Percentage of adolescents' opinion about meaning of family planning by different background characteristics $(\mathrm{N}=1125)$

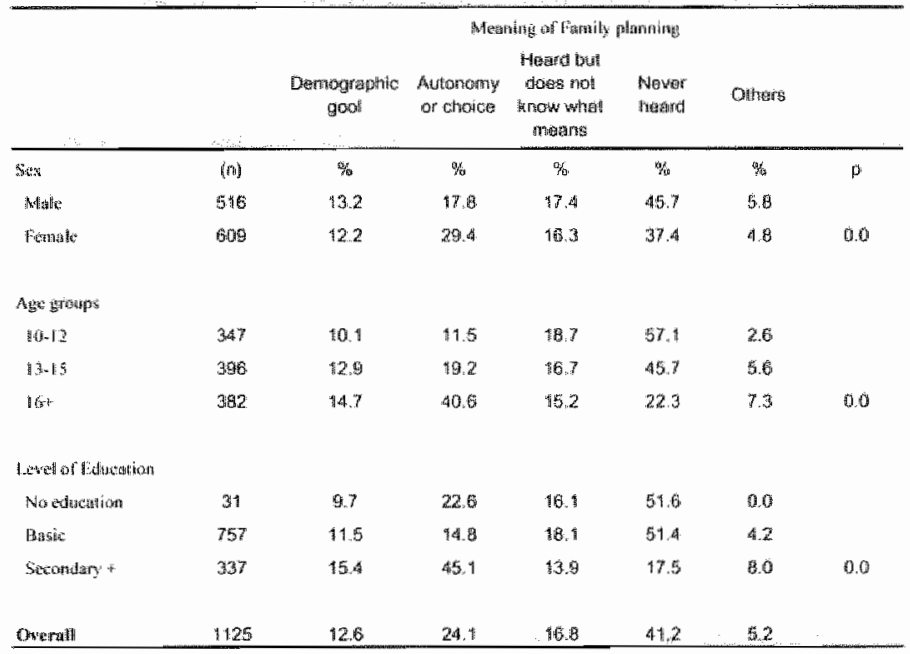


Table 4 shows that the majority $(75.5 \%)$ of adolescents gave incorrect responses about the right time of the fertile period. Highly reported by younger age $(10-12)$ and those without and with basic education. The level of knowledge, reflected by correct answers, increased with age and level of education.

Table 4. Percentage of adolescents' knowledge about the correct time of fertile period by different background characteristics $(\mathrm{N}=1200)$

\begin{tabular}{|c|c|c|c|c|c|}
\hline & \multicolumn{5}{|c|}{ 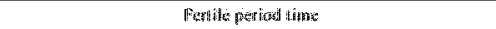 } \\
\hline & & Dors is have & $\begin{array}{l}\text { Correst } \\
\text { reteporiste }\end{array}$ & 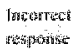 & \\
\hline Seax & (6) & wetis & $\%$ & $\%$ & B \\
\hline \multicolumn{6}{|l|}{ Malat } \\
\hline \multirow[t]{2}{*}{ Fetalitife } & 562 & 1.8 & 24,2 & 74,6 & \\
\hline & 638 & 0.5 & 22.3 & 96.8 & 0.70 \\
\hline \multicolumn{6}{|l|}{ Age gavosph } \\
\hline 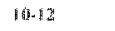 & $37 \%$ & 1.6 & 16.8 & 823 & \\
\hline $13-15$ & 428 & 1.6 & 25.9 & 72.5 & \\
\hline $16 *$ & 393 & 0.11 & 27.7 & $72: 3$ & 0.00 \\
\hline \multicolumn{6}{|c|}{ 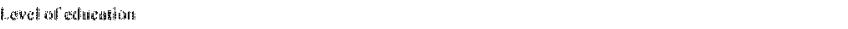 } \\
\hline Mu cathewhian & 34 & 29 & 26.5 & 70.6 & \\
\hline Heasic & 819 & 1,3 & 271 & $3 \mathrm{x}^{\mathrm{s}} \mathrm{s}$ & \\
\hline Satodusiny " & 347 & 0.3 & 39.8 & 68.8 & 0.00 \\
\hline Overtatl & 1260 & 1.1 & 23.4 & 75.5 & \\
\hline
\end{tabular}

Table 5 shows HIV/AIDS is the STD most adolescents are familiar with. More than one third of respondents indicated that they did not know any STD. Their level of knowledge showed an increase with age and level of education. Overall, two or more diseases are mentioned by one fourth of total adolescents.

Table 5. Percentage of respondents who reported knowledge of sexually transmitted diseases (STDs) by different background characteristics $(\mathrm{N}=1169)$

\begin{tabular}{|c|c|c|c|c|c|c|c|c|}
\hline & & $\begin{array}{c}\text { Don hite know } \\
\text { anysthos }\end{array}$ & DIVWALtes & Golabhen & $3 y$ phints & 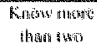 & Ohines & \\
\hline & (ii) & 雨 & rea & $y_{6}$ & sis & 㭻 & $\%$ & pis \\
\hline \multicolumn{9}{|l|}{ yes } \\
\hline Whithe? & 318 & 38.1 & 3.0 & 1.3 & 0.5 & $2 x, x$ & [3.? & \\
\hline Wentalis & 521 & +22 & 28.8 & 0. & 13 & 36.2 & I. & 0.27 \\
\hline \multicolumn{9}{|l|}{ 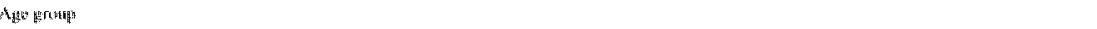 } \\
\hline $16 \times 12$ & .267 & 64.3 & 28,68 & 0.5 & 0.3 & 83 & 19.5 & \\
\hline 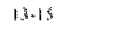 & Ha & +6. & 37.5 & 1.2 & 8.4 & 18.4 & 4.4 & \\
\hline $6: 6$ & 386 & 16.8 & 285 & 0.8 & in & 58 & 0.5 & i) a \\
\hline \multicolumn{9}{|c|}{ 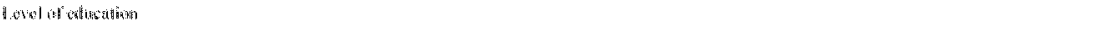 } \\
\hline Wo dilatiting & $3+4$ & 41.2 & 28.4 & 0.0 & 0,0 & 36.4 & a. in & \\
\hline Masice & 705 & $\$ 13$ & 20.4 & 1.5 & 0.9 & 11.8 & 1.98 & \\
\hline Scotendery & Sili & $10, y$ & 3.1 & 08 & 1.2 & 5.5 & 0.69 & 0.69 \\
\hline Oreiall & 169 & 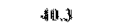 & 30.8 & $0 . \%$ & 99 & $2,6,3$ & 0.9 & \\
\hline
\end{tabular}


Table 6 shows the negative initial reaction to menarche reported. Negative reactions were reported more frequently with increase in age. Circumcision is highly reponted by older age and those with high level of education. The most significant age for a girl in all subgroups to be circumcised between 6-10 years old. Complications are highly reported by older adolescent girls and those without education. Report of who are with circumcision as a necessary practice for a woman to be married is reported by more than one third of all age groups and significantly high reported by those without education.

Table 6 . Percentage of negative responses to their first-time cycle, circumcision, their age at circumcision, complications of circumicision and the opinion of girls about the necessity of circumcision by different background characteristics $(\mathrm{N}=638)$

\begin{tabular}{|c|c|c|c|c|c|c|c|c|c|c|c|c|c|}
\hline & $\begin{array}{l}\text { Rewetion to } \\
\text { the cyota" } \\
\text { Reganded }\end{array}$ & & \multicolumn{2}{|l|}{ Corotatsession } & \multicolumn{4}{|c|}{ 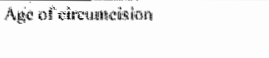 } & \multicolumn{3}{|c|}{ 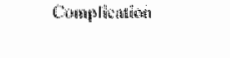 } & \multicolumn{2}{|c|}{ 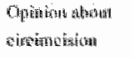 } \\
\hline & $9 / 6$ & $\rho$ & $x_{x}$ & $p$ & 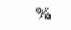 & wing & $\%$ & $\%$ & $p$ & 8 & $\mathrm{p}$ & 96 & $\mathfrak{l}^{\mathrm{B}}$ \\
\hline \multicolumn{14}{|l|}{ 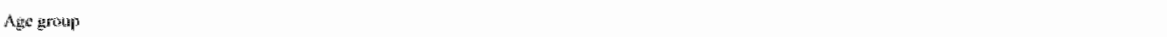 } \\
\hline $13-15$ & 864 & & $57 ?$ & & 314 & 44.9 & $\vec{P} \theta$ & $0 . \overline{0}$ & & 35.5 & & 46.5 & \\
\hline tent & 91.3 & 0.001 & 94.6 & a) & 33.2 & $A \omega_{1} 4$ & 6.6 & 0.5 & $0.8 \mathrm{2}$ & $42 \%$ & 0.944 & 32.2 & 0141 \\
\hline \multicolumn{14}{|l|}{$\begin{array}{l}\text { Lonet of } \\
\text { atikctat forit }\end{array}$} \\
\hline
\end{tabular}

$p<0.005$

\section{Discussion}

This is the first study to address issues of adolescents" reproductive health in Sudan. The data show that levels of knowledge about maturation signs for both sexes are low.

The role of the family is very low in learning about maturation. Furthermore the media have no role in educating adolescents on the topic of maturation signs. This supports the idea that adolescents' knowledge is acquired in some degree of isolation. Around half of the adolescents reported that they had heard about family planning. However, most have only a vague idea of what it means.

Inspite of active campaigning for family planning in Sudan, there still seems to be a lack of adequate information. In this study it became evident that even those who had been exposed to relevant information, did not understand the meaning of family planning and thus did not know how to interpret the information.

The majority of adolescents did not know the correct time of a woman's fertile period. Ignorance in this matter was evident, ewen among the girls, who should have been expected to have basic information about the reproductive process, specially as female and reproductive health information in general. 
The study demonstrated that the level of knowledge about STDs is low, inspite of mass media campangns about the danger of STD and the fact that the study area is a part of the capital city of Sudan. The most commonly known STD is HIV/AIDS. The outcome of this studly indicates that schooling is a predictor of adolescents' knowledge, with the exception of HVIAIDS. Furthermore it was noted that females have less knowledge of STD than males.

One of the dramatic events for females may be the onset of menstruation. The majority reported negative reactions to the onset of menses. It is apparent, therefore, that females need more information and guidance about the menarche, and how to overcome the negative consequences this normal event positively.

Self-reported prevalence of FGM is $89.6 \%$ among adolescent girls. This result shows that the practice is still very common in Sudan due to social desirability. This study is the frrst ever to have been undertaken on circumcision among single adolescent females. Compared to the $89.2 \%$ (with variation between different regions of Sudan from $86 \%$ to $98 \%$ ) of married women who report $\mathrm{FGM}$ (SDHS, 1990), this finding is noteworthy and it deserves further investigation why the practice is still prevalent.

Deduced from the data gathered from females in this study, the common age for circumcision ranges between $6-10$ years $(48.2 \%)$, which is prior to puberty. More than a third of circumcised females developed some sort of health or medical complications. More than one third believed that circumcision was necessary for women to be married.

From this study it can be concluded that many adolescents do not have the necessary basic information about reproductive health. The information adolescents need and are entitled to should be part of a safe and supportive environment for them. Provision of information is the foundation upon which to offer the additional interventions of skill building, counselling when needed, and access to health services. Adolescents require basic information about growth and development and the changes experienced physically, psychologically (both emotionally and cognitively), and socially during maturation (WHO, 1999). Parents and schools should be more active in reproductive health education campaigns in the media.

Family planning efforts should be more specifically aimed at adolescents. Simple, understandable messages should reach them before marriage through families, the media, the community or the schools. As the global AIDS epidemic has grown, campaigns explaining the danger should be considered. Particularly parents are in need of more information and guidance about the harmful of FGM practice and their future consequences on their children, because they are responsible of their children and should protect them from this harmful practice. These needs can be provided for in a variety of ways, the most appropriate or effective of which might well vary by gender, stage in the development process, and possibly an individual's setting.

There should be an adoption of a clear national policy for the abolition of FGM. Application and enforcement of existing legislation, prohibiting the practice (Sudan Attomey General Records 1946 \& 1983) might be of help in preventing future women's generation.

One of the limitations of our study is the fact that no questions were asked about sexual activities type and age of sexual partmers or about the nature of STDs that the study participants experienced. At the time of the study it was perceived as difficult to ask such sensitive questions (from our pretest outcome and some parents objection to such questions) although such data would be important for the design of effective 
interventions. There is need for further research on sexual behaviour activity among adolescents in Sudan.

A broad and genuine commitment to the reproductive health and well being of adolescents will be the most findamental necessity of all. Creating the political will to put into action the desire of Sudanese society to invest in the future may be the most difficult challenge involved. Those advocates, parents, policymakers, health and service providers, and researchers who recognize the critical role of reproductive health within the broad comprehensive approach needed to improve adolescent health, will find this a challenge hard to resist (Ford \& English, 2002). 


\section{References}

Brabin, L., Kemp, J., Obunce, OK, Ikimalo, J., Dollimore, N., Odu, N.N., Hart, C.A. \& Briggs, N.D. (1995). Reproductive tract infection and abortion among adolescent girls in rural Nigeria Lancet, $345,300-304$.

Chen. LC. (1974). Maternal mortality in rural Bangladesh. Study family planning, $5(11): 334-341$.

English, A., Morreale, M., \& Stinnett,A.(1999). Adolescents in Public Health Insurance Programs: Medicaid and CHIP, Center for Adolescent Health and the Law, Chapel Hill, NC.

Ford, C., English, A. (2002). Limiting confidentiality of adolescent health services: What are the risks? Joumal of American Medical Association, $288,252-253$

Harrison. KA. (1985). Childbearing, health and social priorities: a survey of 22774 consecutive hospital births in Zaire, Northern Nigeria. British joumal of obstetrics and gynaecology, 92 (suppl. 5): 1-119.

International Conference on Population and Development. (1994). ICPD, Cairo, Egypt.

Konde-Lule, J.K., Wawer, M.J., Sewankambo, N.K., Serwadda, D., Kelly, R., Li, C., Gray,R.H., \& Kigongo, D. (1997). Adolescents, sexual behaviour and HIV1 in rural Rakai district, Uganda. Joumal of Aids, 11, 791-799.

Kulin, H.E. (1988). Adolescent pregnancy in Africa: a programmatic focus. Social Science and Medicine, 26, 727-735.

Munodawafa, D. \& Gwede, C. (1996). Patterns of HIV/AIDS in Zimbabwe: implications for health education. AIDS Education and Prevention, 8, 1-10.

Obasii, I., Mosha, F., Quigley, M., Sekirassa,Z., Gibbs., T., Munguti, K., Todd, J., Grosskurth, H., Mayaud, P., Changalucha, J., Brown, D., Mabey, D., \& Hayes, R. (1999). Antibody to herpes simplex virus type 2 as a marker of sexual risk behaviours in rural Tanzania. Joumal of infectious Disease, $1.79,1.6-24$

Obasi, A., Cleophas Frisch, B., Chima, K., Mataba, S., Mmassy, G., Balira, R.,Todd,J., Ross, D., \& Mujaya, B.(2000). Health workers and head teacher attitude to provision of reproductive health education and services to adolescents in rural Mwanza region, Tanzania. $13^{\text {th }}$ International AIDS Conference, Durban, South Africa, Abstract WePpD1334. 
PAPCHLD. (1993) Pan Arab Project for Child Development, Sudan Maternal and Child Health Survey $1992 / 93$.

Sudan Attomey General Records: Sudan Penal Codes 1925, 1946, 1974, 1983 and 1991.

Sudan Demographic and Health Survey (1979). (SDHS) Department of Statistics, Ministry of Economic and National Planning, Institute for Resource Development / Macro international, Inc.

Sudan Demographic and Health Survey (1990). (SDHS) Department of Statistics, Ministry of Economic and National Planning, Institute for Resource Development /Macro international, Ine.

Sudan Safe Mother Survey. (1999).SSMS ,Department of statistics Ministry of Health.

UNAIDS (1997). Report on the global HIV/AIDS epidemic. Geneva.

UNFPA (2003). Investment in Adolescents" reproductive health Needs to Fighting Poverty and HIV/AIDS, UNFPA report October 2003.

WHO (1986). Expert Committee on Venereal Diseases and Treponematoses, Sixth Report (WHO) Technical Report Series, No. 736) WHO, Geneva.

WHO (1995). Sexually transmitted diseases: three hundred and thirty-three million new 3, curable cases in 1995.Geneva, World Health Organization (WHO) press release, $\mathrm{WHO} / 64$ 1995).

WHO (1994). Health, population and development. Position paper prepared for International Conference on Population and Development, Cairo, 1994. Geneva, World Health Organization (WHO/FHE/94.1).

WHO (1996). Female Genital Mutilation: Information Package: The practice.

WHO (1997). Coming of age, From Facts to Action for Adolescents Sexual \& Reproductive Health (WHO/FRH/ADH/97.18).

WHO (1999). Programming for Adolescent Health and Development, report of WHO/UNFPA/UNICEF Study group on Programming for Adolescent Health, WHO, Geneva. 



\title{
Chapter 8
}

\section{General discussion and implications}

\begin{abstract}
This last chapter aims to outline and discuss the main findings related to the five general research questions of this $\mathrm{PhD}$ thesis on the hhealth profile of Sudanese adolescents (HPSA). Limitations of the study including reliance on self-reports questionnaires and remarks about possible overestimation using this method in data collection are mentioned. Generalization of the findings had been pointed out. Policy implications of the study are discussed. Future researches are outlined and suggestions for replication of this study in other states in Sudan prior to embarking on a national study are indicated. Finally general recommendations to provide Sudanese government with a framework for action aimed at developing powerful. policy.
\end{abstract}




\section{General discussion and implications}

This last chapter aims to outline and discuss the main findings related to the five general research questions of this $\mathrm{PhD}$ thesis on the health profile of Sudanese adolescents (HPSA).

The first research question posed in this study is concemed with self-reported health problems and haemoglobin status among adolescents. The main conclusion from our study, contradicts the traditional assumption that adolescence is the healthy period in human life. This finding supports various previous empirical findings (High level of experienced health complaints, mental health complaints, report of chronic illness, health risk beliaviours and high level of anaemia), (Geckova et al., 2001; Tunistra 1998; Eltawila 1997; King 1996; Glendinning et al., 1992; West et al., 1990).

Although the majority of the adolescents in our study rated their own health as good or even excellent, relatively high numbers of subjective health complaints were reported. Headaches and stomachaches were most frequently mentioned by the adolescents. One fifth of the respondents reported some chronic illness. For six out of the seven listed chronic diseases, reports by females were higher than those of males. Multiple morbidities (suffering from more than one disease) were reported by $17.8 \%$. Most prevalent, about $80 \%$ (within the range of $71.9 \%-85.9 \%$ ) reported having suffered of Malaria, this being independent of sex, age and level of education.

Furthermore, it was found that one third of the study population had anaemia $(32.2 \%),(46.9 \%$ of male respondents and $19.2 \%$ of female respondents).

Some of the possible causes are the inadequate intake of iron or other blood forming mutrients (i.e., poor quality diet), poor absorption of iron, extreme breakdown of the red blood cells and excessive loss of blood due to menstruation, malaria and parasitic worms, infections and genetic disorders like sickle cell disease

Anaemia was higher for the younger adolescents (39.8\%) and for those enrolled in basic education $(36.7 \%)$ compared to older adolescents and those with high level of education.

Female adolescents reported more psychological complaints than male respondents and older adolescents reported more psychological problems. A possible explanation could be the physical changes in puberty, in combination with greater stress, resulting from societal expectations that are different for females than for males, and also the earlier biological and cultural maturation of females, in comparison to males. In the adolescent years, these problems are still preventable, reversible or they could at least be influenced favourably.

The second research question focused on health related behaviours and their determinants in adolescence compared across different demographic categories of Sudanese adolescents.

The findings show that the overall prevalence of smoking is higher in male adolescents, with older age and also in those who have enjoyed higher education. Drinking alcohol is significantly more common among males althougli very seldomly reported. Drinking was slightly more often reported by adolescents with older age. Contrary to the tendency recorded for smoking, uneducated adolescents reported drinking more often than those who are educated. 
As far as nutrition and physical activity are concerned, it was clear that a significant proportion of adolescents were prone to unhealthy habits and behaviour.

First, more than half of the female adolescents, almost half of the older age group, and almost half of those without education are reportedly physically inactive.

Secondly, approximately half of the study population experienced or had experienced hunger. Once again, males scored higher on this item than females. Similar patterns emerged with regard to older age group.

Both males and females scored relatively high in consuming non-nutritious lood such as tea, sweets, soft drinks and salty food. Those in the age group 13 to 15 consumed more sweets and the younger reported more often drinking tea. In contrast to other age groups, adolescents above the age of 16 years consumed significantly less mutritious (healthy eating) as well as non-nutritious food (unhealthy eating) than other age groups. This could reflect the low availability of food in general.

In contrast to the consumption of non-nutritious food, where distinct differences between various subgroups were recorded, the consumption of nutritious food was similar for all subgroups, with only some degree of variation.

The effect of these determimants on health will be manifested only in the future during adulthood, when the negative impact of unhealthy behaviours has lasted long enough to affect health.

The third research question aimed to explore the association between general health problems and health related behaviours among Sudanese adolescents. The findings show that two important health behaviours, namely smoking and hunger were associated with less favourable self-rating of health. Adolescents who smoke or experienced hunger actually reported poorer subjective/ perceived health than those who did not use these substances. Anaemia was found to be associated with smoking. The study also revealed a significant association between psychological complaints and experiences of hunger. On these grounds it was concluded that subjective health (rated health and psychological complaints) and objective health (anaemia) were sensitive and scientifically interesting indicators that could be meaningfully related to health behaviours such as smoking and eating patterns.

The fourth research question concerns the social context and health. The natures of family and peer relationships among Sudanese adolescents were examined. Social context variables such as structure of the family and peer relations were analysed to determine the association with lhealth status variables.

The findings show that the majority of respondents, especially in the younger age group, are living with both parents. The majority of respondents found it easy to communicate with their mothers, while two-thirds indicated that they talked easily to their elder sisters. In contrast, the majority of the study population found it difficult to communicate with their fathers and elder brothers. In general, female adolescents showed more difficulty in takking to family members of the opposite sex (father and elder brother) and friends than males. This could be due to the cultural habits and norms, which shape and influence the typical Sudanese family.

Furthermore it was found that, in contrast to other subgroups, especially male adolescents and the younger age group (10 to 12 years) had more than three close friends. Males were more frequently permitted to meet and go out with friends, 
While females were more likely to be limited to exchanging wisits with friends at their respective homes, or were not at all allowed to visit friends.

This study further revealed that living with both parents and good communication within the family are related to a good rating of health, happy feelings and optimistic feelings about the future. Permission to socialize with peers (i.e. "have three or more close friends", "meet with friends and go out", and "easy to talk to friends of the same sex ) was manifested in a higher degree of happiness.

It is interesting that respondents who reported good communicative relationships with friends of the opposite sex were shown to have an increased level of anaemia and experienced loneliness. Similarly interesting, those who had three or more close friends were less optimistic about the future. The inverse relationship between good communicative relationships on the one hand, and heightened anaemia and pessimistic feelings on the other, needs further investigation.

It is also worth noting that the differences between males and females, which were apparent in the prevalence of health problems, also became evident in the area of social relations. This means that the health of female adolescents compared to male adolescents ${ }_{n}$ is more vulnerable to social influences.

Research question five was devoted to adolescents' reproductive health, the level of knowledge about human reproduction and the harmful practice of FGM, with a special reference to the female population. Respondents' level of knowledge about maturation signs was found to be low. The role of the family in the process of gaining knowledge about maturation was not often mentioned by respondents . Only one-third of the respondents knew the exact meaning of family planning and they lacked basic knowledge of the reproductive process: the majority did not know how to determine the fertile period in women; almost half of the respondents had never heard of family planning; knowledge about STDs was limited, especially among those of the younger age group and those who had had very little or no education.

Once again, it was evident that the female adolescents were in a more vulnerable position than males. For example, females needed more information and guidance about the reproductive health process in general and about the onset of menstruation and its effects. "he majority of (female) respondents reported a negative reaction towards the onset of the menstrual cycle because they did not know about it. The majority of females were circumcised $(89.6 \%)$ Almost for half of the circumcised female respondents, the procedure was carried out between the ages of six and ten years. More than one-third reported some sort of complications, following mutilation. However, almost two-fifths of the respondents believed that circumcision is a prerequisite for marriageability.

\section{Limitations of the study}

This study relied heavily on reports of respondents, except for the data on anaemia. Self-reported data might be considered a source of bias, given the possibility of overor under-reporting. Kookier (1996), for example, remarks that self reported questionnaires overestimate the prevalence of self rating of ill health, health problems and health related behaviours. Objectivity of some subjective health complaints (e.g. head ache) is difficult to determine the cause even for well-trained 
people. However, despite the possibility of this overestimation, various other studies validate the use of self-reported data (cf. Thinstra 1998; West \& Sweeting 1996). Also Holland et al (1985) were able to prove, in their study on adolescents" health behaviour with regard to consumption of sweets, that self reported health and health related behaviours can be a reliable source of data.

Surveys of smoking behaviours rely on self-reports. The reliability and validity of smoking self- reports among adolescents have been extensively investigated, as have possibilities to increase the reliability and validity of self reported cigarette use. Validation of self- reports by biomedical measures like $C O$ rates in the breath and cotinine level in the blood (Klesges, Klesges \& Cigrang, 1992) and bogus pipeline procedure (Jones \& Sigall, 1971) had been tried by several authors. Although research has shown that adolescents can report accurately, this is only the case when sufficient assurance of confidentiality is given (Dolcini et al., 1996; Hansen et al., 1985; Williams, Eng, Botvin, Hill \& Wynder 1979).

In alignment with the latter viewpoint, self-reported data were considered appropriate for this study focusing on the experienced health and health-related behaviours.

The main reason is that research based on self-reported health indicators reveals differences between the adolescents' own perception of their health and the results of epidemiological studies based on mortality and morbidity. Actually, the study is as much about perception as about 'objective' health, also in view of the usual WHO definition.

The selection of a suitable method for gathering data on adolescent health was complicated by two reasons. Firstly, there is no consensus in the literature on the best indicators of health in adolescence. Secondly, there are no standardised instruments available for assessing health among adolescents (Tuinstra, 1998). In solving this problem, the researcher allowed him-self to be guided by international literature. In following Spruijt (1996) and Cobb (1992) who maintain that health related behaviours are mainly established in adolescence, the following health related determinants were selected for assessment: smoking, alcohol consumption, physical inactivity, eating lhabits and hunger experiences. These determinants were chosen not only because of their known influence on future health and well-being (of. Steptoe \& Butler 1996; Raitakari et al., 1995), but also because they are mainly established during adolescence.

Another limitation of this study was the variation in numbers (N) in the analyses of data, due to differences in missing values between variables. The omission of answers to some questions may be attributed to the sensitive nature of these questions, or alternatively, to a lack of understanding on the respondents" part. In some instances, the offered ranges of answers to a particular question did not satisfy the respondents or fit their opinion. The overall results, however, were not affected by this shortcoming since only relatively little values, scattered over different variables, were missing. In no instance did a particular variable lack a lot of values.

A serious shortcoming of this study stems from the fact that it was not recorded which adolescents live in the same household. As a result, the statistical dependency in the data could thus not be corrected for. Despite this problem, analysis of single adolescents (without peers) generated results that were consistent with the overall outcome, with the exception of anaemia. In the latter case, single adolescents were 
less anamic compared to adolescents who have brothers and sisters in the same household.

\section{Strong point}

In general, however, the high response rate that was achieved in this study may be considered a strong point, owing to the degree of cooperation that the researcher experienced from the community.

\section{Generalisation of results}

Athough respondents who formed the study sample were selected from a community comprising the whole range of adolescents in terms of lewel of education, regions, tribes and ethnic groups, representing the diverse cultural and religious backgrounds of the majority of the Sudanese population, the results obtained in this study can be generalised to the area of the Khartoum state only. The results of the study may not; however, be generalized to the whole Sudanese population due to the special circumstances prevalent in areas such as the south and west of the Sudan where there is waging war with complicating effects on the health and well being of the majority of the populations living in those areas.

\section{Further research}

The high prevalence of reported health problems among Sudanese adolescents requires more in-depth research. Future research should investigate whether this prevalence increases, and, if it does, what is the origin of the increase. Specific areas that need attention are the following:

Identified differences in anaemic status among male and female adolescents should be studied in coherence with the causes that led to this situation, for example, eating patterns, and other factors (prewentable and chronic diseases).

Further studies to test hypotheses generated from this study as for example the effect of hunger experiences on anaemia controlling for smoking.

The differential influence of parents and peers on health and onset of health risk behaviours.

The influence of gender relations within the family, with specific reference to the difficulties experienced by girls to communicate with members of the opposite sex. More insight is needed on the cultural and religious origins of this problem and strategies for overcoming difficulties related to poor communication.

The sexual behaviour and activities of adolescents with a view to identify measures for future intervention.

Analysis of trends in mental health problems, their origins and the possibilities of improving mental health in adolescence.

Intervention studies to test the results generated from this study are required to deepen the evidence base for programme development and to further refine and validate the study strategy, methods and techniques.

Replications of the study in other states and districts are required for designing intervention programmes at district and provincial levels, prior to embarking on a national study. Replication at these levels is deemed necessary because the data generated by the study reported in this thesis may not be sufficiently sensitive or 
specific to address the diversity and variation among the total Sudanese population. As a result, these data may not be appropriate for macro-level policy and planning.

\section{Policy implications}

A general overview of the health profile of Sudanese adolescents formed the focus of this thesis. In the conviction of the researcher, addressing the health and development needs of adolescents is one of the nost important commitments a country can make towards its future economic, social and political progress and stability. Health promotion in general and adolescent health in particular, should be the prime concern of the Sudanese govermment. Furthermore, following the peace agreement in the southern Sudan and, hopefully, in the future, in other regions too, health promotion and peace could be a new arena in improving health of the Sudanese population in affected areas. Furthemore, the multiple causes and solutions of adolescent health problems in Sudan require synergistic action and intersectoral cooperation, which implies that policy formulation by the Ministry of Health in Sudan should be regarded as an urgent meed.

The potential contribution of this study in providing direction to policy makers and program implementers in addressing this need, is highlighted by the following findings:

- The majority of self-reported health problems are subjective, chronic and preventable in nature, and are amenable to change. This was found to be a common tendency across all subgroups.

- The high level of anaemia found among the adolescent study population could be considered an alarming phenomenon for this age group. Screening mechanisms, improved levels of nutrition and hygiene education campaigns would thus be important steps in eradicating these health problems. Such campaigns should address the importance of a healthy diet that is rich in iron, includes the regular intake of fruit and vegetables and excludes the drinking of tea after meals. Iron supplementation should be provided for selected cases through school health services. Such an initiative could be effective in improving the haemoglobin level of some school children (Ballin et al., 1992), but simultaneously would require considerable logistic and financial resources from international organization (WHO, UNICEF, UNFPA). Furthermore, it should be borne in mind that the overall benefits of iron supplementation or fortification programmes remain to be clearly scientifically demonstrated in the developing country setting (Brabin \&Brabin, 1992).

- In order to prevent chronic disease epidemics in adulthood, programmes should be put in place to facilitate early diagnosis and preventive measures. Diagnostic and treatment services for specific health problems, as well as the provision of information regarding health behaviours and health promotion should be provided efficiently at school-based services points. Such a strategy needs clear commitment from the society, governmental/political to school health promotion at the school level and not only just periodical examination and some health services (if any), as is the case at present. 
- The character of health services should be addressed, because for some population sub-groups, for example adolescents who tend not to use health services, the features of service delivery are important. Assessment strategies, confidentiality, flexible access points and the professional knowledge and skills of health care providers all contribute to make serwice provision more users friendly (WHO, 1999).

- Campaigns could furthermore embrace interventions to distribute knowledge about health risk behaviours, to promote smoke-free schools and communities and to encourage involvement in sport. The latter was found to be low, especially among females.

Adolescents should be encouraged to participate in sport because it is an important component of a healthy lifestyle. As recorded profusely in academic and popular literature, sports activities positively affect both the physical and psychosocial functioning of people (WHO, 1999). One way of engaging a larger proportion of adolescents in a minimal level of sports activities is to ensure that every school is equipped with a playground and sporting facilities. Similar amenities should be available at community level. Physical education programmes should promote an active lifestyle through recreation and sports activities and discourage sedentary habits. Especially sports facilities for females deserve greater investment.

- The family context emerged as a major agent of socialisation for adolescents. Special education programs for parents focusing on the physical, psychological and life stage changes of adolescents, and also the development of communication skills would help adolescents to cope with the changes that occur during this period of their lives.

- It became clear that adolescents do not have information about reproductive health matters that will sufficiently help them to manage their future reproductive roles. Most of the respondents reported that they had gained knowledge on matters pertaining to reproduction on their own or through observation. Therefore, programs designed to equip adolescents with knowledge and communication skills in the area of reproductive health will be needed. Schools should also play a role in this process by providing information at appropriate ages, by developing pupils' communication skills, and through the use of counselling services provided by specially trained staff.

- The school has the potential to provide an excellent base for large-scale programming and high coverage of adolescents for both male and female adolescents (Olukoya, 1994). There is a need to strengthen the school as a setting for health interventions because of the potential for high coverage. The structured nature of school curricula provides opportunities for the inclusion of developmentally appropriate provision of information and training of skills. Nevertheless, the school as an important institution in the community can play a role in addressing issues in the social environment beyond its perimeters, such as looking at the environmental factors, which drive young people out of school. The school can be part of a larger community group concerned with adolescent health programming and can be a catalyst in starting such groups if none exist. There are many opportunities for adolescent participation in schools, from planning and representation on advisory 
committee to peer education as a school approach to the prevention of substance use and to reproductive health. Some schools offer opportmities such as family life education clubs.

Schools can provide many services to young people in addition to formal education. These include:

-Healthy and safe environment-often combining good nutrition with clean water and sanitation;

-Health education (including skill training);

-Monitoring growth, health and development, and offering health services (including primary health care and counselling) or referral to other services; -Sports and recreational skills and facilities.

The school also helps health providers forge links with the families of adolescent students and strengthen the capabilities of families to help young people (WHO, 1996).

The impetus and direction for increased action to promote adolescent health could originate from a variety of sources. The basic right and obligation concerning the promotion of adolescent health are articulated in the United Nations Convention on the Right of the Child. Other action plans and recommendations formulated by the United Nations further strengthen and support these rights and obligations. Explicit measures to support, stimulate and strengthen national laws, policies and programs for adolescent health have also been adopted by the World Health Organisation (WHO), United Nations Fund for Population Activity (UNFPA) and United Nations Children's Fund (UNICEF).

\section{Recommendations}

These general recommendations are developed to provide the Sudanese government with a framework for action aimed at developing powerful policy and planning tools for the promotion of health of adolescents in Sudan.

1. The government of Sudan should recognise the potential contribution of adolescent health to public health in general and also the economic benefits, which accrue from advocating the needs for, and investing in the health and development of young people.

2. The government should take care of the needs in adolescent health and generate commitment to meeting those needs by co-sponsoring situation analyses, research and planning activities. Further initiatives could include the creation of multisectoral national task forces and the convening of national workshops, in order to forge coalitions with interested governmental and non-governmental organizations (NGO's) at the community level and develop common plans of action.

Successful implementation requires reform of policy, identification of problems and groups that can be involved in the design of a policy to overcome barriers and obstacles. Inadequate funding presents an array of problems to the government, problems that are likely to persist until economic conditions improve. Also, health is not a priority in the political agenda of the government. This situation, however, presents an opportunity to ask government to reassess priorities and create new and 
sustainable funding sources specifically directed to adolescent development and health programs:

3. Health policies should pary more attention to psychological health especially for the older age groups of adolescents, as well as to physical health, preventable and chronic diseases. Whe health of adolescents may be promoted through education, technical assistance and training of parents, grandparents, teens, schools, communities and service providers for adolescent health.

4. Iron deficiency anaemia control must be integrated with existing primary health care activities.

Communities and families should be empowered to increase the intake and bioavailability of iron source foods within locally prevalent resources and circumstances; the entire family should be focused on. In an intervention strategy the effectiveness of weekly iron supplementation in preventing iron deficiency, increasing iron reserves, and correcting mild to moderate iron-deficiency anaemia has been proven by many studies around the world (WHO, 2004; http:/www.emro.who.int/nfs/Flourfortification-ironDeficiency-Chapter 7.htm).

Fortification programmes should be considered because they are highly effective provided that the selected food is widely consumed by the affected population. However fortification should be closely watched in terms of adequacy and scientific evaluation. The success of any intervention to correct and control anaemia depends on whether the intervention deals with the underlying causes. In many cases, it is unlikely that all anaemia results from iron deficiency, because other nutritional deficiencies as well as malaria, heavy loads of some helminths and other inflammatory/infectious diseases also cause anaemia.

5. Programs to promote healthy behaviours should be stimulated. These include the creation of smoke free environments, and restriction of the availability and affordability of tobacco and alcohol. There is, however, a need to develop tailored interventions reinforcing existing cultural resilience factors anong non-smoking adolescents. Also, suitable cessation programmes particularly towards adolescents should be developed to reduce the current prevalence of tobacco use.

Food supplementation, avallability, price reduction and stimulation of use of fruits and vegetables could be an effective school-based health promotion programs.

6. Improvements of opportunities for physical activities are needed. Changing atiitudes and policy in favour of female welfare should encourage female's involvements in physical activities. Especially sports facilities for girls, in consideration of the specific cultural and religious background, deserve greater investment.

The content of physical education programmes should be acceptable to adolescents, and enough time should be provided for the daily plrysical activities.

7. Adolescents require basic information about reproductive health, growth and development and the physical, psychological and social changes experienced during maturation. It became clear that adolescents do not have information about reproductive health matters that will sufficiently help them to manage their future 
productive roles. Therefore, programs designed to equip adolescents with knowledge and communication skills in the area of reproductive health are needed. Schools should also play a role in this process by providing information at appropriate ages; by developing pupils' communication skills, and through the use of counselling services provided by specially trained staff.

8. School health programs, and health insurance schemes for school children (to which most of the study population belong) will be the most effective way to develop an effective delivery point for adolescent health services. There is a need to strengthen the school as a setting for health interventions because of the potential for high coverage. Health authorities and school health departments should co-operate and co-ordinate in establishing school health insurance scheme.

Against this background, it can be concluded that preparing adolescents to take over the front seat tomorrow demands that they be placed at the forefront of the state agenda today. 


\section{References}

Ballin, M.D., Berar, M., Rubinstein, U, Kleter, Y., Hershkovitz, A, \& Meytes, D.(1992). Iron state in female adolescents. American Jownal Diseases of Children, 146, $803-805$.

Cobb, NJ (1992). Adolescence continuity, change and diversity. Mountain View, Mayfield Publishing Company, Califomia, London, Toronto.

Dolcmi, M. M., Adler, N. E., \& Ginsberg, D. (1996). Factors influencing agreement between self-reports and biological measures of smoking among adolescents. Joumal of Research on Adolescence, 6, 515-542.

EL-Tawila. S., Ibraham. B., Salam. S., El Gibaly. O., \& El Sahan. F. (1997). Transition to Adulthood, A National Survey of Egyptian Adolescents.

Geckova, A., Tumistra, J., Pudelsky, M., Kovarova, M., Van Dijk., JP., Groothoff, JW., \& Post, D. (2001). Seli- reported health problems of Slovak adolescents, Journal of Adolescence, 24, 635-645.

Glendinning, A., Love, JG., Hendry, LB., \& Sucksmith, J. (1992). Adolescence and Health Inequalities: extension to Macityre and West. Social Science and Medicine, 5, 679-687.

Hansen, W. B., Mallotte, K. C., \& Fielding, J. E. (1985). The bogus pipeline revisited: the use of the threat as a measure of increasing self-reports of tobacco use. Journal of Applied Psychology, 70, 789-792.

Holland, U., Theiland, E., \& Poulsen, S. (1985). Validity of dietary interviewing method for use in caries prevention. Community Dentistry and Oral Epidemiology, 13, 231-250.

Jones, E. E., \& Sigall, H. (1971). Bougius pipeline: A new paradigm for measuring affect and attitude. Psychological Bulletim, 76, 349-364.

Klesges, L. M., Klesges, R. C., \& Cigrans, J. A. (1992). Discrepancies between selfreported smoking and carboxyhemoglobin: an analysis of second national health and nutrition survey. American Joumal of Public Healh, 82, 10261029.

King.A., Wold.B., Smith.C.T., \& Harel.Y. (1996). The Health of Youth a Cross National survey, Development patterns of behaviours and attitudes. WHO Regional Publications. European serious No.69.

Kooiker, S. (1996). Illness in everyday life. A health diary study of common symptoms and their consequences. Thesis, University of Groningen. 
Kruz, K.M., \& Johnson-Welch, C. (1994). The nutrition and lives of adolescents in developing countries: Findings from the nutrition of adolescent Girls Research Program. Washington, D.C.: International Center for research on Women.

Olukoya, A. (1994). A survey on adolescent reproductive health services provision. Lagos, Institute of Child Health and Primary Care.

Raitakari, OT., Leino, M., Raikkonen, K., Porkka, KVK., Taimela, S., Rasanen, J., \& Viikari, ISA. (1995). Clustering of risk habits in young adults. The cardiovascular risk in young Finns study. American Jotunal of Epidemiology, 142, 1:36-44.

Stepto, A., \& Butler, N. (1996). Sport participation and emotional wellbeing in adolescents. The Lancet, 347, 1789-92.

Spruijt-Metz, D.(1996). On everyday health related behaviour in adolescence. Thesis, Free University Amsterdam.

Tuinstra, J. (1998). Health in Adolescence. An Empirical Study of Social Inequality in Health. The Prevalence of self- reported health problems in male and female Dutch adollescents. Thesis, Groningen University, the Netherlands.

West, P, \& Sweeting. H. (1996). No job, No future: young people and health in a context of unemployment. Healh and social care in the community, 4 , $50-62$.

West, P., Macintyre, S., Annandale, E., \& Hunt, K. (1990). Social Class and health in Youth: findings from the West of Scotland Twenty 07 Study. Social Scienc: e and Medicine, 6, 665-673.

WHO (1996). The status of school health: annex 1 to the working paper of the WHO Expert Committee on Comprehensive School Health Education and Promotion. Geneva, World Health Orgnization (WHO/HPR/HEP/96.1).

WHO (1999). Programming for Adolescent Health and Development, report of WHO/UNFPA/UNICEF Study group on Progranming for Adolescent Health, WHO, Geneva.

WHO (2004). http:/www.emro.who.int/nfs/FlourFortification-ironDeficiencyChapter7.htm

Williams, C. L., Eng, A., Botvin, G. J., Hill, E., \& Wynder, P. L. (1979). Validation of students' self reported cigarette smoking status with plasma cotinine llevels. American Jourmal of Public Health, 69, 1272-1274. 


\section{Summary}

Adolescent health has become an important issue on the international health agenda. Evidence has accumulated from many studies around the world that contrary to the traditional assumption that adolescence is the healthiest stage in human life, there are many factors during this period affecting health immediately or later in life.

This study aims to describe the health profile of Sudanese adolescents to give answers to the question how (un) healthy adolescents in Sudan are. The results shed light on the current situation and provide information to build health policies in Sudan.

Chapter I introduces the study of adolescent health, its importance and others' experiences around the world. The objective and the aim of the study are to provide a description and explanation of the health profile of Sudanese adolescents. As reflected in the studly objectives we are concerned with the experienced health problems and with haemoglobin status (as a marker for objective health), health related behaviours and their determinants in adolescence, and how these variables are related. Another objective is to gain understanding of the social context and how the relationships and communication between family members and peers affect health. The last objective is to investigate knowledge of and practice in reproductive health and to understand when and how adolescents acquire this knowledge, which prepares them for their future role as parents. This study intends to gather social epidemiological data that may underpin Sudanese health policies for adolescents.

Chapter 2 describes the research methodology and the process of data gathering in the area of Umbada town. A cross-sectional, cluster random sampling design was used $(n=1200)$. A total sample of 1200 adolescent ( $53.2 \%$ girls and $46.8 \%$ boys) within the age group 10-19 years was selected. A self-reported questionnaire was developed for data collection by trained interviewers. A biomedical test for haemoglobin determination was applied to the selected adolescents. For ethical reasons a statement about the study was first read by the interviewers to the head of the household as well as to the respondents, to obtain verbal consent. This chapter allso reports on the training of the data collectors, pilot testing, data management and our experiences with the fieldwork.

Chapter 3 examines the health status of adolescents in Sudan. Several health problems are assessed, namely self-reported health, experienced health complaints, conmon and chronic illness. Furthermore, haemoglobin status was used as a simple and reliable test to detect anaemia. The findings were analysed using sociodemographic characteristics (sex, age group and level of education) as stratification criteria. The results indicate that adolescence is not synonymous to health. A large number of adolescents from all of the subgroups reported specific physical and psychological complaints. Females, adolescents of age group 13-15 and those with a high level of education reported relatively high prevalence of chronic diseases. Malaria was consistently found to have relatively high prevalence in all age groups. The overall prevalence of anaemia in our study was $32.2 \%$ (46.9\% males, $19.2 \%$ females). 
Chapter 4 focuses on the health related behaviours and the lifestyle of adolescents. Interestingly, the data shows very little variation on health related behaviours among all sub-groups of adolescents except for females who reported fewer health risk behaviours than males.

Overall smoking prevalence was $4.9 \%$ (9.1\% males, $1.3 \%$ females). Alcohol consumption was more common among males than females, and sligltly more reported by older than by younger adolescents. There were no differences in alcohol consumption among those with and those without education.

Males were more actively engaged in sports than females. More than hall of the males go hungry because there is not enough food available; this is somewhat less. pronounced among females.

Adolescents above 16 years of age reported significantly less consumption of nutritious and non-mutritious food than other age groups.

Chapter 5 discusses the outcome of the associations between health status and health related behaviours. One important health behaviour, namely smoking and hunger experiences as a health determinant were associated with a less favourable self-rating of health. Those who smoke or experienced hunger actually reported poorer subjective/perceived health than those who did not smoke or experience hunger. Anaemia was found to be associated with smoking and the psychological complaints were found to be associated with experiences of hunger. On these grounds it was concluded that subjective health (self-rated health and psychological complaints) and objective health (anaemia) were sensitive and scientifically useful indicators that could be meaningfully related to health behaviours such as smoking and hunger experiences.

Chapter 6 examines the social context of the family and the circle of influential people around the adolescents. In particular, it focuses on whether there are differences in social context between demographic categories and on the association between social context and health, adjusted for health behaviours. The findings showed that the majority of respondents lived with their parents. The majority of adolescents communicated more easily with their mothers and older sisters than with their fathers and brothers respectively.

Female adolescents reported more difficulty in communicating with family members (namely father and brother) and friends of opposite sex. A positive family environment correlated significantly with a good health status as indicated by good self-reported health, happy feelings and optimism about the future.

Chapter 7 identifies the level of knowledge of reproductive health, e.g. about maturation signs, family planning, fertile period and knowledge about STDs and reproductive health practices (i.e. Fenale Gental Mutilation (FGM) among adolescent girls, their experience and the negative consequences of this practice). We found that adolescents" level of knowledge about maturation was low. Only one third of respondents knew the exact meaning of family planning. The majority did not know how to determine the fertile period in women. Knowledge about sexually transmitted diseases is limited. The majority of females were genitally mutilated. For about half of them the procedure was carried out between the ages of six and ten years. More than one third reported some sort of complication following mutilation. 
However, almost two-fifth of female respondents believed that circumcision is a prerequisite for marriageability.

Finally Chapter 8 , the last chapter of this thesis, outlines the general discussion and offers answers to the research questions posed. Furthermore we highlight the implication of the results for designing health promotion programs for adolescents in the Studan. A discussion of the study limitations and recommendations for future regards are also presented.

Our findings suggest the need for in-depth studies on self-reported health problems between adolescent and replication of this study in other states and districts prior to embarking on a national study. We also recommend that the government and other key stakeholders should build a framework of action for policies on adolescent health in Sudan. 


\section{Samenvatting}

De gezondheidstoestand van jongeren is een belangrijk onderxerp op de internationale gezondheidsagenda. Wereldwijd wijzen vele wetenschappelijke onderzoeken er op dat, in tegenstelling tot de gangbare aanname dat de adolescentie de gezondste periode is, deze levensfase juist veel factoren kent die de onmiddellijke dan wel latere gezondheid negatief beünvloeden. Het doel van dit promotieonderzoek is een beschrijving te geven van het gezondheidsprofiel van Sudanese adolescenten om daarmee een antwoord te geven op de vtaag hoe gezond of ongezond deze jongeren feitelijk zijn. Naast inzicht in de huidige situatie, zijn de resultaten van dit onderzoek ook bruikbaar om het Sudanese gezondheidsbeleid vorm te geven.

Hoofdstuk I vormt een introductie op het promotieonderzoek dat tot doel heeft het gezondheidsprofiel van Sudanese adolescenten te beschrijven en te verklaren. Het hoofdstuk onderbouwt allereerst het belang van een dergelijk onderzoek en presenteert een overzicht van ervaringen met soortgelijk onderzoek elders in de wereld. Wat betreft het gezondheidsprofiel schenkt het huidige onderzoek special aandacht aan de gezondheidsproblemen die Sudanese jongeren ervaren, de prevalentie van bloedarmoede (als objectieve indicator voor gezondheid), gezondheidsgerelateerde gedragingen en de determinanten van deze gedragingen, en de manier waarop deze factoren aan elkaar zijn gerelateerd. Daarnaast beoogt dit onderzoek inzicht te geven in de invloed van de sociale context op de gezondheid van adolescenten en in de wijze waarop de relaties en gesprekken van jongeren met hun familie en vrienden hierin een rol spelen. Ten slotte inventariseert het onderzoek de kennis van adolescenten op het gebied van de voortplanting en de ervaringen van vrouwelijke respondenten met besnijdenis. Van belang hierbij is te achterhalen wamneer de jongeren kennis omtrent de voortplanting verwerven en wie hen voorbereidt op het toekomstig ouderschap. Tezamen zijn de verzamelde sociaalepidemiologische gegevens bedoeld als basis voor Sudanees gezondheidsbeleid gericht op adolescenten.

Hoofdstuk 2 beschrijft de onderzoeksmethode en het proces van gegevensverzameling in de stad Umbada en omgeving. De opzet wan het onderzoek was cross-sectioneel an omvatte een viertal op basis van toeval geselecteerde clusterts met in totaal 1200 jongeren in de leeftijd van 10 tot 19 jaar. De groep bestond uit iets meer meisjes $(53.2 \%)$ dan jongens $(46.8 \%)$. De meeste gegevens werden verzameld via een speciaal geconstrueerde vagenlijst die werd afgenomen door een getrainde interviewer. Als maat voor bloedarmoede werd het hemoglobinegehalte in het bloed bepaald met een bestaande biomedische test. Vanwege ethische owerwegingen lazen de interviewers voorafgaand aan het onderzoek aan zowel het gezinshoofd als aan de adolescente respondent telkens eerst een verklaring over het onderzoek voor om zo ieders mondelinge toestemming tot deelname te verkrijgen. Het hoofidstuk doet verslag van de ontwikkeling van de vragenlijst, de training van de interviewers, de pretests, het gegevensbeheer en de ervaringen van de onderzoekers tijdens het veldwerk. 
Hoofdstuk 3 onderzoekt de gezondheidstoestand van Sudanese jongeren. Diverse gezondheidsproblemen werden in kaart gebracht: zelfgerapporteerde gezondheid, ervaren gezondheidsklachten en de mate waarin veel voorkomende en chronische ziekten zich voordoen. De hemoglobinetest werd gebruikt als eenvoudige maar betrouwbare methode om bloedarmoede op te sporen. De aldus verkregen gegevens werden gestratificeerd geanalyseerd met de sociaal-demografische variabelen geslacht, leeftijdsgrocp en opleidingsniveau als stratificatiecriteria. De resultaten laten zien dat adolescentie niet synoniem staat aan gezondheid. In elk van de subgroepen rapporteerde een groot aantal jongeren specifieke fysieke en psychosociale klachten. Drie subgroepen, te weten vrouwelijke adolescenten, jeugd in de leeftijd van 13 tot 15 jaar en jongeren in de hoogste opleidingsklasse, rapporteerden een relatief hoge prevalentie van chronische aandoeningen. Een consistente bevinding in alle leeftijdscategorieën was de relatief hoge prevalentie van malaria. Anemie bleek bij $32.2 \%$ van alle jongeren voor te komen, maar vaker onder mannelijke (46.9\%) dan onder vrouwelijke adolescenten (19.2\%).

Hoofdstuk 4 richt zich op de leefstijl en het gezondheidsgerelateerde gedrag van de adolescenten. Opmerkelijk was het geringe verschil dat er tussen de diverse subgroepen bleek te bestaan in gezondheidsgerelateerde gedragingen. Een uitzondering daarop was dat vrouwelijke adolescenten minder gezondheidsbedreigend gedrag rapporteerden dan mannelijke. Over het geheel genomen rookte $4.9 \%$ van de jongeren ( $9.1 \%$ van de jongens, $1.3 \%$ van de meisjes). Mannelijke adolescenten gebruikten vaker alcohol dan vrouwelijke, en alcoholgebruik werd iets vaker gerapporteerd onder oudere dan onder jongere respondenten. Het al dan niet gevolgd hebben van een opleiding speelde bij het gerapporteerd alcoholgebruik geen rol. Jongens bleken actiever te sporten dan meiden.

Meer dan de helft van de mannelijke adolescenten rapporteerde honger vanwege het onvoldoende beschikbaar zijn van voedingsmiddelen. Ook vrouwelijke respondenten rapporteerden honger vanwege voedseltekorten, zij het minder uitgesproken. Adolescenten boven de 16 jaar rapporteerden minder voedzame en niet-voedzame etenswaren te nuttigen dan andere leeftijdsgroepen.

Hoofdstuk 5 bespreekt de associaties tussen gezondheidsstatus en gezondheidsgerelateerd gedrag. Twee belangrijke gedragsgerelateerde factoren, namelijk roken (gedrag) en ervaren honger (gedragsdeterminant), waren geassocieerd met een minder goede zelfgerapporteerde gezondheid. Adolescenten die rookten of honger hadden geleden, makten melding van een slechtere ervaren, ofwel subjectieve, gezondheidstoestand dan degenen die niet rookten of die aangaven geen honger te hebben gehad. Bloedarmoede was geassocieerd met roken, en psychosociale klachten hingen samen met ervaren hongergevoelens. Geconcludeerd werd dat zowel de subjectieve gezondheidsmaten (zelfgerapporteerde gezondheid en psychosociale klachten) als de objectieve gezondheidsmaat (bloedarmoede) gevoelige en wetenschappelijk bruikbare indicatoren vormden die op een betekenisvolle manier in verband konden worden gebracht met een aantal gezondheidsgerelateerde gedragingen. 
Hoofdstuk 6 onderzoekt de sociale context van de familie en de kring van invloedrijke personen rondom de adolescenten. Het richt zich in het bijzonder op de vraag of er verschillen bestaan in sociale context voor de divers sociali-demografisch categorieën en op de vraag welke associaties er, gecorrigeerd voor gezondheidsgerelateerd gedrag, bestaan tussen sociale context en gezondheid.

Het merendeel van de jongeren woonde bij hun ouders. De meeste adolescenten communiceerden gemakkelijker met hun moeder en oudere zusters dan met hun vader en broers. Vrouwelijke adolescenten gaven aan moeilijker te communiceren met hun familieleden (namelijk vader en broers) en met vrienden van de mannelijke kunne. Een familiekring waarin de communicatie gemakkelijk verliep correleerde positief met een goede gezondheid van de adolescent, te weten een goede zelfgerapporteerde gezondheid, gevoelens van geluk en optimisme aangaande de toekomst.

Hoofdstuk 7 beschrijft het kennisniveau van de jongeren aangaande de geslachtrijping, gezinsplanning, de wruchtbare periode en seksueel overdraagbare aandoeningen (soa's). Wat betreft voortplantingsgebruiken rapporteert het hoofdstuk met name de toepassing van besnijdenis onder vrouwelijke adolescenten, hun ervaringen daarmee en de mogelijk negatieve consequenties daarvan.

Jongeren bezaten weinig kennis over de geslachtsrijping. Slechts een derde van de adolescenten kende de precieze betekenis wan gezinsplanning, en de meerderheid wist niet hoe ze de vruchtbare perioden van een vrouw konden bepalen. De kennis over soa's was beperkt. De meeste vrouwelijke adolescenten waren op enigerlei wijze besneden. Bij ongeveer de helft van hen had die procedure plaatsgevonden tussen het zesde en tiende levensjaar. Meer dan een derde rapporteerde enige vorm van klachten als gevolg van de genitale verminking, al zag twee vijfde van de vrouwen de circumcisie ook als een voorwaarde om te kunnen trouwen.

Hoofdstuk 8 biedt plaats aan de algemene discussie. Die geeft antwoord op de gestelde onderzoeksvragen en bespreekt de beperkingen van het huidige onderzoek en doet aanbevelingen voor toekomstig onderzoek. Daarna volgt een aantal implicaties voor het opzetten van gezondheidsbevorderende programna's voor adolescenten in Sudan.

Op grond van de bevindingen van dit onderzoek lijkt het raadzaam om aanvullend onderzoek te doen naar de zelfgerapporteerde gezondheidsproblemen en om het huidige onderzoek in andere districten te herhalen, alvorens over te gaan tot verder landelijk onderzoek. Het hoofdstuk sluit af met de aanbeveling dat de overheid en andere belanghebbende organisaties een raamwerk voor een actieplan ontwikkelen ten behoeve van gezondheidsbeleid voor adolescenten in Sudan. 


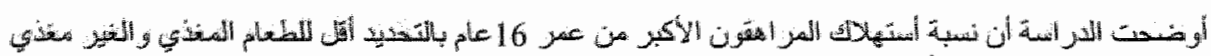

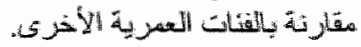

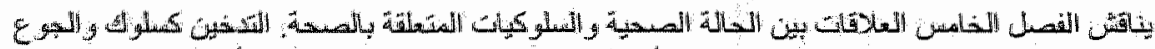

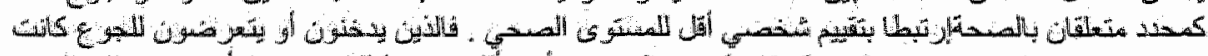

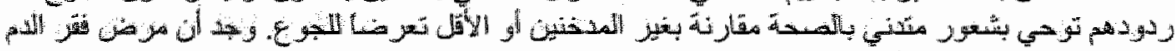

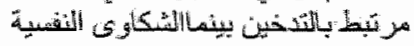

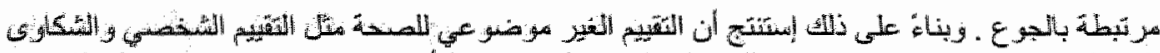

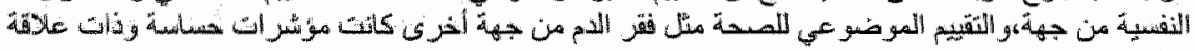

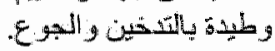

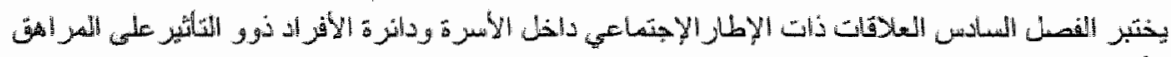

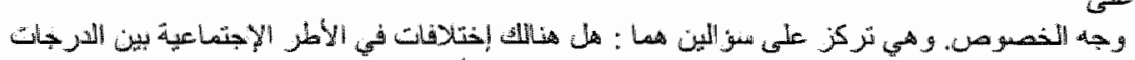

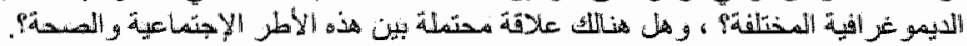

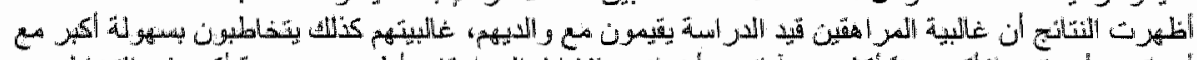

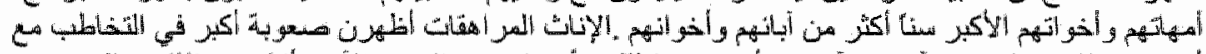

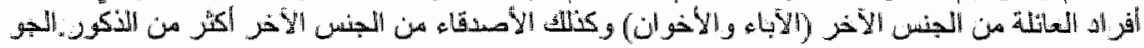

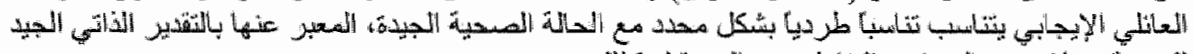

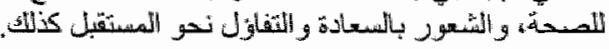

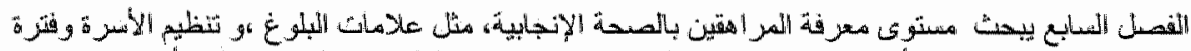

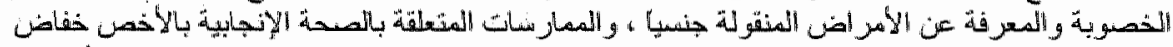

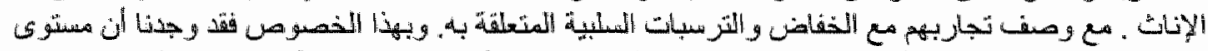

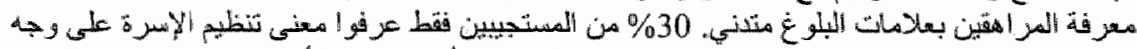

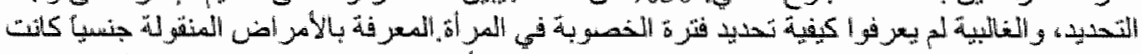

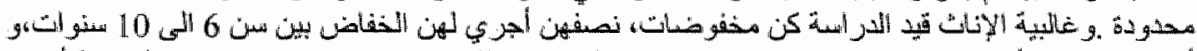

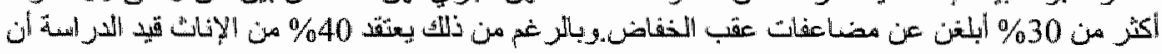

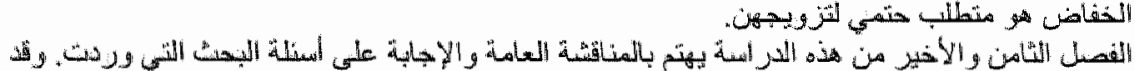

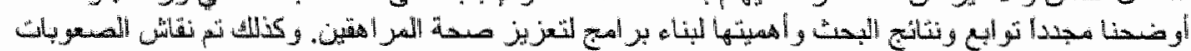

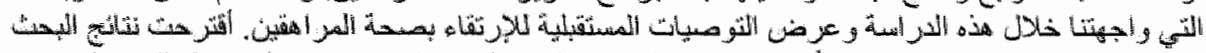

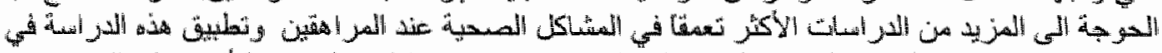

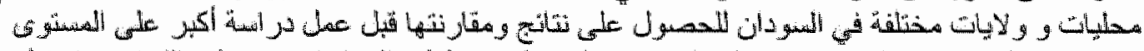

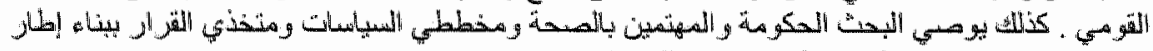

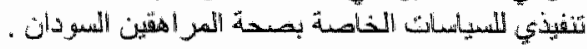




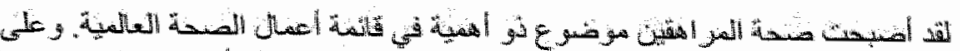

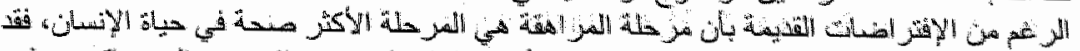

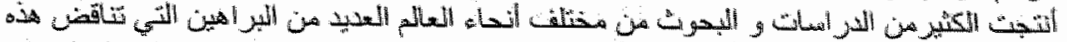

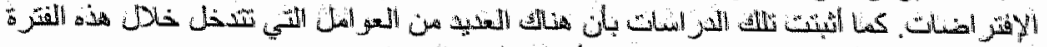

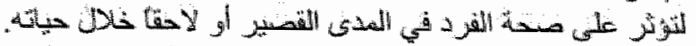

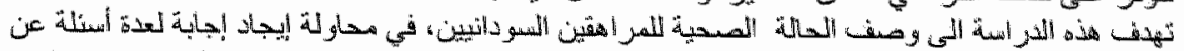

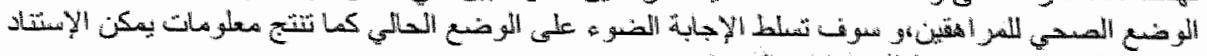

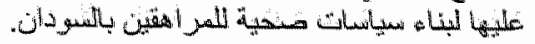

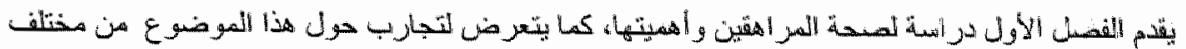

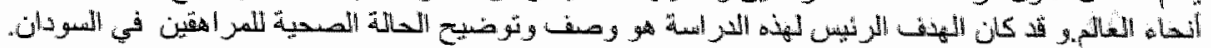

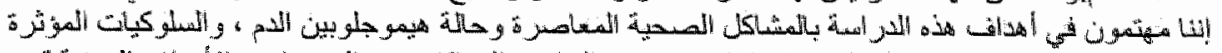

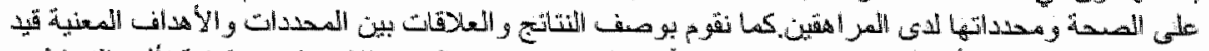

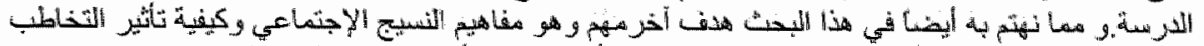

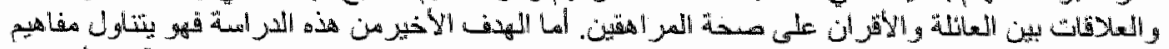

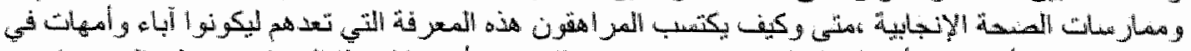

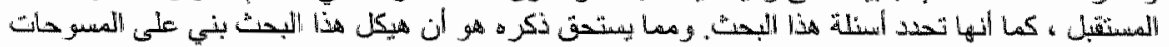

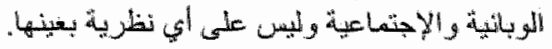

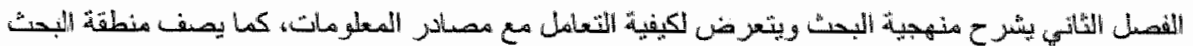

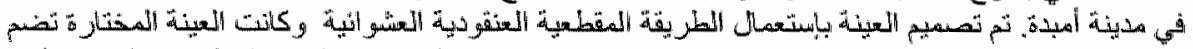

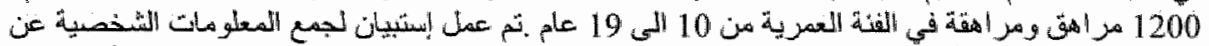

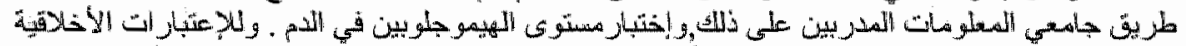

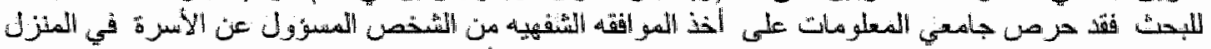

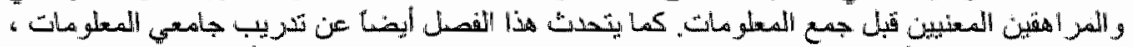

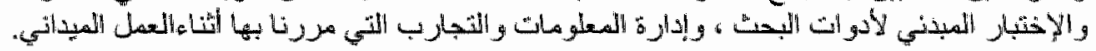

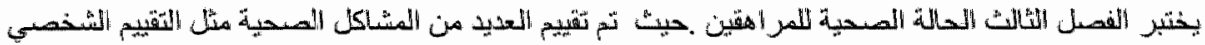

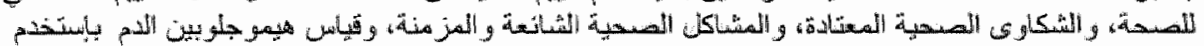

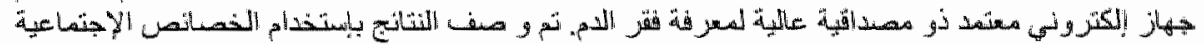

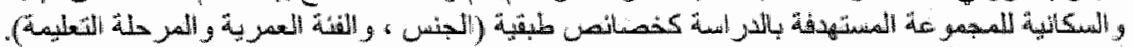

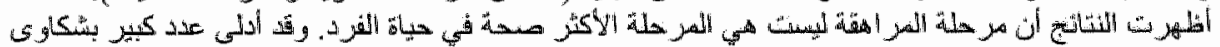

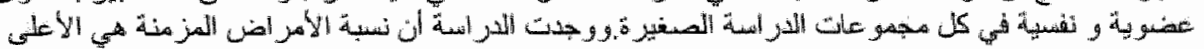

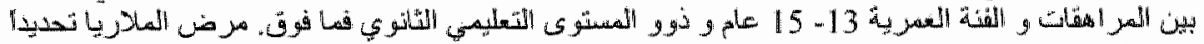

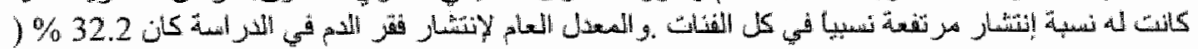

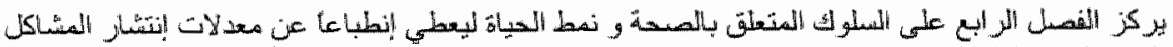

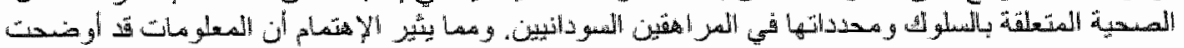

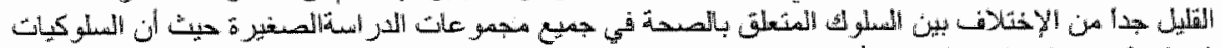

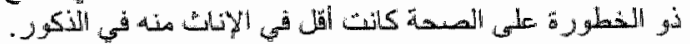

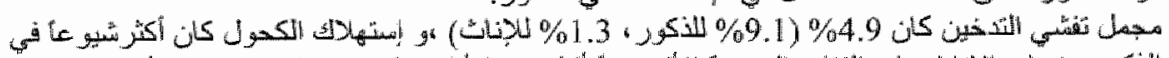

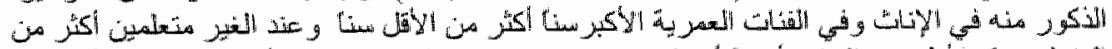

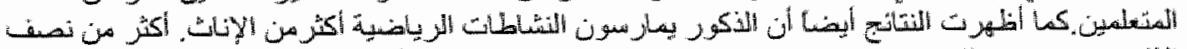

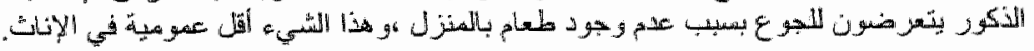




\section{Acknowledgements}

I would like to extend my gratitude and appreciation to the many people who have contributed to the successful completion of my PhD study.

First of all, my great appreciation goes to my promoters, Prof Jacques Van Eijk and Prof Nanne de Vries, for their sincere guidance and support during this learning process.

I thank the members of the scientific committee for the time and effort spent in reviewing my thesis.

If would like to thank Prof Gasim Badri and Ahfad University for Women for their financial support during my study period in the Netherlands and during fieldwork in Sudan. My appreciation also goes to the United Nation Fund For Population Activities (UNFPA), Khartoum Office in Sudan, especially to Dr Zahid Ulhag the Country Director for UNFPA and Dr Adil Syghroon for their partial financial support during my first year of study.

I thank Prof Huda Rashad and DR Sahar El-Tawila from the Social Research Centre (SRC) at the American University in Cairo for their help and guidance during the period I spent writing my Ph.D proposal.

I thank Prof A Salam Salih, the former Dean of the School of Medicine at Ahfad University for Women, Prof Farouk A/ Aziz, the current Dean of the School of Medicine as well as the staff for their continuous support and encouragement during my study.

I $m$ grateful to Prof Ahmed Abdelmageed, Dr Amar Hassan for their invaluable advice and suggestions during the fieldwork procedure and Mr Yassir Eltiganie for his help in the coding process of the data.

I thank all the respondents and their families for their help and patience, which enabled me to successfully complete this process. I thank the data collectors from the Community Animators Friendly Association (CAFA) especially Mr Yasir Ibrahim, Zainab Hamid and Amira as well as Walla, Zainab, Dalia, Ibtisam, Nahla, Nada, Nafesa and Amna from Ahfad University for Women. I am also indebted to Molnamed Elamin, the lab technician, for his effort in collecting blood and haemoglobin samples in the field. I extend my appreciation to Ms Badria and her team for the great effort in entering and cleaning the data.

I would like to thank the staff members of the Department of Medical Sociology for their help and cooperation during the first two years of my stay in Maastricht. Special thanks to Handrika, Majorka, Hans, Jan, Jos, Sylvia, and Marjion.

I would also like to extend my gratitude to the staff members of the Department of Health Education and Promotion with whom I spent the rest of my stay in Maastricht. 
I thank Marja, Janneke, Stef, Leon, Helga, Rose, Marjan, Irene and Madelief for their continued support throughout this process and my room mates Pamela and Saadhra for their support and friendship.

I am grateful to my friends in Maastricht who supported me during this period; Gerard Majoor and his family, Marcel and Geraldine Van Kasteren, Henie Sijen from Mundo, Pauline Vluggen from the Network office as well as the rest of the staff:

My thanks also go to all the Sudanese friends and colleagues in the Netherlands especially in Maastricht, who supported me during this process.

I extend my gratitude and appreciation to all my family members in Sudan and all around the world especially my beloved mother Amna and my sisters Haja and Elham and their families.

I extend great thanks to my dearest brother Eltahir for his continuous and endless support, which played a great role in the complete of this mission. God bless you!

I offer great thanks to my lovely daughter Madina. I appreciate your understanding and sacrifice in being away from the family sometimes during our stay in Maastricht. Amna and Nafesa thank you for the wonderful time we spent together and for your help and support to accomplish this mission.

Lastly but by no means least, I would like to thank my dearest wonderful wife Aziza. Your love has been my inspiration, and your invisible hands my support. I will never forget your great help and concern and I wish you all success to accomplish your study mission in the near future. 


\section{Curriculum Vitae}

Mohamed Eisa Eltahir Moukhyer was born in Omdurman Sudan. He completed his higher education at Kost High School in central Sudan. From 1975 to 1981 he studied general medicine at the Faculty of Medicine, Cluj-Napoca Romania, where he received his degree in general medicine. He joined the Ministry of Health in Sudan and worked as a general practitioner from 1981 to 1983 . From 1983 to 1987 he worked as an emergency room physician and chief of ambulatory care at Al-Saim Hospital in the Yemen Arab Republic for the Whttiker Corporation (USA) and Saudi Medical Services. In 1988 he joined the Royal College of Physicians were he attended the Internal Medicine course and was attached to the Royal Infirmary Hospital in Edimburgh, UK. From 1989 until 1993 he joined the Ministry of Health in Libya as a general practitioner. He then returned to Sudan where he joined the School of Medicine at Ahfad University for Women in Omdurman as a teaching assistant. From October 1994 until October 1995 he trained in family medicine at Suez Canal University in Egypt. From October 1995 to September 1996 he worked as a teaching assistant at School of Medicine and family physician at the University Reproductive Health Centre in collaboration with UNFPA. He then completed a Masters Degree in Public health at Mastricht University from September 1996 until September 1997. Following his return from Maastricht University, he was appointed as a Lecturer in Public Health at the School of Medicine as well as Director of the Reproductive Health Centre at Ahfad University for Women. In 1999, he was awarded a Ford Foundation Fellowship to prepare a proposal on Adolescent Health in Sudan at the Social Research Centre (SRC), American University in Cairo, Egypt.

In January 2001, he initiated his PhD study at the Departments of Medical Sociology and Health Education and Health Promotion at Maastricht University. During his Ph.D study he was involved in the educational and teaching programs at the Faculties of Health Sciences, Medicine and the International Masters Degree of Public Health at Maastricht University. Mohamed Moukhyer is a full active member of the Network: Towards Unity For Health (TUFH) and Women and Health Task Force. He is actively involved in the area of public health, reproductive health, adolescent health and women's health in the African region and Eastern Mediterranean Region (EMR). Mohamed will return to Ahfad University for Women in Sudan and will take up the position of Assistant Professor of Public Health.

M.E. Moukhyer

Ahfad University for Women

P.O.Box 167, Omdurman,

Sudan

ahfad@sudanmail.mail

E-mail: moukhyer@hotmail.com 